\title{
IV. Die Landeskirche in Bayern
}

\section{Kirche und Nationalsozialismus}

Bis zum Zusammenbruch des Kaiserreichs 1918 hatte die Evangelisch-Lutherische Kirche in Bayern rechts des Rheins, so die offizielle Bezeichnung, unter dem Summepiskopat der katholischen Könige aus dem Hause Wittelsbach gestanden, die ihre landesherrlichen Rechte durch ein von ihnen eingesetztes Oberkonsistorium wahrnahmen. Der konfessionelle Gegensatz führte, verstärkt durch die Minderheitensituation im katholischen Bayern, zur Ausbildung einer betont ,,reichstreuen " Gesinnung in den fränkischen Kernlanden des bayerischen Protestantismus.

Nach der Revolution von 1918/19 wurde der Aufbau einer eigenständigen Kirchenleitung notwendig. Die 1920 von der Generalsynode verabschiedete Kirchenverfassung trug demokratische Züge: Als gesetzgebendes Organ wirkte die Landessynode, die sich zu zwei Dritteln aus Laien und zu einem Drittel aus Geistlichen zusammensetzte. Die Leitung der Kirche übernahm ein gewählter Kirchenpräsident, dem der Landeskirchenrat als kollegiale Verwaltungsbehörde mit Sitz in München zur Seite stand. Als behördliche Mittelebene wurden die drei Kirchenkreise Ansbach, Bayreuth und München geschaffen; $1935 \mathrm{kam}$ als vierter Kirchenkreis Nürnberg hinzu1 ${ }^{1}$. Erster Landessynodalvorsitzender war von 1919 bis 1922 der Münchner Bankdirektor Wilhelm Freiherr von Pechmann, der von 1921 bis 1930 auch als Präsident des Deutschen Evangelischen Kirchentages wirkte ${ }^{2}$. Der frühere Oberkonsistorialpräsident Friedrich Veit amtierte als nunmehr gewählter Kirchenpräsident bis April 1933. Er gehörte zu denjenigen Kirchenführern, die die Befreiung der evangelischen Kirche von staatlicher Bevormundung als Folge des landesherrlichen Kirchenregiments begrüßten und als ,,Vernunftrepublikaner" einzuschätzen sind $\mathbf{3}^{3}$.

Die Zusammensetzung der Landessynoden zeigt das für die evangelische Kirche typische Bild der sozialen Milieuverengung auf ländlich-bäuerliche und mittelständische Schichten ${ }^{4}$. In der Pfarrerschaft dominierte ebenfalls der Mittelstand: Insgesamt stamm-

${ }^{1}$ Zur historischen Entwicklung vgl. Matthias Simon, Die Evang.-Lutherische Kirche in Bayern im 19. und 20. Jahrhundert, München 1961; Claus-Jürgen Roepke, Die Protestanten in Bayern, München 1972; Friedrich Wilhelm Kantzenbach, Evangelischer Geist und Glaube im neuzeitlichen Bayern, München 1980.

${ }^{2}$ Vgl. Friedrich Wilhelm Kantzenbach (Hrsg.), Widerstand und Solidarität der Christen in Deutschland 1933-1945. Eine Dokumentation aus den Papieren des D. Wilhelm Freiherrn von Pechmann, Neustadt 1971.

${ }^{3}$ Vgl. Friedrich Wilhelm Kantzenbach, Friedrich Veit, in: Götz Freiherr von Pölnitz (Hrsg.), Lebensbilder aus dem bayerischen Schwaben, Bd. 12, Weißenhorn 1980, S.244-257.

41920 gehörten der Synode 154 Mitglieder an, unter ihnen befanden sich: 52 Pfarrer, 23 Beamte (14 Lehrer, 5 sonstige höhere Beamte, 4 Post- und Bahnanwärter), 25 Freiberufler (darunter 7 Fabrikanten, 6 Ärzte, 3 Gutsbesitzer), 4 eher leitende Angestellte, 5 Handwerksmeister, 20 Bauern (davon 7 Bürgermeister) und 4 Arbeiter. In der Synodalperiode 1923-1929 waren von 90 Mitgliedern: 31 Pfarrer, 36 Beamte (13 Juristen, 12 Lehrer, 6 sonstige höhere Beamte, 4 mittlere Beamte, 1 Offizier), 5 Angestellte, 9 Freiberufler (davon 3 Fabrikanten, 2 Gutsbesitzer), 8 Bauern (teils Bürgermeister), 1 Handwerksmeister. Ganz ähnlich war die folgende Synode zusammengesetzt, auch wenn hier wieder 2 Arbeiter vertreten waren. Vgl. Zorn, Bevölkerung, S. 327. 
ten 60 Prozent der bayerischen Pfarrer aus akademischen Elternhäusern, 20,5 Prozent kamen bereits aus Pfarrhäusern 5 . Die traditionelle Frömmigkeit war in den vorwiegend agrarischen Gebieten Frankens ungebrochen hoch, und die meßbare Kirchlichkeit, der Gottesdienst- und Abendmahlbesuch sowie der Spendeneifer, ging deutlich langsamer zurück als im Reichsdurchschnitt ${ }^{6}$. Im Unterschied zu anderen Landeskirchen war die bayerische Pfarrerschaft in theologischer Hinsicht schon in den 20 Jahren ein ,,bemer-

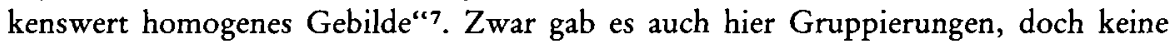
scharfen Gegensätze. Seit Mitte des 19. Jahrhunderts trat der ausgeprägt lutherische Charakter der Landeskirche, der mit einer zunehmenden Verkirchlichung und Konfessionalisierung einherging, immer dominierender hervor. Nach dem Ersten Weltkrieg war die Epoche des liberalen Kulturprotestantismus in Bayern endgültig zu Ende. Besonders die jungen Pfarrergeneration, die - geprägt von der Jugendbewegung und dem ,,Fronterlebnis" - nach $1918 \mathrm{ihr}$ Studium aufnahm, suchte nach einer neuen Orientierung, die sie in der ,"Luther-Renaissance“, aber auch in der ,,dialektischen Theologie" Barths fand.

Die Revolution von 1918/19 erschütterte das hierarchisch-patriarchalisch geprägte Weltbild der Pfarrer, die dem bereits im Kaiserreich einsetzenden sozialen Wandlungsprozeß verständnislos gegenübergestanden war, zutiefst. Etwa 10 Prozent der aktiven bayerischen Pfarrerschaft traten den konterrevolutionären Freikorps bei ${ }^{8}$. Symptomatisch für das antirepublikanische Selbstverständnis war es, daß die Kirchen beider Konfessionen zur Ermordung des bayerischen Ministerpräsidenten Kurt Eisner schwiegen. Bereits 1923/24 stieß die völkische Bewegung, wie die entsprechenden Jahrgänge des , Korrespondenzblattes für die evang.-luth. Geistlichen in Bayern“ ausweisen, auf groBes Interesse. Auch der Hitler-Putsch 1923 fand weithin Sympathien. So sprach sich damals nicht nur Wilhelm Stählin, ein führender Nürnberger Pfarrer der evangelischen Jugendbewegung und nach 1945 Landesbischof von Oldenburg, anerkennend über den Idealismus der Putschisten aus ${ }^{9}$. 1924 vertrat Pfarrer Helmuth Johnsen, später Landesbischof von Braunschweig, den Völkischen Block, die Nachfolgeorganisation der verbotenen NSDAP, im bayerischen Landtag. Parteipolitisch lagen Mitte der zwanziger Jahre die Präferenzen eindeutig bei der DNVP, zu deren Abgeordneten von Pechmann und der Erlanger Theologe Hermann Strathmann zählten. Auf dem Münchner Parteitag der DNVP 1921 hielt der Erlanger Theologe Friedrich Brunstäd das Hauptreferat über , völkisch-nationale Erneuerung“ “. Der SPD gehörte nur ein evangelischer Pfarrer an; die Zahl der SPD-Sympathisanten wird auf höchstens ein halbes Dutzend geschätzt. Nach Einschätzung des Kirchenhistorikers Kantzenbach stand die bayerische Pfarrerschaft ,,so gut wie geschlossen rechts"10. Entsprechend orientierte auch die evangelische Kirchenpresse die kirchentreuen Bevölkerungskreise ${ }^{11}$.

5 Ebenda, S. 329.

${ }^{6}$ Vgl. Ernst Eberhard, Kirchenvolk und Kirchlichkeit. Eine Untersuchung mit besonderer Berücksichtigung der ev.-luth. Landeskirche Bayerns in der Nachkriegszeit, Diss. Erlangen 1938.

7 Meier, Kirchenkampf, Bd.1, S. 456.

8 Baier, Deutsche Christen Bayerns, S. 31, gibt die Zahl mit 144 Pfarrern und Kandidaten der Landeskirche an. Zur Zuspitzung des „,Pastorennationalismus“ im Ersten Weltkrieg vgl. Kantzenbach, ,Kriegstheologie“.

9 Wilhelm Stählin, Die völkische Bewegung und unsere Verantwortung, Sollstedt 1925. Vgl. IfZ,

Fa 323, Steinbauer, Erinnerungen, S. 5 f.; Kuessner, Landesbischof Johnsen, S. $4 \mathrm{ff}$.

${ }^{10}$ Kantzenbach, Der Einzelne, S. 108.

11 Vgl. Meier-Reutti, Politik, S. $273 \mathrm{ff}$. 
Großen Einfluß auf die sich selbst zumeist als unpolitisch verstehende Pfarrerschaft übte die Theologische Fakultät der Universität Erlangen aus. Gerade bei ihren beiden profiliertesten Theologen, den Neulutheranern Paul Althaus und Werner Elert, fand die völkische Bewegung verständnisvolle Fürsprecher. Die von ihnen vertretene Theologie der ,,Schöpfungsordnungen“ sah in Volk und Volkstum ,,Urordnungen“ und damit Offenbarungen Gottes. So konnte Althaus von der ,,Heiligkeit des Volkes als einer uns fordernden Ordnung“" sprechen, und Elert legte in seinem Hauptwerk ,,Morphologie des Luthertums" (1931/32) die biologische Bindung an das Volk zugleich als sittliche Forderung der lutherischen Soziallehre aus ${ }^{12}$. Mithin erwies sich das Neuluthertum als eine politische Theologie, deren Attraktivität vor allem darin lag, daß sie religiöse mit nationalen Anliegen verband. Obwohl vor 1933 kein Ordinarius der theologischen Fakultät der NSDAP beitrat, bekundeten doch die meisten - bei gewissen Vorbehalten gegen die primitive NS-Rassenideologie - unüberhörbar ihre Sympathie ${ }^{13}$. Daher war es wohl kein Zufall, daß der NS-Studentenbund als erste Universität gerade das protestantisch geprägte Erlangen eroberte.

Mit dem Nationalismus gingen Antisemitismus und Antijudaismus, die andere Hypothek des 19. Jahrhunderts, einher, die durch Luthers antisemitische Streitschriften tief im Protestantismus verwurzelt war. So forderte ein mittelfränkischer Pfarrer bereits 1921 öffentlich zum Boykott jüdischer Geschäfte auf ${ }^{14}$. Der Direktor des Nürnberger Predigerseminars, der spätere Landesbischof Hans Meiser, vertrat 1926 in der Kirchenpresse die Ansicht, daß die Juden Volksverderber seien und die Kirche Mischehen nicht billigen dürfe. Viele Pfarrer dachten wohl wie Meiser, der es für einen Gewinn hielt, ,, wenn unser Volk durch die völkische Bewegung wieder an seine Pflicht gegen die eigene Art und das eigene Blut erinnert wird" "15. Es gab aber auch warnende Stimmen, die das Eindringen des völkischen Antisemitismus in die kirchliche Verkündigung klar als Verleugnung des Evangeliums erkannten. Kirchenpräsident Veit warnte schon 1923, daß der „,haßerfüllte Rassenantisemitismus" nicht „,bloß unterchristlich, sondern widerchristlich" und , ,antibiblisch" sei ${ }^{16}$. Nicht minder deutlich protestierte 1933 Pechmann gegen das Schweigen der Kirche zur Judendiskriminierung. Obwohl Veit und Pechmann hohe kirchliche Ämter innehatten, verhallte ihr Ruf ungehört. Erbittert über die Weigerung der evangelischen Kirche, den jüdischen Mitbürgern beizustehen und das Gebot der Nächstenliebe in der Praxis zu bezeugen, trat Pechmann 1934 aus der Kirche aus.

Die politische Polarisierung gegen Ende der Weimarer Republik spiegelte sich auch in der Pfarrerschaft wider. Zunehmend richteten viele Geistliche ihre nationalen Hoffnungen und Sehnsüchte auf die NS-Bewegung. Nach einer unvollständigen Statistik des Landeskirchenrats aus dem Jahre 1948 traten der NSDAP vor 193353 Pfarrer bei - zumeist

${ }^{12} \mathrm{Zu}$ Althaus vgl. Tilgner, Volksnomostheologie, S. $197 \mathrm{ff}$.; Ericksen, Theologians, S. $79 \mathrm{ff}$. Zu Elert vgl. Tilgner, S. $201 \mathrm{ff}$.

${ }_{13} \mathrm{Vgl}$. Loewenich, Erlebte Theologie, S. $105 \mathrm{ff}$.

14 Friedrich Auer, Das jüdische Problem. Ein wissenschaftlicher Versuch, Lorch 1921. Vgl. allg. Brosseder, Luthers Stellung.

15 Zit. nach Hambrecht, Aufstieg der NSDAP, S. 528. Zur Kirchenpresse vgl. Arndt, Judenfrage; Altmann, Judenfrage. Die besonders starke Virulenz des Antisemitismus im protestantischen Franken zeigt Ian Kershaw, Antisemitismus und Volksmeinung. Reaktionen auf die Judenverfolgung, in: Bayern in der NS-Zeit, Bd.2, München 1979, S. 281-348.

${ }^{16} \mathrm{Zit}$. nach Kuessner, Landesbischof Johnsen, S. $107 \mathrm{f}$. 
1931/32. Die Zahl der Sympathisanten dürfte erheblich höher gelegen haben, da die Kirchenleitung unter Veit den Pfarrern jegliche aktive politische Betätigung verboten hatte. Während des Dritten Reiches gehörten mindestens 209 Pfarrer der NSDAP an; an der Spitze lagen die Dekanate Coburg mit 23, gefolgt von Nürnberg mit 20, Bayreuth mit 17 und Windsbach mit 16 Geistlichen (Missionshaus Neuendettelsau) ${ }^{17}$. Starken Zulauf erhielt die NSDAP vor allem aus volksmissionarisch eingestellten Kreisen, die sich vom Nationalsozialismus die Rechristianisierung des deutschen Volkes erhofften ${ }^{18}$.

Bei der Reichstagswahl im Juli 1932 erhielt die NSDAP in allen überwiegend protestantischen Landkreisen die absolute Mehrheit, außer in Erlangen (48,1 Prozent) und Schwabach (47 Prozent). In den agrarischen und zu mehr als 70 Prozent protestantischen Stimmkreisen erreichte sie teilweise sogar über 70 Prozent. Absolute Mehrheiten erzielte die NSDAP auch in den nicht großindustriell geprägten, überwiegend protestantischen Städten, dagegen in keinem überwiegend katholischen Landkreis. Besonders in kleinen protestantischen Landgemeinden gewann sie bereits 1932 zwischen 90 und 100 Prozent aller Stimmen ${ }^{19}$. Der 1930 regional teilweise beachtliche Erfolg der DNVP-Abspaltungen, ,Landvolkpartei“ und in geringerem Maße des „Christlich-Sozialen Volksdienstes", in Mittel- und Oberfranken war eine kurzfristige Episode geblieben ${ }^{20}$. Der Vergleich mit sozial ähnlich strukturierten katholischen Stimmbezirken zeigt, welch großen Einfluß die Kirchen auf die Wahlentscheidung ausübten. Hatte sich die Verurteilung der NS-Bewegung durch die katholischen Bischöfe vor 1933 als ein wirksames Bollwerk erwiesen $^{21}$, so gelang den Nationalsozialisten in den protestantischen Gebieten Bayerns noch vor ihren großen Wahlerfolgen auf Reichsebene der entscheidende Durchbruch.

Als besonders wirksam erwies sich die vom NSDAP-Gauleiter der ,Bayerischen Ostmark" Hans Schemm ausgegebene Parole ,Unsere Politik heißt Deutschland, unsere Religion heißt Christus!" , mit der die NSDAP die deutschnationale Gesinnung der Pfarrerschaft anzusprechen vermochte. Viele Geistliche sahen in Schemm, den Scholder als den Typus des religiös-gläubigen Nationalsozialisten charakterisiert ${ }^{22}$, den Garanten einer kirchenfreundlichen, aber nicht einseitig konfessionell festgelegten Politik. Hinzu kam der Artikel 24 des NSDAP-Parteiprogramms von 1920, der von der Bindung der NSDAP an ein , positives Christentum“" sprach, andererseits aber ausführte, daß die Religionsfreiheit nur soweit gewährleistet sein dürfe, solange sie nicht den Bestand des Staates gefährde oder gegen das "Sittlichkeits- und Moralgefühl der germanischen Rasse“ verstoße, und die Nationalsozialisten zur Bekämpfung des ,,jüdisch-materialistischen Geistes in und außer uns" anhielt. In einer hellsichtigen Analyse hatte der Erlanger Theo-

${ }^{17}$ LKAN, LKR 214, Spruchkammerverfahren gegen Geistliche nach dem Stand vom 1.6.1948.

18 Vgl. Henn, Volksmission; Friedrich Wilhelm Kantzenbach, Das Neuendettelsauer Missionswerk und die Anfänge des Kirchenkampfes, in: ZbKG, 40 (1971), S. 227-245.

19 Thränhardt, Wahlen, S. 181. Vgl. Hambrecht, Aufstieg der NSDAP; Martin Broszat, Ein Landkreis in der Fränkischen Schweiz. Der Bezirk Ebermannstadt 1929-1945, in: Bayern in der NSZeit, Bd.1, München 1977, S.21-92; Jürgen Erdmann, Coburg, Bayern und das Reich 1918-1933, Coburg 1969; Zdenek Zofka, Die Ausbreitung des Nationalsozialismus auf dem Lande. Eine regionale Fallstudie zur politischen Einstellung der Landbevölkerung in der Zeit des Aufstiegs und der Machtergreifung der NSDAP 1918-1936, München 1979.

${ }^{20}$ Vgl. Zorn, Bevölkerung, S. $322 f$.

21 Vgl. Scholder, Kirchen, Bd.1, S. $166 \mathrm{ff}$.

22 Ebenda, S. $243 \mathrm{ff}$. Vgl. Hans Schemm spricht. Seine Reden und sein Werk, Bayreuth 1935, S. $176 \mathrm{ff} ., 373 \mathrm{ff}$. 
loge Hermann Sasse dazu 1932 unmißverständlich festgestellt, daß jede Diskussion mit der NSDAP unmöglich sei, da die evangelische Kirche offen eingestehen müsse, daß ihre Lehre eine ,,vorsätzliche und permanente Beleidigung des ,Sittlichkeits- und Moralgefühls der germanischen Rasse “" sei und sie ,,demgemäß keinen Anspruch auf Duldung im Dritten Reich" habe'23.

Obwohl die Kirchenleitung unter Veit im März 1932 nochmals die strikte parteipolitische Neutralität der Pfarrer forderte und im Oktober sogar Disziplinarstrafen androh$\mathrm{te}^{24}$, wurde die geforderte Neutralität von der in nationaler Aufbruchstimmung erfaßten Pfarrerschaft vielfach nicht mehr gewahrt. Im Januar 1932 schrieb etwa der Münchner Dekan Friedrich Langenfaß: , Ich bin in schwerer Sorge, namentlich um unsere Kirche. Denn unsere Pfarrer benehmen sich zum Teil unglaublich und verraten Kirche und Evangelium an ihre augenblicklichen Gefühle. So hat sich mein Amtsvorgänger Lembert zu einer öffentlichen Kundgebung für Hitler im ,Völkischen Beobachter ${ }^{`}$ bereit finden lassen." 25 Die große Sympathie, die die NSDAP spätestens ab 1930 in kirchlichen Kreisen genoß, führt Broszat darauf zurück, daß die evangelische Kirche in Bayern ,,ihren kräftigsten Rückhalt meist in denselben sozialen Schichten und demselben soziokulturellen Milieu" wie der Nationalsozialismus hatte ${ }^{26}$. Umgekehrt wirkte die durch die politische Theologie des Neuluthertums legitimierte national-völkische Gesinnung der Pfarrerschaft in die sozialen Milieus der kirchlich gebundenen Bevölkerung zurück.

Die Machtübernahme Hitlers beflügelte die nationalsozialistisch gesinnten Pfarrer, die sich in dem 1932 gegründeten Nationalsozialistischen Evangelischen Pfarrerbund (NSEP) sammelten, nun auch die Neuordnung der Landeskirche zu fordern. Sie verlangten den Rücktritt des bürgerlich-konservativen Kirchenpräsidenten und die Neuwahl der Synode. Am 11. April 1933 trat Veit, der im 72. Lebensjahr stand, zurück ${ }^{27}$. Zwei Tage später huldigte der Landeskirchenrat unter Führung von Oberkirchenrat Meiser mit einem ,,Wort an die Gemeinde" dem neuen Regime:

,,Ein Staat, der wieder anfängt, nach Gottes Gebot zu regieren, darf in diesem Tun nicht nur des Beifalls, sondern auch der freudigen und tatkräftigen Mitarbeit der Kirche sicher sein. Mit Dank und Freude nimmt die Kirche wahr, wie der neue Staat der Gotteslästerung wehrt, der Unsittlichkeit zu Leibe geht, Zucht und Ordnung mit starker Hand aufrichtet, wie er zur Gottesfurcht ruft, die Ehe heilig gehalten und die Jugend christlich erzogen wissen will, wie er der Väter Tat wieder zu Ehren bringt und heiße Liebe zu Volk und Vaterland nicht mehr verfemt, sondern in tausend Herzen entzündet." 28

Die Erklärung zeigt, wie sehr man im Einklang mit der populären Zivilisationskritik eines Oswald Spengler oder Wilhelm Stapel die Jahre der Weimarer Republik als Jahre der moralischen und nationalen Dekadenz empfunden hatte. Auch die evangelische Kirche lebte wie das konservative Bürgertum in Illusionen und Selbsttäuschungen. Rückblickend beschrieb der Nürnberger Kreisdekan Julius Schieder die Zeit der naiven Hoff-

${ }^{23}$ Die Kirche und die nationale Bewegung, in: KJ 1932, S. 58-77. Weitere kritische Stimmen von Zeitgenossen bei Meier, Kirchenkampf, Bd.1, S.536f., Anm. 121.

${ }^{24}$ Baier, Landeskirche, S. 38.

${ }^{25}$ Zit. nach Bühler, Kirchenkampf, S.26. Vgl. Dietzfelbinger, Veränderung, S. 17.

${ }^{26}$ Brozat, Lage, S. 375.

${ }^{27}$ Dazu ausführlich Henn, Führungswechsel.

${ }^{28}$ Ebenda, S. 345 f. Vgl. ebenda, S. 337 f., Erklärung des bayerischen Pfarrervereins vom 10.4. 1933.

Zitate aus der bayerischen Kirchenpresse bei Meier-Reutti, Politik, S. $310 \mathrm{ff}$. 
nungen: ,Viele Parteimitglieder, deren kirchliche Treue und Aktivität über allen Zweifel stand, hegten, erweckten und stärkten die heiße Hoffnung, daß hier eine Volksbewegung entstanden sei, die das Volk nach langem Irrgang wieder in gesegnete, alte Bahnen der Frömmigkeit und Ehrbarkeit zurückführen wolle; ja man konnte glauben, es erneuerten sich bald die Zeiten der Reformation, wo die Anliegen des Glaubens und der Rückkehr zu Gott die eigentlich treibenden Kräfte waren. "29 Bereits zur Machtübernahme Hitlers waren in Bayern teilweise die Kirchenglocken geläutet worden; und am 1. Mai 1933 marschierten die Münchner Pfarrer auf Anweisung des Landeskirchenrats mit Hakenkreuzbinden zu einer Massenkundgebung auf der Theresienwiese. Wer sich, wie Hermann Dietzfelbinger, weigerte, weil er darin eine unwürdige , Prostitution“ der Kirche vor den politischen Mächten sah, hatte im Kollegenkreis keinen leichten Stand ${ }^{30}$.

Im Mai 1933 wählte eine außerordentliche Synode Meiser zum Landesbischof. Der bis dahin unbekannte Titel ,Landesbischof“" sollte die Abwendung vom synodal-demokratischen Prinzip, das im bisherigen Titel „Kirchenpräsident" zum Ausdruck kam, verdeutlichen. Das politische Motiv der Titeländerung ist offensichtlich, da ihr keine Diskussion über das dem lutherischen Bekenntnis angemessene Kirchenverständnis vorausgegangen war. Bedeutsamer war die Entscheidung der Synode, sich mit einem kirchlichen Ermächtigungsgesetz, das zum Teil wortwörtlich dem Ermächtigungsgesetz für Hitler nachgebildet war, selbst zu entmachten ${ }^{31}$. Mit der Wahl Meisers, die von den Deutschen Christen unterstützt wurde, übernahm allerdings ein bekenntnistreuer Lutheraner die Kirchenleitung, so daß sich das Ermächtigungsgesetz, das bis Mitte 1946 in Kraft blieb, für die Sicherung und den Bestand der Kirche positiv auswirkte, während es in anderen Landeskirchen verheerende Folgen hatte.

Hans Meiser, Jahrgang 1881, entstammte einer alteingesessenen, nationalliberalen Nürnberger Kaufmannsfamilie. Nach einem Volkswirtschafts- und Theologiestudium begann er seine Laufbahn als Pfarrer der Inneren Mission in München. Dort wurde er während der Revolutionswirren der Münchner Räterepublik kurzfristig als Geisel verhaftet, was seine politische Orientierung nachhaltig bestimmte. Von 1922 leitete Meiser das neugegründete Predigerseminar in Nürnberg, ab 1928 gehörte er dem Landeskirchenrat als Oberkirchenrat an. Meiser war kein bedeutender Theologe oder hinreißender Prediger, sondern ein Mann der Kirche, vor allem der kirchlichen Verwaltung. Dibelius beurteilte ihn treffend als einen ,,verantwortungsbewußten, sorgfältigen Hausvater seiner Kirche. Er war eine Beamtennatur - freilich von hohen Graden“32. Geprägt vom orthodoxen Luthertum des 19. Jahrhunderts, lebte Meiser in tiefem Respekt und Gehorsam vor der Obrigkeit. Der Erhalt der bayerischen Landeskirche, die Bewahrung des lutherischen Einflusses in den Gremien der evangelischen Kirche und die Festigung der gesellschaftlichen Position der Kirche galt ihm als oberstes Ziel.

Meiser übernahm sein Amt in einer Zeit schwerer innerkirchlicher Konflikte. Zwar waren die Deutschen Christen bis Mitte 1933 in Bayern nicht stark vertreten, doch nach und nach traten ihnen 100 bis 200 Pfarrer bei ${ }^{33}$. Bei den staatlich aufgezwungenen Kir-

29 LKAN, Kreisdekan Nürnberg 14-502, Übersicht über den Kirchenkampf vom Mai 1945.

$30 \mathrm{Vgl}$. Henn, Führungswechsel, S. 328; Dietzfelbinger, Veränderung, S. 111.

$31 \mathrm{Vgl}$. Henn, Führungswechsel, S. $360 \mathrm{ff}$.

${ }^{32}$ Dibelius, Ein Christ, S.265. Vgl. Dietzfelbinger, Landesbischof Meiser.

${ }^{33}$ Baier, Deutsche Christen Bayerns, S. 52. 
chenwahlen im Juli 1933 erreichten sie eine deutliche Mehrheit. Auffallend hoch ist unter den führenden Deutschen Christen der Anteil an ausgezeichneten Kriegsteilnehmern und Freikorpskämpfern ${ }^{34}$. Ihr Altersdurchschnitt lag 1933 bei 40 Jahren, es gab aber auch wesentlich ältere Pfarrer, die sich stark für die Deutschen Christen engagierten: wie Heinrich Daum und Max Sauerteig, der als ,,alter Kämpfer" mit Hitler persönlich bekannt war. Diese Angaben erlauben zwar keine repräsentativen Aussagen über die Gesamtmitgliedschaft, zeigen aber doch, daß das Verhalten führender DC-Pfarrer nicht mit jugendlichem Idealismus erklärt werden kann, sondern als Ausformung nationalprotestantischer Traditionen zu verstehen ist.

Im Oktober 1933 billigte Meiser die Richtlinien, die sich die bayerischen Deutschen Christen in Abgrenzung zur Reichsleitung in Berlin gegeben hatten. Sie enthielten die Verpflichtung zum „Kampf gegen die Gegner des Christentums“, wozu namentlich Liberalismus, Atheismus und Marxismus, aber auch das Neuheidentum völkischer Provenienz zählten, und den Aufruf zur ,,Vermittlung zwischen Nationalsozialismus und evangelischer Kirche“. Neben dem Bekenntnis zum ,,unverfälschten Evangelium“ stand das Bekenntnis zu Adolf Hitler, ,,der deutsche Art und deutsches Wesen kraftvoll gegen undeutsches Wesen und fremde Art durchsetzt" ${ }^{\text {"35. }}$. Bereits zuvor hatte Meiser Vikar Eduard Putz, NSDAP-Mitglied seit 1927, als theologischen Hilfsreferenten in den Landeskirchenrat berufen und Friedrich Klein, NSDAP-Mitglied seit 1927 und seit 1931 Leiter der Arbeitsgemeinschaft nationalsozialistischer evangelischer Pfarrer auf Reichsebene, zu seinem Beauftragten für die Verhandlungen mit Reichsbischof Müller ernannt ${ }^{36}$. Auch die Stelle des ,,Sonderbeauftragten“ für Volksmission wurde mit einem Mitglied des NS-Pfarrerbundes und der Deutschen Christen besetzt. Helmut Kern erwies sich jedoch wie Putz als ein unbedingt loyaler Gefolgsmann Meisers. Die Volksmission verstand sich als die ,,SA der Kirche" und wollte zugleich dem ,, völkischen Erwachen" wie dem Evangelium dienen ${ }^{37}$. Nach der DC-Kundgebung im Berliner Sportpalast, in der ,,die Befreiung von allem Undeutschen im Gottesdienst und im Bekenntnismäßigen, Befreiung vom Alten Testament mit seiner jüdischen Lohnmoral, von diesen Viehhändlerund Zuhältergeschichten " gefordert worden war ${ }^{38}$, verpflichtete Meiser im November 1933, in Anwendung des Führerprinzips, alle Pfarrer auf ,, unbedingten Gehorsam “. Von 1266 Geistlichen, deren Antwort überliefert ist, gelobten 1236 unter allen Umständen Treue, 19 stimmten bedingt zu, 11 lehnten die geforderte Erklärung $\mathrm{ab}^{39}$. Anfang Dezember erklärten dann die bayerischen Deutschen Christen ihre Selbstauflösung.

Bei den Auseinandersetzungen um die Nominierung des Reichsbischofs hatte Meiser von Anfang an Ludwig Müller, den Vertrauensmann Hitlers und Schirmherrn der Deut-

${ }^{34} \mathrm{Zu}$ ihnen gehörten die Pfarrer: Hans Baumgärtner, Ludwig Beer, Hans Gollwitzer, Gottfried Fuchs, Friedrich Klein, Friedrich Kroll, Kurt Halbach, Friedrich Möbus, Christian Seiler, Hans Sommerer und Karl Werlin. Zu den DC-Aktivisten zählten ferner Wolf Meyer und Hans Greifenstein. Biographische Angaben bei Baier, Deutsche Christen Bayerns, S.83f., 111, 130, 98, 185, 131, 100, 98, 97, 59, 111, 257. Zu Klein vgl. Verantwortung, Bd.1, S. 535.

${ }^{35}$ In: Baier, Deutsche Christen Bayerns, S.346ff.

36 Vgl. Verantwortung, Bd. 1, S. 553, 535.

${ }^{37}$ Die Berichte der Volksmission von 1933/34 sind auszugsweise abgedruckt, in: Bayern in der NS-Zeit, Bd. 1, S. 369-406. Vgl. Henn, Volksmission.

${ }^{38}$ Vgl. Scholder, Kirchen, Bd. 1, S. 702 ff.

${ }^{39}$ Baier, Deutsche Christen Bayerns, S.74. 
schen Christen, unterstützt, ,,weil“, wie Baier urteilt, ,,Hitler ihn wünschte“40. Nach dem Sportpalastskandal einigten sich alle nicht-deutschchristlichen Kirchenführer, die Absetzung Müllers zu betreiben. Doch der Vorstoß bei Hitler am 25. Januar 1934, der als Schiedsherr fungieren sollte, endete mit der erneuten Unterstellung der Führer der ,, intakten“ Landeskirchen unter Müller"1. Der ,Pfarrernotbund“ unter Martin Niemöller und die Bruderräte bezichtigten daraufhin die ,,intakten“ Kirchen des Verrats an der gemeinsamen Sache, die ihrerseits den Vorwurf der Spaltung zurückgaben und mit dem Austritt der bayerischen, hannoverschen und württembergischen Pfarrerschaft den Notbund entscheidend schwächten.

Vor dem Hintergrund der rechtswidrigen Gleichschaltungspolitik des Reichsbischofs erfolgte im Frühjahr 1934 die Konstituierung der Bekennenden Kirche, in der sich die „,intakten" Landeskirchen mit den Bruderräten aus den deutschchristlich dominierten Kirchen zusammenfanden. Mit der ,Barmer Theologischen Erklärung“ von Ende Mai 1934 bekräftigte die Bekennende Kirche als innerkirchliche Minderheit ihren Anspruch, einzig legitime und rechtmäßige evangelische Kirche zu sein, und verwarf die Theologie der Deutschen Christen als Irrlehre ${ }^{42}$. Die Gegenbewegung zu Barmen meldete sich in Bayern einen Monat später im ,,Ansbacher Ratschlag“ zu Wort. Er war von führenden Deutschen Christen und Mitgliedern des NS-Pfarrerbundes unterzeichnet; theologisches Gewicht verlieh ihm allerdings erst die Beteiligung von Althaus und Elert. Der Ratschlag beharrte auf der in Barmen verworfenen Auffassung, daß sich Gott neben der Offenbarung in Christus auch in den sogenannten ,Urordnungen“, Familie, Volk und Rasse, offenbare. Das Manifest endete mit dem Dank an Gott für den ,,Führer als ,frommen und getreuen Oberherrn“" und für den NS-Staat als ein ,,,gut Regiment', ein Regiment mit ,Zucht und Ehre'“433.

Im Herbst 1934 erfolgte die offene Rebellion gegen Meiser, als die NS-Fraktion der Landessynode die Eingliederung der Landeskirche in die Reichskirche forderte. Úber diese Auseinandersetzung spaltete sich der NS-Pfarrerbund, dem damals 268 Pfarrer angehörten ${ }^{44}$. Rund 250 Pfarrer schlossen sich der wiedergegründeten DC-Organisation um Heinrich Daum an und verlangten den Rücktritt Meisers, der auch von der NSDAP gefordert wurde. Am 11. Oktober erklärte Reichsbischof Müller, unterstützt vom bayerischen Innenminister Wagner, Meiser für abgesetzt. Delegationen fränkischer Bauern bestürmten daraufhin Partei- und Staatsstellen und erklärten im Namen von 75000 Unterzeichnern warnend: ,,Die fränkischen Bauern sind ebenso fanatische Vorkämpfer für ihren Glauben, wie sie es gewesen sind für das Dritte Reich. "45 Auch die Regierung registrierte, daß die politische Loyalität auf dem Spiel stand. Reichsstatthalter Epp berichtete

\footnotetext{
${ }^{40}$ Baier, Verhalten, S. 94. Einen Überblick über die Haltung der bayerischen Landeskirche im Kirchenkampf gibt Meier, Kirchenkampf, Bd. 1, S. 455-468, Bd.2, S. 355-341, Bd.3, S. 461-474. Zur Beurteilung der Situation durch Meiser vgl. die bedeutende Dokumentation der Mitschriften Meisers: Verantwortung.

${ }^{41} \mathrm{Vgl}$. Scholder, Kirchen, Bd. 1, S. $37 \mathrm{ff}$; Verantwortung, Bd. 1, S. $201 \mathrm{ff}$.

42 Vgl. Scholder, Kirchen, Bd.2, S. $159 \mathrm{ff}$.; Nicolaisen, Weg nach Barmen.

43 In: Baier, Deutsche Christen Bayerns, S. $383 \mathrm{ff}$. Weitere Unterzeichner waren die Pfarrer Gottfried Fuchs, Hans Grießbach, Christian Seiler, Hans Sommerer, Karl Werlin sowie Studienrat Ernst Fikentscher.

${ }_{44}$ Meier, Kirchenkampf, Bd. 1, S. 462.

45 In: Georg Mack, Entscheidungsvolle Tage der evangelisch-lutherischen Kirche in Bayern 1934, Ansbach 1958, S.22f. Vgl. Baier, Deutsche Christen Bayerns, S. $128 \mathrm{ff}$.
} 
nach Berlin, daß mit polizeilichen Mitteln keine Befriedung mehr möglich sei: ,,Diese ist umso dringender geboten, als in beiden evangelischen Lagern zahlreiche alte Kämpfer stehen und ein lang andauernder Streit die Keimzelle zu einem Zwiespalt in der Bewegung bilden kann. "46 Âhnlich hieß es in einem Lagebericht der Regierung von Ober- und Mittelfranken: ,,Gerade die kirchlich gesinnten evangelischen Kreise, die hinter ihrem Landesbischof stehen, zählten und zählen auch jetzt noch mit zu den treuesten Anhängern des Nationalsozialismus. Es ist ein tragisches Verhängnis, daß gerade sie in dem Konflikt zwischen Reichsbischof und Landeskirche durch den von ihnen freudigst bejahten Staat gekränkt werden müssen. "47 Die Erregung nahm schließlich solche Ausmaße an, daß die NS-Führung, nicht zuletzt aus außenpolitischen Gründen, ihre Unterstützung des Gleichschaltungsversuchs aufgab. Nach einem Empfang bei Hitler konnten Meiser und Wurm, der ebenfalls für abgesetzt erklärt worden war, Anfang November die Amtsgeschäfte wieder aufnehmen ${ }^{48}$.

Dennoch befürwortete Meiser auch weiterhin die Tolerierung der Deutschen Christen, die er zu integrieren hoffte, und ging einer Auseinandersetzung mit der von ihnen vertretenen völkischen Theologie aus dem Wege. Fünf von 63 unbotmäßigen Pfarrern, die sich hinter die von Reichsbischof Müller eingesetzte Kirchenleitung gestellt hatten, wurden allerdings entlassen ${ }^{49}$. Bis Kriegsende gehörten dem Landeskirchenrat mit Dekan Friedrich Hanemann, NSDAP-Mitglied seit 1929, und Hans Greifenstein zwei gemäßigte Deutsche Christen an, die als Referenten für Schul- und Jugendfragen bzw. für den theologischen Nachwuchs bedeutende Positionen innehatten. Mitte 1935 zählten die Deutschen Christen in 167 Ortsgruppen 14304 Mitglieder, denen bei einer Gesamtseelenzahl von 1,6 Millionen 398171 eingeschriebene Mitglieder der Bekennenden Kirche gegenüberstanden ${ }^{50}$. Die Masse der Kirchenmitglieder verhielt sich, wie nicht anders zu erwarten, neutral und nahm an den innerkirchlichen Konflikten nicht teil. 1935/36 kam Meiser den Deutschen Christen weit entgegen und bot ihnen die Uberlassung von Kirchen und Pfarrstellen an. Die Befriedungsverhandlungen scheiterten jedoch seitens der Deutschen Christen. Als sich die ,, weltanschaulichen Distanzierungskräfte“ innerhalb der NSDAP 1937/38 immer mehr durchsetzten und die NSDAP schließlich den Deutschen Christen die Unterstützung entzog, versanken sie in Bayern in die Bedeutungslo-

${ }^{46}$ Epp an Frick vom 20.9.1934. Zit. nach Baier, Landeskirche, S. 77. Vgl. Siebert an Frick vom 20.10.1934. Zit. bei Scholder, Kirchen, Bd.2, S. 332.

${ }^{47}$ Lagebericht vom 9.10.1934, in: Kirchliche Lage, Bd. 2, S.33. Bis Herbst 1934 wurde die evangelische Kirche in den Regierungspräsidentenberichten von Ober- und Mittelfranken überhaupt nicht erwähnt, während die katholische Kirche und ihre Verbände von Anfang an als regimekritisch galten.

$48 \mathrm{Vgl}$. Scholder, Kirchen, Bd.2, S. $309 \mathrm{ff}$.

49 Vgl. Baier, Deutsche Christen Bayerns, S. 145.

so Eine Statistik der Dekanate vom Juni 1935 ergibt folgendes Bild:

\begin{tabular}{lccc} 
Kirchenkreis & Seelenzahl & BK-Gemeinde & DC-Gemeinde \\
\hline Ansbach & 344066 & 140227 & 4245 \\
Bayreuth & 522386 & 76620 & 2380 \\
München & 291822 & 48324 & 1671 \\
Nürnberg & 481844 & 133000 & 6000 \\
\hline
\end{tabular}

\begin{tabular}{llll}
\hline Summe & 1640118 & 398171 & 14304
\end{tabular}

(Baier, Deutsche Christen Bayerns, S. $446 \mathrm{ff}$. ). 
sigkeit. Lediglich in einzelnen Gemeinden vermochten sie sich noch zu halten, wobei eine zunehmende Radikalisierung festzustellen ist, die im Aufruf zum Kirchenaustritt gipfelte. Dennoch zog der Landeskirchenrat bis Mai 1945 die von Deutschen Christen gezahlten Kirchensteuern auf ein Sonderkonto zur freien Verfügung der DC-Gemeinden ein ${ }^{\mathbf{5 1}}$.

Im Unterschied zu den Deutschen Christen trat die im Mai 1934 gegründete Pfarrbruderschaft, die sich als geistliche Sammlung der BK-Pfarrer verstand, nach außen kaum in Erscheinung. Charakteristisch für die ungeklärten Fronten des Kirchenkampfes war der Beschluß, die gleichzeitige Mitgliedschaft im NS-Pfarrerbund zuzulassen ${ }^{52}$. Hierin spiegelte sich das allgemeine Selbstverständnis der Bekennenden Kirche wider, die ihre kirchenpolitische Opposition gegen die Deutschen Christen nicht als politische Opposition gegen das NS-Regime begriff. So ist es nicht verwunderlich, daß gerade auch in Bayern nicht wenige BK-Pfarrer meinten, gleichzeitig gute Nationalsozialisten und gute lutherische Theologen sein zu können. Wegweisende theologische Stellungnahmen zur christlichen Bekenntnisproblematik sind von der Pfarrbruderschaft, die sich nicht als Organ des Reichsbruderrats verstand, während der NS-Diktatur nicht erarbeitet worden. Dennoch erwartete sie, zumal in späteren Jahren, wie Dietzfelbinger berichtet, ,,bei vielen Entscheidungen statt der Anpassung an die Situation eine größere Klarheit des Zeugnisses gerade bei dem [Meiser], der so stark von der Bindung an das lutherische Bekenntnis sprechen konnte" 53 . Auf Unverständnis stieß etwa der Beschluß, nach der Verhaftung Niemöllers seinen Namen nicht in die sonntägliche Fürbitte aufzunehmen, die Kanzelabkündigung zum ,,Anschluß“ Osterreichs oder die Anordnung, die Pfarrhäuser am Tage der Beisetzung Ludendorffs, eines führenden Propagandisten des völkischen Neuheidentums, feierlich zu beflaggen ${ }^{54}$.

Zwar hatte das Ansehen der NSDAP durch die Gewaltakte des Kirchenkampfes gelitten, doch wirkte der , Führermythos“, gestützt auf die außenpolitischen Erfolge Hitlers, weiter. Viele Pfarrer und Gemeindeglieder waren nach den Worten Karl Steinbauers "wie benommen, trunken in nationaler Begeisterung und stockblind"55. Auch Meiser forderte im März 1936 die Geistlichen auf, ihre ,,schweren Gewissensbedenken“ wegen der ,, widerchristlichen und gegenkirchlichen Bestrebungen“" gewisser Parteikreise zurückzustellen und in dem Referendum anläßlich der Remilitarisierung des Rheinlandes mit , Ja" zu stimmen ${ }^{56}$. Im Oktober 1936 distanzierte sich Meiser, zusammen mit Marahrens und Wurm, von der Denkschrift der 2. Vorläufigen Leitung der Bekennenden Kirche an Hitler, in der die Bruderräte erstmals die permanente Verletzung rechtsstaatlicher Grundsätze beim Namen genannt hatten, und wehrte sich gegen den Vorwurf der

51 Vgl. ebenda, S. $347 \mathrm{ff}$.

52 Vgl. Meier, Kirchenkampf, Bd.3, S. 468f. Zum inneren Führungskreis gehörten Kurt Frör, seit 1932 Inspektor des Nürnberger Predigerseminars; Helmut Kern, Leiter der Volksmission, ab 1939 Dekan in Nördlingen; Eduard Putz; Julius Schieder, Direktor des Nürnberger Predigerseminars, ab 1935 Oberkirchenrat und Kreisdekan von Nürnberg; Hans Schmidt, Studentenseelsorger; Hermann Schlier und Julius Sammetreuther, ab Oktober 1934 Oberkirchenrat. Dem NS-Pfarrerbund gehörten zeitweise Putz, Kern und Schlier an.

53 Dietzfelbinger, Veränderung, S. 117.

54 LKAN, LKR 285, Aktennotiz Meisers über Besprechung mit Vertretern der Pfarrbruderschaft vom 28.4.1938. Kanzelabkündigung, in: Amtsblatt für die Evangelisch-Lutherische Kirche in Bayern rechts des Rheins, Nr.7 vom 18.3.1938, S. 43.

55 IfZ, Fa 323, Steinbauer, Erinnerungen, S. 106. Vgl. allg. Kershaw, Hitler-Mythos.

56 Rundschreiben Meisers vom 20.3.1936. Ebenda. 
nationalen Unzuverlässigkeit mit der Kanzelabkündigung: „,Und das alles geschieht in einer Zeit, wo unsere Kirche mit dem ganzen deutschen Volk im Kampf gegen die heutigen Greuel des Bolschewismus in Rußland und Spanien steht und wo alle Kräfte zur Durchführung des Vierjahrplanes zusammengefaßt werden müssen. " 57 Im gleichen Jahr unterstellten sich die ,,intakten" Landeskirchen dem staatlich eingesetzten Reichskirchenausschuß, der von den Bruderräten, soweit sie an den Beschlüssen der Dahlemer Bekenntnissynode von 1934 über das kirchliche Notrecht festhielten, boykottiert wurde. Als sich die lutherischen Bischöfe von der Friedensliturgie des altpreußischen Bruderrats zur Tschechenkrise 1938 aus ,, religiösen und vaterländischen Gründen“ distanzierten 58 , war der Bruch der Bekennenden Kirche endgültig besiegelt.

Ende September 1939 rief der Landeskirchenrat in einer Kanzelabkündigung zum Polenfeldzug die Gemeinden auf, Gott zu danken: ,, Wir danken Ihm, daß Er unseren Waffen einen schnellen Sieg gegeben hat. Wir danken Ihm, daß uralter deutscher Boden zum Vaterland heimkehren durfte und unsere deutschen Brüder nunmehr frei und in ihrer Zunge Gott im Himmel Lieder singen können. "599 Ebenso wurden die Gemeinden nach dem Frankreichfeldzug aufgerufen, ,,Adolf Hitler, dem Schöpfer und obersten Befehlshaber der sieggekrönten Wehrmacht", zu danken und für einen ,,baldigen Endsieg “ zu beten ${ }^{60}$. Zu Beginn des Rußlandfeldzuges hieß es dann, daß die evangelische Kirche im Kampf gegen den ,,Todfeind aller Ordnungen und aller abendländischen christlichen Kultur" geschlossen hinter Hitler stehe und hoffe, daß , in ganz Europa unter Ihrer Führung eine neue Ordung erstehe und aller inneren Zersetzung, aller Beschmutzung des Heiligsten, aller Schändung der Gewissensfreiheit ein Ende gemacht werde" ${ }^{\text {c61 }}$. Noch 1943 wurde zum „Führergeburtstag“ von den bayerischen Kanzeln dafür gebetet, daß Gott dem Führer , ,zur Seite stehe und sein Werk mit Segen kröne“, was manchen Pfarrern immer schwerer fiel ${ }^{62}$. Die Auswirkungen solcher Abkündigungen und Fürbitten können kaum überschätzt werden, mußten sie doch vielen Gemeindegliedern die Überzeugung geben, für eine gute und gerechte Sache zu kämpfen.

Ernüchterung setzte erst langsam ein, als die Verbrechen des NS-Regimes in den besetzten Ostgebieten und die systematische Vernichtung des europäischen Judentums bekannt wurden. Dennoch weigerte sich Meiser 1943, die Denkschrift eines Münchner Laienkreises, die in seltener Klarheit zur Judenvernichtung Stellung nahm, als kirchlichen Protest an staatliche Stellen weiterzuleiten. Den Laien erklärte Meiser, daß er per-

57 Kanzelabkündigung zum Reformationsfest vom 29.10.1936. Ebenda, S. 191. Daraufhin schrieb Steinbauer, der damals in harten Konflikten mit der Kirchenleitung stand, am 12.12.1936 an Meiser: ,Wenn wir zur Bezeugung des Kreuzes Christi aufgerufen sind, haben wir nicht die Existenzberechtigung der Kirche durch ihre Rentierlichkeit als Bolschewistenbekämpfer und Helfer des Vierjahrplanes irgendwie beweisen zu wollen. "Ebenda. Zur Denkschrift der 2. Vorl. Leitung vgl. Greschat, Widerspruch.

${ }^{58}$ Vgl. Meier, Kirchenkampf, Bd. 3, S. 54 ff. Die Friedensliturgie wurde auch von der Pfarrbruderschaft abgelehnt. Vgl. ebenda, S. 470.

59 In: Höchstädter, Strudel der Zeiten, S. 60.

${ }^{60}$ In: Amtsblatt für die Evangelisch-Lutherische Kirche in Bayern rechts des Rheins, Nr. 17 vom 26.6.1940, S.61. Vgl. Baier, Kirche in Not, S.24.

61 Telegramm des Geistlichen Vertrauensrates der DEK an Hitler vom 30.6.1941, in: KJ 1933-1944, S. 478. Das Telegramm wurde auch in Bayern von den Kanzeln verlesen.

${ }^{62}$ In: Amtsblatt für die Evangelisch-Lutherische Kirche in Bayern rechts des Rheins, Nr. 8 vom 15.4.1943, S.23. Vgl. Dietzfelbinger, Veränderung, S. $118 \mathrm{f}$. 
sönlich die Verbrechen aus ganzem Herzen verurteile; als Bischof trage er jedoch die Verantwortung für eine große Landeskirche und schließlich wäre mit seiner Verhaftung den Juden auch nicht geholfen ${ }^{63}$. Dem Schweigen der evangelischen Kirche als Institution, sieht man von den Protesten Wurms ab, lag neben taktischen Erwägungen, die bei Meiser offensichtlich sind, das theologisch unbewältigte Problem des christlichen Antisemitismus zugrunde. Nur so ist es zu verstehen, daß der Landeskirchenrat noch im August 1944 einen offen antisemitischen Vortrag des Tübinger Theologieprofessors Gerhard Kittel als „Berufshilfe“ an die Pfarrerschaft verschicken konnte. Empört schrieb daraufhin Sasse an Meiser: , Ich fürchte, das Maß an Mitschuld, das wir alle an gewissen Vorgängen haben, ist schon zu groß, als daß wir nun auch noch die Sünden des Herrn Kittel uns aufladen sollten. " 64

Andererseits leisteten auch bayerische Pfarrer als Privatpersonen mutigen Widerstand wie Walter Höchstädter mit einer Mitte 1944 in Frankreich illegal gedruckten Flugschrift, die zum christlichen Bekenntnis für die Juden aufrief: ,,Das Blut von Millionen hingeschlachteter Juden [...] schreit heute gen Himmel. Da darf die Kirche nicht schweigen. Sie darf nicht sagen, die Regelung der Judenfrage sei eine Angelegenheit des Staates, wozu er aufgrund von Röm. 13 ein Recht habe. Die Kirche darf auch nicht sagen, in der heutigen Zeit vollziehe sich eben die gerechte Strafe für die Sünden der Juden. [...] Alle Ergebenheitskundgebungen und -telegramme von Kirchenführerkonferenzen und Bischöfen lutherischer Prägung fällten höchst unbiblische Werturteile und trugen damit nur mit bei zu der heillosen Verwirrung der Geister." 65

Mit den Schilderungen des Kirchenkampfes aus der unmittelbaren Nachkriegszeit ${ }^{66}$ als eines heroischen Widerstands um des christlichen Bekenntnisses willen hat die Realität nur wenig gemein. Legt man die von Bethge entwickelte Typologie zur kirchlichen Widerstandsproblematik zugrunde ${ }^{67}$, so leistete die bayerische Landeskirche auf der Ebene der kirchenpolitischen Opposition Widerstand, der seinen Höhepunkt im Herbst 1934 in der Abwehr des Gleichschaltungsversuchs mit der deutschchristlich dominierten Reichskirche erreichte. Der partielle Übergang zur offenen weltanschaulich-religionspolitischen Gegnerschaft, den Teile der bruderrätlich orientierten Bekennenden Kirche ab 1936 vollzogen, wurde von der Kirchenleitung nicht mehr mitgetragen, um die behauptete landeskirchliche Autonomie nicht zu gefährden. Im Vergleich zu den deutschchristlich dominierten Kirchen bewahrte sich jedoch die bayerische Landeskirche eine weitgehende Resistenz gegen die Indienstnahme der Verkündigung zur Propagierung nationalsozialistischer Weltanschauungstheoreme. Unter dem Gesichtspunkt der Erhaltung der volkskirchlichen Substanz und der institutionellen Bestandssicherung ist das taktierende Verhalten Meisers, der die überwiegende Mehrheit der Pfarrerschaft hinter sich wußte, verständlich und als durchaus erfolgreich zu beurteilen. Gelang es doch nur der bayerischen und der württembergischen Landeskirche, die Einsetzung eines staatlichen ,Lan-

${ }^{63}$ Vgl. Baier, Kirche in Not, S. 233; Diem, Sine vi sed verbo, S. 108 ff.; Höchstädter, Strudel der Zeiten, S. $228 \mathrm{ff}$.

64 Zit. nach Baier, Kirche in Not, S. $235 \mathrm{f}$.

${ }^{65}$ Darum seid nüchtern! Ein Gruß an die Brüder (Sommer 1944), in: Greschat, Schuld, S. 32-36, Zitat S. 34f. Vgl. Höchstädter, Strudel der Zeiten, S. $262 \mathrm{ff}$.

66 So beispielsweise 1946 der Vorsitzende des bayerischen Pfarrervereins Klinger, Dokumente zum Abwehrkampf, sowie 1947 Kirchenrat Schmid, Apokalyptisches Wetterleuchten.

${ }^{67}$ Bethge, Umstrittenes Erbe, S. $103 \mathrm{ff}$. 
deskirchenausschusses“ als Kirchenleitung und die Errichtung einer staatlichen ,,Finanzabteilung" zur Kontrolle des Haushalts abzuwehren. Auch wird man im historischen Urteil berücksichtigen müssen, daß keine Gruppierung der evangelischen Kirche zur Ebene des politischen Widerstands vorgestoßen ist. Dieser wurde immer nur von einzelnen Pfarrern und Laien aus eigener Verantwortung geleistet.

Neben dem Aspekt des partiellen Widerstands im weiten Begriffssinn, präziser der kirchenpolitischen Opposition, ist andererseits der Aspekt der Kooperation und der politischen Loyalität zu sehen. Im Konflikt zwischen der - auch von Meiser später als solcher erkannten - kirchen- und christentumsfeindlichen Politik der NS-Machthaber und den vermeintlich vom NS-Regime zu unterscheidenden Zielen des deutschen Staates überwog bis zuletzt die nationale Loyalität zu Hitler als dem politischen Führer Deutschlands. Selbstkritisch hielt daher Schieder, ein Sprecher der Pfarrbruderschaft, im Mai 1945 in einem persönlichen Rechenschaftsbericht fest: ,,Je fester sich eine kirchliche Gruppe an das Evangelium gebunden wußte, um so rückhaltsloser war und ist sie bereit, die eigenen Fehler zuzugestehen und mit ihnen strenger ins Gericht zu gehen als außenstehende Betrachter es wissen können. [. . . ] Jetzt, wo sich der Druck zu lösen beginnt, ist uns nicht ruhmvoll zu Mute." 68

\section{Zusammenbruch und Entnazifizierung}

Einen Einblick in die seelische Verfassung weiter evangelischer Bevölkerungskreise unmittelbar bei Kriegsende geben die Stimmungsberichte von Pfarrämtern an den Landeskirchenrat. Ubbereinstimmend registrierten die Pfarrer eine große Erleichterung über das Kriegsende. Aus Erlangen berichtete beispielsweise Dekan Walther Künneth: ,,Ohne Frage wurde das Einrücken der amerikanischen Wehrmacht als eine Befreiung vom Gewissenszwang der Partei begrüßt und vor allem das damit gekommene Ende der Bedrohung durch Luftangriffe dankbar empfunden. "69 Aus dem Dekanat Feuchtwangen hieß es: , Ein vernichtendes Urteil über die zusammengebrochene Parteiherrschaft liegt in der Tatsache, daß die Bevölkerung trotz des Verlustes äußerer Freiheit in mehr als einer Hinsicht aufatmet. Es mußte als Knebelung der inneren Freiheit empfunden werden, wenn die Drohungen mit Konzentrationslager und Galgen nicht aufhörten. “70 Etliche Pfarrer berichteten aber auch, daß der Glaube an den deutschen Endsieg teilweise bis zuletzt vorhanden war.

Der Zusammenbruch des Dritten Reiches wurde durchweg mit gemischten Gefühlen aufgenommen. Einerseits bedeutete er die Befreiung der Kirche von äußerem Druck, andererseits den Zusammenbruch des deutschen Staates. ,, Nun hat der Feind die Macht im Lande. Aber wir können Gott nur danken, daß er uns in die Macht eines Feindes gegeben hat, der bisher wenigstens nicht rücksichtslos von seiner Gewalt Gebrauch machte. “71

${ }^{68}$ LKAN, Kreisdekan Nürnberg 14-502, Ubersicht über den Kirchenkampf vom Mai 1945.

${ }^{69}$ Bericht des Dekanats Erlangen vom 17. 8. 1945. Die Berichte von 31 fränkischen Pfarrämtern und Dekanaten, deren Erstellung der Landeskirchenrat am 7. Mai 1945 angeordnet hatte, sind in dem unverzeichneten Faszikel ,, Berichte über die Vorgänge bei der militärischen Besetzung“ (zit. Berichte) im Bestand LKR des LKAN erhalten.

${ }^{70}$ LKAN, LKR, Berichte, Bericht vom 31.7.1945.

${ }^{71}$ LKAN, LKR, Berichte, Bericht des Pfarramts Ickelheim vom 6.6.1945. 
Nicht nur in Uffenheim wurden Ubergriffe der amerikanischen Truppen penibel notiert: „Die Redensarten von Gerechtigkeit, Humanität und christlicher Liebe, die man im Rundfunk zu hören bekommt, klingen uns dann seltsam in den Ohren. Empört mußten wir zusehen, wie deutsche Kriegsgefangene von Schwarzen durch unser deutsches Städtchen geführt wurden. “ In dem Bericht hieß es aber auch: ,Große Freude herrscht darüber, daß die Kirche wieder frei geworden ist zu ihrem Dienst und daß die amerikanische Militärregierung der Kirche für Predigt, Unterricht und Seelsorge allen Schutz angedeihen läßt. "72 Besorgt äußerten sich viele Pfarrer nach der Besetzung über den Niedergang von Moral und Sitte: ,,Was erlebt man nicht überall an menschlicher Schlechtigkeit und Gemeinheit. Mädchen und Weiber werden feil um Schokolade. Unwürdiges Verhalten von Alt und Jung läßt uns zum Gespött werden. Angeberei, Verleumdung und Bespitzelei treiben übelriechende Blüten." 73

Fast alle Pfarrämter berichteten von einer starken Zunahme des Kirchenbesuchs. 1945 und 1946 überwogen erstmals seit 1933/34 die Kircheneintritte (9895) wieder die Austritte (2031). Doch vermochten die sprunghaft erhöhten Eintrittszahlen der ersten Nachkriegsjahre die Verluste der Austrittswelle der Jahre 1935-1944 bei weitem nicht auszugleichen ${ }^{74}$. Wenig Illusionen über die vielzitierte ,Stunde der Kirche“" machte sich der Würzburger Dekan Georg Merz: ,, Der Zusammenbruch der Partei hat wohl bei den meisten eine Erschütterung der von der Partei propagierten Weltanschauung mit sich gebracht. Unbewußt verbindet sich damit bei vielen eine Zunahme der Achtung vor der Kirche. Daß sich die Kirche nicht umzustellen braucht, daß ihre gottesdienstliche Ordnung, ihre Lieder, ihr Katechismus die gleichen bleiben, ob nun das Hakenkreuz Hoheitszeichen einer Stadt ist oder das amerikanische Sternenbanner, empfinden sicherlich die meisten als einen Abglanz der Ewigkeit, die dem Werk der Kirche Gehalt und Bestand gibt. Aber über ein dumpfes Empfinden werden ganz wenige hinauskommen. "75

Einen anderen Vorgang, der die politische Kultur der Nachkriegszeit nachhaltig prägen sollte, benannte Künneth: ,,Ein merkwürdiges Licht auf den Charakterzustand der fränkischen Bevölkerung wirft freilich der Umstand, daß sofort nach der Besetzung durch die Amerikaner niemand etwas mit dem Nationalsozialismus zu tun haben wollte und ein Gesinnungswandel auch bei denen zur Schau getragen wurde, die eng mit der Partei verbunden waren. "76 Unverhohlene Skepsis sprach auch aus dem Bericht des Pfarramts Bad Soden: ,Viele kommen nun auf einmal wieder und suchen Anschluß an die bekennende Gemeinde, meist aber nicht aus ehrlicher, innerer Uberzeugung, sondern aus der berechnenden Hoffnung, die bisherige nationalsozialistische Parteizugehörigkeit und weltanschauliche Gesinnung auf jede nur irgendmögliche Weise zu vertuschen und zu verleugnen. "77 Landesbischof Meiser stellte hingegen als pastorale Richtlinie in seinem ersten Rundschreiben vom 7. Mai auf: ,,Alles in allem kann es jetzt nicht unsere Aufgabe sein, den Blick in die Vergangenheit zu richten und durch verdammende Urteile anderer nur die eigene Haltung zu rechtfertigen. [...] An denen, denen mit dem militäri-

\footnotetext{
72 LKAN, LKR, Berichte, Bericht des Dekanats Uffenheim vom 10.8.1945.

${ }^{73}$ LKAN, LKR, Berichte, Bericht des Dekanats Markt Erlbach vom 30.6.1945.

${ }^{74}$ Baier, Kirche in Not, S.32, Anm. 196. 1930-1932 standen 5007 Eintritten 6295 Austritte gegenüber, 1933-1944 betrug das Verhältnis 21463 zu 72978.

75 LKAN, LKR, Berichte, Bericht des Dekanats Würzburg vom 4.9.1945.

${ }^{76}$ LKAN, LKR, Berichte, Bericht des Dekanats Erlangen vom 17.8.1945.

77 LKAN, LKR, Berichte, Bericht vom 23.5.1945.
} 
schen und politischen Zusammenbruch alle Hoffnungen zerborsten sind, auf die sie ihr Leben bisher gebaut hatten, hat die Seelsorge der Kirche eine besondere Aufgabe. " 78 Untersucht man die vorhandenen Stimmungsberichte und Rundschreiben, so zeigt sich, daß der Blick der Gemeinden wie der Kirchenleitung primär auf den Wiederaufbau gerichtet war und die Bewältigung der durch den Nationalsozialismus gestellten Fragen nicht als ein vordringliches Problem der Kirche als moralischer Institution begriffen wurde. In diesen Kontext fügt es sich ein, daß im kirchlichen Amtsblatt kein Abdruck des Stuttgarter Schuldbekenntnisses vom Oktober 1945 erfolgte ${ }^{79}$.

Das Verhältnis zu den Besatzungstruppen wurde allgemein als gut beurteilt. Vielfach waren die Pfarrhäuser die erste Anlaufstelle, wenn es um die Benennung vertrauenswürdiger Personen für die provisorische Besetzung lokaler Verwaltungsstellen ging. , Uberall"c, so hieß es beispielsweise aus Würzburg, ,,bemühten sich die Kommandanten zur Herstellung der Ordnung um den Rat der Pfarrer"80. In Unkenntnis der örtlichen Situation mußten sich die Amerikaner nicht selten auf die Auskunft von Pfarrern verlassen, die selbst der NSDAP angehört hatten. In Coburg etwa bemühte sich ein belasteter Dekan, den ehemaligen NSV-Kreisleiter, Parteigenosse seit 1929, als städtischen Wohlfahrtsdezernenten im Amt zu halten, da er sich stets als ,,Verfechter kirchlicher Interessen“ bewährt habe. Als ihn die örtliche Militärregierung dennoch entließ, wurde er in kirchliche Dienste übernommen. In einem anderen Fall betrieb der Dekan mit Erfolg die Entlassung eines parteilosen Lehrers, der Kirche und Christentum scharf angegriffen hatte ${ }^{81}$. In Langenzenn wurde gar ein aktiver NSDAP-Pfarrer zum Bürgermeister ernannt ${ }^{\mathbf{8 2}}$. Nicht zuletzt aus diesem Anlaß untersagte Ende Mai 1945 der Landeskirchenrat den Pfarrern die Ubernahme jeglicher ,,außerkirchlicher Ämter", um parteipolitische Auseinandersetzungen vom seelsorgerlichen Dienst fernzuhalten. Weiterhin beschloß die Kirchenleitung, der Militärregierung nur über das kirchliche Verhalten einzelner Personen Auskunft zu erteilen ${ }^{83}$.

Am 9. Mai, einen Tag nach der bedingungslosen Kapitulation, suchte Captain Landeen, der Leiter der Religious Affairs Section der Militärregierung für Bayern, Meiser auf und bat ihn um Personalvorschläge für höhere und höchste Staatsämter. Im gleichen Sinne trat auch Colonel Keegan, der später General Patton als Militärgouverneur ablöste,

78 LKAN, LKR 274, Rundschreiben des Landeskirchenrats vom 7.5.1946.

79 Das Schuldbekenntnis wurde erst im März 1946, nachdem es eine heftige Kontroverse ausgelöst hatte, mit einer persönlichen Stellungnahme Meisers, in der er sich gegen jegliche politische Interpretation wandte, veröffentlicht. Vgl. Amtsblatt für die Evangelisch-Lutherische Kirche in Bayern rechts des Rheins, Nr. 5 vom 15.3.1946. Bereits im Juni 1945 plante Meiser die Herausgabe eines , ,kirchlichen Weißbuches", das den ,,Widerstand gegen die nationalsozialistische Kirchenfeindschaft und gegen die antichristliche Weltanschauung" dokumentieren sollte. Vgl. Rundschreiben Meisers vom 13.6.1945.

${ }^{80}$ LKAN, LKR, Berichte, Bericht des Dekanats Würzburg vom 4.9.1945. Vgl. LKAN, Dekanat Augsburg 284, Rundschreiben des Münchner Kreisdekans Daumiller vom 5. 5. 1945; LKAN, NL Langenfaß 119, Tagebuch des Münchner Dekans Langenfaß vom 30.4.-18.6.1945.

${ }^{81}$ LKAN, LKR, Berichte, Bericht des Dekanats Coburg vom 10.8.1945.

B2 LKAN, Kreisdekan Nürnberg 14-502, Schieder an Landeskirchenrat vom 28.4. 1945.

${ }^{83}$ LKAN, LKR 1759 a, Vollsitzung des Landeskirchenrats vom 31.5.-2.6. 1945. Das Verbot ,auBerkirchlicher Ämter" wurde mehrfach bekräftigt. Vgl. LKAN, LKR 1665 a, Vollsitzung des Landeskirchenrats vom 9./10.10.1945; LKAN, LKR 1188, Erlaß des Landeskirchenrats vom 28.6.1946. 
an den Landesbischof heran ${ }^{84}$. Aus dem Vorschlag Meisers für die Besetzung der bayerischen Staatsregierung wurden zwei Empfehlungen berücksichtigt: Ministerialdirektor Karl August Fischer übernahm im Kabinett Schäffer, den Kardinal Faulhaber als BVPPolitiker vorgeschlagen hatte, die Verwaltung des Innenministeriums; und Hans Meinzolt, der bisherige Vizepräsident des Landeskirchenrats, wurde Staatsrat im Kultusministerium und damit oberster Verwaltungsbeamter ${ }^{85}$.

Als Colonel Colberg, der Leiter der Rechtsabteilung der Militärregierung, am 4. Juni Meiser wegen der Benennung geeigneter Juristen für die Neuordnung des Justizwesens aufsuchte, zeigten sich die Schwierigkeiten der evangelischen Kirche, den ihr indirekt zugestandenen politischen Einfluß zu nutzen. Mußte doch Meiser erklären, daß er ,,nur dann eine Liste geeigneter Juristen vorlegen könne, wenn Parteigenossen nicht von vornherein ausgeschlossen sein sollen" ${ }^{\text {"86. }}$. Von den neun vorgeschlagenen Juristen wurden vier von der Militärregierung akzeptiert und in Führungspositionen eingesetzt. Drei weitere konnten wegen ihrer politischen Belastung erst nach 1947 wieder im Justizwesen tätig werden, die anderen beiden Juristen wurden nach 1945 nicht mehr in den Staatsdienst aufgenommen. Als Ende September 1945 Ministerpräsident Schäffer, dem die Verschleppung der Entnazifizierung vorgeworfen wurde, zurücktreten mußte, wurde auch Fischer seine politische Vergangenheit als NSDAP-Mitglied zum Verhängnis. Meinzolt, dem die Mitgliedschaft im Freikorps Epp und in verschiedenen NS-Organisationen vorgehalten wurde, konnte nur durch den massiven Einsatz des neuen, sozialdemokratischen Ministerpräsidenten Hoegner im Amt bleiben und wurde als Zeichen der kirchenfreundlichen Haltung der bayerischen Sozialdemokratie sogar zum Staatssekretär befördert $^{87}$. Die Vorgänge zeigen, daß Meiser anscheinend kaum kirchlich gebundene Persönlichkeiten mit einwandfreier demokratischer Vergangenheit zur Verfügung standen, was seine ablehnende Haltung gegenüber jeder umfassenden politischen Säuberung erklären dürfte.

Ein weiteres Motiv für Meisers Bedenken hinsichtlich der Entnazifizierung findet sich in Gesprächsnotizen mit amerikanischen Offizieren, so am 15. Mai nach einer Unterredung mit Landeen: , Ich wies auf die Gefahr revolutionärer Strömungen hin, wenn kein Brot und keine Arbeit geschaffen wird. "88 Vier Tage später bat er Knappen, den Leiter der Religious Affairs Abteilung von OMGUS, ,,den General Eisenhower über die allgemeine Lage zu unterrichten, Gefahr der Hungersnot, Verelendung des Volkes, Not der wegen Parteizugehörigkeit Entlassenen, Gefahr der Bolschewisierung“899. Bemerkenswert ist der frühe Zeitpunkt der Fürsprache für entlassene Nationalsozialisten. Denn die ersten Entlassungen richteten sich in aller Regel gegen die politischen Repräsentanten des alten Regimes, Bürgermeister, Landräte und hohe Behördenleiter, während der eigentliche Verwaltungsapparat bis zur festen Etablierung der Militärregierung kaum betroffen war. Im Landkreis Ansbach etwa waren im Juli 1945 von 82 Bürgermeistern erst 47 auf-

${ }^{84}$ LKAN, NL Meiser 212, Aktennotiz Meisers vom 9.5.1945 und 24.5.1945.

${ }^{85}$ Gesamter Personalvorschlag, in: Nicolaisen/Vollnhals, Kirche, S. $134 \mathrm{f}$.

${ }^{86}$ LKAN, NL Meiser 212, Aktennotiz vom 4.6.1945. Vgl. LKAN, LKR 524, Personalvorschläge für Oberst Colberg vom 6.6.1945 und 8.6.1945.

${ }^{87} \mathrm{Vgl}$. Wilhelm Hoegner, Der schwierige Außenseiter. Erinnerungen eines Abgeordneten, Emigranten und Ministerpräsidenten, München 1959, S. 204.

B8 LKAN, NL Meiser 212, Aktennotiz vom 15. 5. 1945.

${ }^{89}$ LKAN, NL Meiser 212, Aktennotiz vom 19.5.1945. 
grund ihrer politischen Belastung durch die Militärregierung abgelöst worden ${ }^{90}$. Beständig beschwor Meiser die Vertreter der Militärregierung, die Gefahr des Kommunismus nicht zu unterschätzen: , Ich machte den Gesprächspartner auf die Gefahr der Bolschewisierung und nachträglichen Nazifizierung aufmerksam. Amerika sollte lieber Deutschland für die letzten Weltauseinandersetzungen gewinnen, als es vor den Kopf stoßen. “91

Die Angst vor dem politischen Chaos führte auch in Bayern zu einer partiellen Uberwindung des althergebrachten konfessionellen Mißtrauens, was sich auf politischer Ebene im interkonfessionellen Ansatz der frühen CSU niederschlug. Dabei verband die Kirchen weniger der gemeinsame, aber doch getrennt geführte Kampf gegen ihre Ausschaltung im Dritten Reich als das Trauma der Münchner Räterepublik. In einer Unterredung mit Ministerpräsident Schäffer am 11. Juni betonte Meiser: ,,Die innere Situation der fortschreitenden Gefahr der Bolschewisierung gestattet es nicht, daß sich die beiden Konfessionen in nutzlosen Paritätskämpfen verzehren. “92 Gleichwohl sollte das ungelöste Paritätsproblem zu ständigen Konflikten innerhalb der CSU führen und das Verhältnis der evangelischen zur katholischen Kirche stark belasten. 1945 überwog jedoch noch das gemeinsame Interesse an der Erhaltung der bürgerlichen Ordnung die konfessionellen Rivalitäten. Anfang Juli 1945 teilte Pater Pribilla Meiser vertraulich mit, auch die katholische Kirche sehe ,,im Bolschewismus die uns gemeinsam drohende Gefahr, die uns das Trennende zurückstellen und ohne gegenseitiges Mißtrauen zusammenstehen heiß $\mathrm{t}^{\text {" } 93}$. Befriedigt hatte Meiser bereits in einer früheren Unterredung mit Faulhaber am 23. Juni zur Kenntnis genommen, daß der Papst verbindlich erklärt habe, , daß er eine Teilung Deutschlands nicht wünsche, denn er sehe das geeinte Deutschland als festen Wall gegen den Bolschewismus an" ${ }^{\prime 94}$. Faulhaber und Meiser vereinbarten, sich gegenseitig über alle Verhandlungen mit der Militärregierung und der bayerischen Staatsregierung zu informieren, um das Vorgehen der Kirchen abzustimmen.

Drei Tage nach dieser Unterredung führte Meiser in einem Lagebericht vor dem Landeskirchenrat aus, daß die ,Radikalisierung“ des Volkes stark zugenommen habe. Die Amerikaner würden mit ihren Maßnahmen vielfach zu weit gehen, ,, besonders bei der Entfernung der Nationalsozialisten aus ihren Ämtern". Anschließend beschloß die Kirchenleitung, deshalb mit einer Eingabe bei der Militärregierung vorstellig zu werden, zumal die katholische Kirche einen ähnlichen Schritt plane ${ }^{95}$. Am 20. Juli unterzeichneten Faulhaber und Meiser gemeinsam einen scharfen Protest gegen die Entnazifizierung. Die Initiative hatte vermutlich Meiser ergriffen ${ }^{96}$, doch lagen bereits Eingaben der katholischen Bischöfe von Regensburg und Passau vor. In ihrer Eingabe an OMGUS forderten die Kirchenführer die Militärregierung auf, ,, in den Strafgerichten über das System des

90 Woller, Gesellschaft, S. 82. Vgl. Niethammer, Entnazifizierung, S. $138 \mathrm{ff}$.

91 LKAN, NL Meiser 212, Aktennotiz über Besprechung mit einem namentlich nicht bekannten Offizier vom 14.7. 1945. Vgl. die Aktennotizen Meiser über Gespräche mit amerikanischen Offizieren vom 29.5.1945, 4.6.1945, 5.6.1945, 4.7.1945, 14.7.1945 und 21.7.1945.

92 LKAN, NL Meiser 212, Aktennotiz vom 11.6.1945.

${ }_{93}$ LKAN, NL Meiser 212, Aktennotiz vom 4.7.1945.

94 LKAN, NL Meiser 212, Aktennotiz vom 23.6.1945. Vgl. Nicolaisen/Vollnhals, Kirche, S.137f.

95 LKAN, LKR 1759 a, Vollsitzung des Landeskirchenrats vom 16.6.1945.

96 Vgl. LKAN, NL Meiser 212, Aktennotiz Meisers vom 18.7.1945: „Kardinal Faulhaber erklärt sich bereit, zugunsten der Pg's und der SS-Leute ein gemeinsames Wort an die Militärregierung in Frankfurt zu richten." 
Unheils die Grundsätze der Gerechtigkeit und Menschlichkeit walten zu lassen und die Schuld der Einzelnen durch persönliche Uberprüfung, also nicht pauschal zu bemessen“. Es sei ein ,,gewaltiger Unterschied", ob der Parteieintritt , in dem guten, wenn auch naiven Glauben" an die Versprechungen des Parteiprogramms erfolgt sei, oder ob jemand aktiv die NS-Weltanschauung propagiert habe. Die schematischen Massenentlassungen gefährdeten nicht nur den Wirtschafts- und Staatsapparat aufs ,,äußerste“, sondern trieben auch ungezählte Familien dem , Nihilismus“ zu. Weiterhin wandte sich die Eingabe gegen die pauschale Verurteilung aller SS-Männer und trat für die Freilassung verhafteter Industrieller und Bankiers ein ${ }^{97}$. Der Protest enthielt die typischen Merkmale der konservativen Entnazifizierungskritik: die Differenzierung zwischen einer breiten Masse von gutwilligen Parteimitgliedern, die das Beste gewollt hätten, und einer kleinen Schar fanatischer NS-Aktivisten, die Würdigung jedes Einzelfalls nach dem Maßstab der subjektiven Motivation und die Beurteilung der Entlassung von Parteimitgliedern, die vor dem 1. Mai 1937 eingetreten waren, als unzumutbare Strafe und Verletzung rechtsstaatlicher Grundsätze. Im dunkeln blieben die Maßstäbe der geforderten Einzelfallprüfung und ihre konkrete Durchführung.

Der tatsächliche Umfang der Entlassungen bis Anfang August ist nicht genau bekannt, doch wird man kaum von Massenentlassungen sprechen können. Die Statistik der Special Branch nennt für den Zeitraum vom 21. Mai bis zum 19. Juli 19452094 entlassungspflichtige und 791 zur Entlassung empfohlene Personen, wovon jedoch in nur 977 Fällen der Vollzug der Anordnungen bekannt war ${ }^{98}$. Richtig in Schwung kam die Entnazifizierung erst nach dem Sturz des für Bayern verantwortlichen Militärgouverneurs General Patton, der als traditioneller Militär der Funktionsfähigkeit der Verwaltung eindeutig den Vorrang vor der politischen Säuberung gegeben hatte. Aber auch Ministerpräsident Hoegner, der als Sozialdemokrat die Entnazifizierung prinzipiell unterstützte, sah sich bald mit dem Dilemma konfrontiert, daß die enorme Ausweitung des betroffenen Personenkreises durch das Militärgesetz Nr. 8 vom September 1945 die Durchführung der politischen Säuberung immer mehr in Frage stellte.

Am 8. August verschickte der Landeskirchenrat die Eingabe an die Dekanate mit der Bemerkung, daß sie vielen Pfarrern in der täglichen Seelsorge eine Hilfe sein werde ${ }^{99}$. Das Eintreten der Kirche für ehemalige Nationalsozialisten stieß nur vereinzelt auf Kritik. Wohl am heftigsten bestritt Pfarrer Waldemar Link, dessen jüdische Verwandten ermordet worden waren, dem Landesbischof das moralische Recht, die Maßnahmen der Besatzungsmacht zu kritisieren: Meiser habe nicht nur zur Entlassung der ,Nichtarier“ und dem Boykott jüdischer Geschäfte geschwiegen, sondern auch ,,als die Juden aus ihren Häusern und Wohnungen getrieben wurden, um zu den Mordstätten geschleppt zu werden. Er hat auch nicht protestiert, als die Verfolgung der Christen und Juden durch die Nazis in Polen bekannt wurde, ja, er hat nicht einmal seine eigenen Pfarrer wirksam in Schutz genommen, als diese durch die Nazis verfolgt wurden. [...] Wenn jetzt der Herr Landesbisch of sein Schweigen bricht und zugunsten der Nazis öffentlich Stellung nimmt, so gewinnt man zwangsläufig den Eindruck, daß auch das bisherige Schweigen des Herrn

${ }^{97}$ Eingabe vom 20.7. 1945, in: Akten deutscher Bischöfe, Bd.6, S.585f. Vgl. Kap. III/2.

98 Niethammer, Entnazifizierung, S. 230, Anm. 349.

${ }^{99} \mathrm{Vgl}$. Boyens, Kirchenpolitik, S. 97, Anm.1. 
Landesbischof zu den erwähnten Vorgängen nicht zufällig gewesen sein dürfte, sondern gewollt." 100

Die Haltung der Kirchen wurde in SPD-Kreisen aufmerksam registriert. Sorgenvoll schrieb Joseph Kiene, Landrat in Traunstein und einer der bayerischen Verfassungsväter, an Hoegner über die Predigten des Trostberger Ortspfarrers: „,Unser Pfarrer predigt Liebe für die verlorenen Schafe und, wer Haß im Herzen trägt, soll aus der Kirche drauß bleiben. Ein Bekehrter ist mir lieber als 99 Gerechte“." Der politische Sinn solch allgemeiner Predigtmeditationen war Kiene, der im Dritten Reich zweimal verhaftet worden war, unzweifelhaft: Der Aufruf zur Vergebung der Sünden solle den ,, braunen Schafen“" die Rückkehr in die ,,vaterländischen Kreise“ ermöglichen. Pessimistisch fügte er hinzu, falls dies allenthalben im Lande die Meinung sein sollte, ,,dann ist die antifaschistische Front ja bereits am Abbröckeln, und man könnte heute schon sagen: Laßt alle Hoffnungen fahren!“'101 Aus Bamberg berichtete ein Informant an Hoegner, daß in den Kirchen ständig zugunsten der entlassenen Nationalsozialisten Stimmung gemacht werde. So habe der katholische Pfarrer im sonntäglichen Gottesdienst im Dom erklärt: ,,Der Krieg ist vorüber, aber es scheint, als ob die Not erst jetzt begänne. Zum Beispiel erinnere ich Euch nur an unsere armen Beamten, die 12 Jahre diesen furchtbaren Druck ausgehalten haben und jetzt auf die Straße gesetzt werden, brotlos mit ihren ganzen Familien." In Wahrheit aber seien diese Beamten nicht die Opfer des NS-Regimes, sondern seine Träger und Vollstrecker gewesen. Dennoch versuchten die Pfarrer falsches Mitleid zu erregen, ,,um die Hasen in die Küche der Kirche zu jagen. Indem er aus Nazis Märtyrer macht, verfemt er die auf Ausrottung der Nazis gerichtete alliierte Politik. [...] Die Klerikalen sind heute Herz und Mittelpunkt des Nationalismus und Chauvinismus. So wird die öffentliche Meinung unausgesetzt durch tausend Kanäle vergiftet und zersetzt. “102

Der Kampf um die Entnazifizierung, um die personelle Besetzung der Verwaltung, war, wie Befürworter und Gegner gleichermaßen wußten, weniger eine moralische Auseinandersetzung über Schuld und Sühne als ein politischer Machtkampf, der - aus der Perspektive von 1945 - die gesellschaftliche Neuordnung zu entscheiden schien. Die politischen Dimensionen des kirchlichen Engagements benannte eine gemeinsame Eingabe der katholischen und evangelischen Pfarrerschaft Hofs an die örtliche Militärregierung vom 8. August 1945: Zwar habe der Nationalsozialismus , total abgewirtschaftet", doch aufgrund der ,,tiefen Abneigung gerade bürgerlicher Kreise gegen alle politische Betätigung " profitiere davon allein die KPD. Mit ihrer falschen Entnazifizierungspolitik würden die ,Retter der bürgerlichen Ordnung“, womit die Westalliierten gemeint waren, ,,ungewollt, aber zwangsläufig zu ,Schrittmachern des Kommunismus‘ oder eines sonstigen krankhaften Radikalismus"103.

Anfang Dezember 1945 verfaßten Meiser und Faulhaber eine weitere Petition an die Militärregierung, in der sie sich besonders für die infolge des, , automatischen Arrests “ internierten Funktionsträger aus dem Partei- und Staatsapparat des Dritten Reiches verwandten. Weiterhin setzten sie sich für die Pensions- und Rentenempfänger ein, denen

${ }^{100}$ NA, RG 260, 10/49-3/5, Link an Dekanat Neustadt a. d. Aisch vom 26.8.1945, mit Bitte der Weiterleitung an Meiser.

101 IfZ, NL Hoegner 202, Kiene an Hoegner vom 9.7.1945.

102 IfZ, NL Hoegner 123, Etzel an Hoegner vom 16.10.1945.

${ }^{103}$ LKAN, LKR, Berichte, Eingabe vom 8.8.1945. 
wegen der Zugehörigkeit zur NSDAP die Bezüge gesperrt worden waren. Sie seien nun dem ,, bittersten Elend“ preisgegeben, was eine um so größere Härte darstelle, da , ,sie für einen Schritt, der damals, als sie ihn taten, durch kein Gesetz verboten war, nachträglich mit der Vernichtung ihrer Existenz bestraft werden sollen“. Die Kirchen wüßten wohl, ,daß die Maßnahmen des Siegers oft hart sein müssen, aber auch der Sieger wird es, wenn einmal alle unsere Taten vor den Augen Gottes gewogen werden, zu bereuen haben, wenn er zu hart gewesen ist, während ihn Großmut und Barmherzigkeit niemals reuen werden" ${ }^{\text {104. }}$.

Die Eingabe wurde Ende Januar 1946 den Pfarrämtern - ,,betreff: Seelsorge“ - bekanntgeben ${ }^{105}$. Nach Angaben Niethammers befanden sich im Dezember 1945 in der gesamten US-Zone rund 117000 Personen in Internierungshaft, vorwiegend untere und mittlere Funktionäre der NSDAP, Mitarbeiter der Gestapo, der SS und des SD, sowie eine größere Anzahl von Landräten, Oberbürgermeistern, Ministerialbeamten und anderen Angehörigen des höheren Dienstes. Nach einer Statistik vom Oktober 1945 befanden sich unter den 4811 Häftlingen des Garmischer Internierungslagers, für das allein genaue Zahlen vorliegen, 812 Mitarbeiter der Gestapo, der SS und des SD, sowie 2102 Funktionsträger der NSDAP, wovon 86,5 Prozent auf Ortsebene und in unteren Parteigliederungen tätig gewesen waren. Die Aufschlüsselung des Sozialprofils ergab 35,9 Prozent Beamte (davon 15 Prozent höhere), 12,1 Prozent Freie Berufe, 11,9 Prozent Bauern, 11,9 Prozent Handwerker, 11,7 Prozent Angestellte, 7,1 Prozent Kaufleute und Gastwirte sowie 3,1 Prozent Offiziere, während Arbeiter nur mit 2,5 Prozent, gefolgt von Unternehmern mit 1,8 Prozent vertreten waren ${ }^{106}$.

Vom seelsorgerlichen Auftrag der Kirche her war es selbstverständlich, daß sie sich auch der ehemaligen Nationalsozialisten anzunehmen habe; strittig blieb in welcher Form. Denn die Fürsprache stieß weit über den engeren Bereich der Seelsorge, etwa in Form der Lagerseelsorge oder des Zuspruchs und der Tröstung von Angehörigen, hinaus zur generellen Kritik der politischen Säuberung vor. Dabei verstrickte sich die kirchliche Argumentation in den Widerspruch, der die konservative Kritik allgemein kennzeichnete: Einerseits befürwortete man die Entlassung und Bestrafung , ,aktiver Nazis"; andererseits argumentierte man rechtspositivistisch mit dem Grundsatz ,,nulla poena sine lege“, den besonders die zweite Eingabe stark herausstellte. Wenn aber die politische Gesinnung der ,,nominellen“ Parteigenossen nicht rückwirkend zum Gegenstand von Sanktionen werden durfte, mußte auch die Differenzierung in Mitläufer und NS-Aktivisten, die im Mittelpunkt der ersten Eingabe stand, hinfällig werden. Unter politischen Gesichtspunkten war nicht das Eintreten für die Masse der NS-Mitläufer, deren gesellschaftliche Integration unumgänglich war, problematisch, sondern daß der Fürsprache für ehemalige Nationalsozialisten kein vergleichbares Engagement für die Opfer des NS-Regimes, für das Millionenheer der rassisch und politisch Verfolgten und ihrer Angehörigen gegenüberstand. Die Frage der Wiedergutmachung an den Uberlebenden des NS-Terrors

${ }^{104}$ Eingabe an OMGUS vom 7.12. 1945, in: Akten deutscher Bischöfe, Bd. 6, S. 861 f. Vgl. LKAN, LKR 1665a, 1. Entwurf der Eingabe vom 30.11.1945 mit Verbesserungsvorschlägen Faulhabers.

105 LKAN, LKR 1665 a, Rundschreiben des Landeskirchenrats vom 25.1.1946.

$106 \mathrm{Vgl}$. Niethammer, Entnazifizierung, S. $255 \mathrm{ff}$. 
wurde in keiner Eingabe behandelt ${ }^{107}$. Auch in der Kirchenpresse wurde das bittere Los der Opfer des NS-Regimes verdrängt und verschwiegen.

\section{Die unterbliebene Selbstreinigung}

Ende Mai 1945 erörterte der Landeskirchenrat erstmals das Problem, wie mit denjenigen Pfarrern verfahren werden sollte, die bis zuletzt den Deutschen Christen angehört hatten. Eine erste Bestandsaufnahme nannte für den Kirchenkreis Ansbach die Pfarrer: August Müller, Johann Stadelmann, Ernst Keupp, den Rektor des Diakonissenhauses Hensoltshöhe, und den ebenfalls dort tätigen Pfarrer Gottlieb Geiß; für den Kirchenkreis Bayreuth: Johannes Hatz, Konrad Munzert, Ernst Daum und Willi Döberich; für den Kirchenkreis Nürnberg: Wilhelm Brather, Josef Ruck, Heinrich Griebel und Wilhelm Wolfrum; aus dem Kirchenkreis München wurde kein Pfarrer gemeldet. Als erste Maßnahmen beschloß man, Brather in den Altersruhestand zu versetzen; Hatz und Wolfrum wurden mit sofortiger Wirkung beurlaubt. Im Falle Döberich und Munzert wurde der Kreisdekan beauftragt, die Meinung der örtlichen Kirchenvorstände einzuholen. Ebenso wurden die Fälle Ruck, Griebel, Müller und Stadelmann dem zuständigen Kreisdekan zur ,weiteren Bearbeitung“ übergeben. Zurückgestellt wurde die Entscheidung bei Daum und Karl Werlin, da sie noch nicht aus dem Kriegsdienst heimgekehrt waren. Anschließend erörterte die Kirchenleitung die Lage einiger Pfarrer, die nicht den Deutschen Christen, wohl aber der NSDAP angehört hatten. Sie erhielten die Weisung, ,,zunächst einen Urlaub anzutreten und sich der öffentlichen Wirksamkeit vorerst zu enthalten“. Gleichzeitig versicherte der Landeskirchenrat den betroffenen Pfarrern Eduard Putz, Hans Kipfmüller, Helmut Mebs, Theodor Kunder und Johannes Schulz-drei von ihnen besaßen das Goldene Parteiabzeichen der NSDAP -, , ,daß die Kirchenbehörde ihre Sache vertreten" werde, falls sie Schwierigkeiten bekommen sollten. Gegenüber der Militärregierung solle darauf verwiesen werden, daß die Kirche bereits die ,,notwendigsten Maßnahmen" ergriffen habe und im übrigen ihren "kirchlichen Weg" gehen wolle ${ }^{108}$.

Einen Monat später entschied der Landeskirchenrat, nachdem Meiser und Oberkirchenrat Bogner die ihnen inzwischen von der Militärregierung bekanntgegebenen Grundsätze der amerikanischen Entnazifizierungspolitik dargelegt hatten: ,, Grundsätzlich bei den Geistlichen Widerstand zu leisten, deren Haltung gegen die Partei einwandfrei war." 109 In Fällen, wo jedoch durch die NSDAP-Mitgliedschaft die Tätigkeit des Pfarrers in der Gemeinde beeinträchtigt sei, solle eine Versetzung erfolgen. Davon waren drei Pfarrer betroffen. Weiterhin beschloß die Kirchenleitung, die DC-Pfarrer Müller, Stadelmann, Hatz, Munzert und Döbrich in Ruhestand zu versetzen bzw. ihnen die Pensionierung nachdrücklich nahezulegen. Kalb und Griebel wurden bis auf weiteres beurlaubt. Griebel ging Anfang August in den Ruhestand, Kalb 1946.

107 Noch im September 1946 bemühte sich Pfarrer Link, der im Kreis Uffenheim die „Beratungsstelle für die Opfer des Nationalsozialismus" leitete, vergeblich darum, vom Evangelischen Hilfswerk Hilfslieferungen aus dem Fonds der ökumenischen Nothilfe zu bekommen. Vgl. LWF, General Correspondence Germany, Series K-M 1945-1949, Link an Okumenischen Rat der Kirchen vom 17.9.1946.

${ }^{108}$ LKAN, LKR 1759a, Vollsitzung des Landeskirchenrats vom 31.5.-2.6. 1945.

${ }^{109}$ LKAN, LKR 1759a, Vollsitzung des Landeskirchenrats vom 26.6.1945. 
Auch im Landeskirchenrat kam es zu personellen Veränderungen. Im September 1945 ging Oberkirchenrat Hans Greifenstein in den Ruhestand, ihm folgte im Juni 1946 Oberkirchenrat Fritz Hanemann. Sie waren im Dezember 1934 als Vertreter derjenigen Deutschen Christen, die während der Amtsenthebung Meisers loyal zur rechtmäß̈igen Kirchenleitung gestanden hatten, in die Kirchenleitung berufen worden und wurden nun unter ausdrücklicher Anerkennung ihrer Verdienste verabschiedet. Mit diesen Maßnahmen, die zur Pensionierung von insgesamt zwölf Pfarrern führten, waren nach Ansicht Meisers die Erfordernisse der kirchlichen Selbstreinigung erfüllt. Die Ruhestandsversetzungen richteten sich ausschließlich gegen Exponenten der Deutschen Christen, während die NSDAP-Mitgliedschaft keine Rolle spielte.

Mitte Juli 1945 berichtete der neuernannte Leiter des Nürnberger Predigerseminars, Hermann Dietzfelbinger, an den Landeskirchenrat, daß die „Entlassungswelle“ nunmehr auch auf die Pfarrer überzugreifen drohe. So fordere die örtliche Militärregierung in Höchstadt an der Aisch die fristlose Entlassung von drei Pfarrern, was der ,,gut katholische, auch sonst wackere" Landrat vorläufig habe verhindern können. Bei den beanstandeten NSDAP-Pfarrern handle es sich um besonders tüchtige Geistliche, die man ,,einfach aus kirchlichem Denken heraus", nicht fallen lassen dürfe ${ }^{110}$. Als sich ab September die Entlassungsforderungen häuften, nahm auch das Kapitel Rothausen Stellung. Die Pfarrkonferenz, der nach eigenem Bekunden kein NSDAP-Mitglied angehörte, stellte sich hinter den Grundsatz, daß die Kirche es prinzipiell ablehnen müsse, , , auf Grund kirchenfremder Erwägungen einen Teil ihrer Diener auf irgendeinem Weg aus dem Dienst zu entfernen". In einzelnen Fällen könnten durchaus berechtigte kirchliche Gründe zur Amtsentlassung führen; die „Parteizugehörigkeit als solche“ könne jedoch kein Argument sein. Wenn die Militärregierung die kirchlichen Einwände unbeachtet lasse, so müsse die Kirche bereit sein, selbst Unrecht zu ertragen. ,Aber niemals darf sie selbst Unrecht tun oder bei einem Unrecht mitwirken." Die Stellungnahme schloß mit dem Satz: ,, Ging es früher um die Reinheit des Evangeliums, so jetzt um das schlichte Rechtoder Unrecht-Tun." ${ }^{111}$ Aus Kulmbach berichtete Mitte Oktober Dekan Heinrich Riedel, daß die Pfarrkonferenz einstimmig der Ansicht sei, daß Pfarrer nur von der Kirche entlassen werden dürften: ,,Jeder andere Vorgang würde einen Eingriff in Bekenntnis und Ordnung der Kirche bedeuten. " Die Kirche selbst dürfe nur dann einen Pfarrer entlassen, wenn er sich ,,bekenntnismäßig, disziplinär oder moralisch“ etwas zuschulden habe kommen lassen. In der NSDAP-Mitgliedschaft als solcher wurde jedoch kein Verstoß gegen die Amtspflichten des Pfarrers gesehen ${ }^{112}$.

Ende Oktober legte Künneth ein ausführliches theologisches Gutachten vor, das der Landeskirchenrat in Auftrag gegeben hatte. Im Unterschied zu den bisherigen Stellungnahmen betonte Künneth im ersten Absatz, daß die Kirchenleitung für die gegenwärtige „schwere Notlage" mitverantwortlich sei, da sie den Pfarrern erlaubt habe, sich politisch zu exponieren. Zudem habe sie, ,, dem Geist der Zeit erliegend, Geistlichen auf Grund ihrer Parteizugehörigkeit eine bevorzugte Rolle zuerkannt und gern die Dienste und Beziehungen jener Pg-Pfarrer in Anspruch genommen. Dieses unkirchliche, aus taktischen Zweckmäßigkeitsgründen erwachsene Handeln jener Zeit rächt sich heute bitter. " Dar-

110 LKAN, LKR 1188, Dietzfelbinger an Landeskirchenrat vom 16.7.1945.

111 LKAN, LKR, Berichte, Seiler an Landeskirchenrat vom 10.10.1945.

112 LKAN, LKR 1188, Riedel an Landeskirchenrat vom 18.10.1945. 
aus zog Künneth den Schluß, daß die Kirche ,,moralisch genötigt“ sei, ihre schützende Hand über die gefährdeten Pfarrer zu halten, und postulierte in einer klassischen Formulierung: ,,Was 1933 kirchlich erlaubt war, kann 1945 nicht kirchlich verboten sein. " Die Ubernahme der politisch motivierten Entnazifizierungsbestimmungen würde eine ,,verhängnisvolle Politisierung " der Kirche bedeuten, wogegen man sich im Kirchenkampf „,erfolgreich“ gewehrt habe. Die Weigerung, aus der NSDAP-Mitgliedschaft von Pfarrern irgendwelche kirchlichen Konsequenzen zu ziehen, bedeutete jedoch nicht, daß die Kirche das ,,verderbliche System" des Nationalsozialismus in Schutz nehmen wolle. Vielmehr habe ja gerade sie ,,den Geist und die Methoden“ des NS-Regimes bekämpft. Auch sei der Beitritt von Pfarrern zur NSDAP, , aus einer ethisch einwandfreien, das Beste erstrebenden Gesinnung erwachsen".

Nach , streng kirchlich-theologischen Gesichtspunkten “ könnten Maßregelungen nur dann erfolgen, wenn ein Pfarrer gegen Lehre und Bekenntnis der Kirche verstoßen habe oder wenn sittliche Verfehlungen vorlägen, , unter welchen selbstverständlich auch die Beteiligung an unchristlichen Maßnahmen des Nationalsozialismus verstanden werden muß". Diesen Punkt führte Künneth, der im Dritten Reich dem Antisemitismus eine prinzipielle Berechtigung zugesprochen hatte ${ }^{113}$, jedoch nicht weiter aus. Ein dritter Entlassungsgrund liege vor, wenn das Verhalten eines Pfarrers die ,,Ordnung und Würde“ der Kirche wesentlich gefährde. Dieser Fall sei bei denjenigen DC-Pfarrern gegeben, die sich im Kirchenkampf für den Reichsbischof und gegen ihre eigene Kirchenleitung entschieden hätten. Die Kernfrage, unter welchen Umständen kirchliche Entlassungsgründe bei NSDAP-Pfarrern gegeben sein könnten, blieb allerdings unbeantwortet.

Um so ausführlicher versuchte Künneth zu begründen, weshalb die Kirchenleitung keinesfalls dem Druck der Militärregierung nachgeben dürfe. Er lehnte selbst Versetzungen von belasteten Pfarrern ab, da sie, ,kirchlich gesehen“, eine , unwahre Maßnahme“ darstellten. Sei erst einmal die ,,schiefe Ebene des unsachlichen Nachgebens aus Nützlichkeitserwägungen“ betreten, so gebe es keinen Halt mehr. Dann könnten auch politische Angriffe gegen , höhere Geistliche, die keine Parteimitglieder waren, ja selbst gegen den Herrn Landesbischof" erhoben werden. Hatte doch die bayerische Kirchenleitung 1933 die Machtergreifung Hitlers emphatisch begrüßt und auch später genügend Erklärungen abgegeben, an die man lieber nicht erinnert werden wollte. Die Kirche müsse sich bewußt sein, so führte Künneth weiter aus, , ,daß sie in ihrem klaren und kompromißlosen Eintreten für ihre Pg-Geistlichen zugleich einen stellvertretenden Kampf für das ganze Volk gegen die Prinzipien der Ungerechtigkeit und Unwahrhaftigkeit zu führen hat". Sie dürfe deshalb nicht schweigen, sondern müsse ,, in Treue gegen ihr aufgetragenes ,prophetisches" Amt" bezeugen:

113 Vgl. die bekannte Anti-Rosenberg-Schrift Künneths, Antwort auf den Mythos, Berlin 1935, S.67: „, Daß in der Charakterisierung des zersetzenden Einflusses des dekadenten Weltjudentums und seiner Gefährdung des deutschen Kulturlebens Rosenberg Wesentliches erkennt und dargestellt hat, ist nicht zu bestreiten. Verständlich ist ferner, daß er aus Liebe zum Volk und der eigenen Rasse mit der ganzen Kraft seiner Seele das deutsche Wesen vor der Vergiftung durch diesen jüdischen Geist bewahren möchte und diesem Fremdgeist den unerbittlichen Kampf ansagt. Der Fehler liegt jedoch darin, daß die ganze Minderwertigkeit und Gefährlichkeit des entarteten Weltjudentums kritiklos auf das Volk Israel und auf das Alte Testament übertragen wird [...], als ob die Geistigkeit des wurzellosen Asphaltjudentums der Gegenwart gleichbedeutend wäre mit dem Geist des Alten Testamens.“ 
„1. Es ist Unrecht, Menschen, die in christlicher Erfüllung ihrer Staatsbürgerpflichten Römer 13,1 gehorsam befolgten, zu disqualifizieren (z. B. das Vorgehen gegen ehemalige Offiziere).

2. Es ist Unrecht, die aus der deutschen Volkszugehörigkeit entspringenden politischen Verpflichtungen in der Vergangenheit als ein ,Vergehen' oder ,Verbrechenc zu brandmarken.

3. Es ist Unrecht, für ein politisches Verhalten, das vor vielen Jahren unter völlig anderen Voraussetzungen sich vollzog, soweit es dem christlichen Sittengesetz nicht widersprach, Menschen heute noch dafür zu bestrafen."

Abschließend betonte Künneth nochmals, daß es darum gehe, ,,jede Form politischer Terrorisierung des kirchlichen Lebens abzuweisen und der im Bekenntniskampf von Gott geschenkten neuen Einsicht in Wesen und Auftrag der Kirche gehorsam zu sein" "114.

Das zentrale Argument in allen kirchlichen Stellungnahmen war der Bezug auf die Autonomie der Kirche, der allein das Recht zustehe, darüber zu entscheiden, wer als Pfarrer tätig sein dürfe. Diese aus dem Kirchenkampf so geläufige Argumentation verdeckt jedoch den Kern des Konflikts: Denn die Mitgliedschaft in der NSDAP oder anderen NS-Organisationen, gar die Ubernahme von Ämtern und Funktionen, stellte eine rein politische Entscheidung dar, zu der der einzelne Pfarrer nicht in Ausübung seines geistlichen Amtes gezwungen war, sondern die er in seiner Eigenschaft als Staatsbürger verantwortete ${ }^{115}$. Und als Staatsbürger, nicht in der Eigenschaft als Inhaber des geistlichen Amtes, betraf die Entnazifizierung den politisch belasteten Pfarrer. Hatte die Verteidigung der kirchlichen Autonomie durch die Bekennende Kirche im Kirchenkampf die Funktion gehabt, die Verkündigung des Evangeliums von deutsch-christlichen bzw. nationalsozialistischen Einflüssen freizuhalten, so diente die scheinbar gleiche Argumentation nach 1945 einem anderen Ziel. Mit ihr sollten nun gerade die NSDAP- und DC-Pfarrer ihrer politischen Verantwortung als Staatsbürger entzogen und vor der Militärregierung geschützt werden.

Auch in Kreisen der bayerischen Pfarrbruderschaft, die sich im allgemeinen der kirchlichen Versäumnisse und Fehler bewußter waren, teilte man weitgehend den Standpunkt Meisers und Künneths. So urteilte Schieder, daß im Parteieintritt wohl ein ,,Stück Schuld" liege, man müsse aber auch prüfen, was individuell - , und zwar ohne Advokatenkünste!" - zur Entlastung vorgebracht werden könne. Von sämtlichen, als aktive $\mathrm{Na}$ zis eingestuften Pfarrern könne vor Gott bezeugt werden, daß sie ,,ehrenwerte Männer“ seien, denen niemand ,,etwas Unehrenhaftes" nachsagen könne. Keiner von ihnen habe auch nur die ,,geringste Entschuldigung “ für das, ,, was von der Partei in der Judenfrage, in der Behandlung des ,unwerten Lebens', in dem Vorgehen gegen Kriegsgefangene usw." geschehen sei. Sie hätten sich leichtgläubig, aber aus ehrlichen und idealistischen Beweggründen der NSDAP angeschlossen, um das Christentum vor dem Atheismus zu

${ }^{114}$ LKAN, LKR 1188, Theologisches Gutachten über die Stellungnahme der Kirche zur Parteizugehörigkeit der Geistlichen vom 26.10.1946.

115 Diesen Sachverhalt bestätigt indirekt ein Rundschreiben des Landeskirchenrats vom 29.7. 1946. Hier hieß es, die Kosten der Spruchkammerverfahren seien grundsätzlich von den betroffenen Pfarrern selbst zu tragen, ,,da die Entlastung eines Geistlichen ebenso seine persönliche Angelegenheit ist, wie seinerzeit sein Beitritt zur NSDAP“. Im Entwurf befand sich anschließend die noch weitergehende Formulierung: , ,oder seine einstige politische Betätigung“. LKAN, LKR 201 und 225. 
schützen. Die , überwiegende und überwältigende Mehrzahl“" in den Gemeinden stehe fest hinter den von der Militärregierung angegriffenen Pfarrern. Weiterhin gab Schieder zu bedenken, daß die Entlassung der NSDAP-Pfarrer die geistliche Versorgung der Gemeinden ernsthaft in Frage stellen könnte. Zudem seien die ,,zerstörenden Kräfte" bereits so stark geworden, daß man nur mit ,,allergrößter Sorge“ an die Zukunft denken könne. ,,Diese zerstörenden Kräfte würden noch stärker werden, wenn der Kirche durch diese Absetzungen der Dienst noch mehr erschwert würde. " ${ }^{116}$ Damit benannte Schieder das politische Motiv, das auch Künneth bewegte. Galt es doch den im kirchlichen Sinne staatstragenden, aber durch den Nationalsozialismus kompromittierten Kräften den Rücken zu stärken.

Ebenso gaben führende bayerische Pfarrer in Gesprächen mit Stewart Herman, der im Auftrag des Okumenischen Rates der Kirchen 1945 mehrfach durch die US-Zone reiste, zu erkennen, daß sie die Entnazifizierung wegen der vermuteten sozialrevolutionären Konsequenzen ablehnten: ,Bavarians are rooted in soil and do not like socialism. " 117 Herman gewann den zutreffenden Eindruck: , That there is less inclination on the part of the Bavarian Church to divorce itself from its Nazi party member pastors than is to be found in any other German church." Die bayerische Landeskirche sei ein Bollwerk des Konservatismus, das jeder radikalen Veränderung, gleich welcher Richtung, widerstehe. Wesentlich zu dieser Beurteilung hatte ein langes Gespräch mit Meiser beigetragen, der Herman unumwunden erklärte, daß er gegen die Parteipfarrer keine Maßnahmen ergreifen werde. Sie seien vielfach bessere Kämpfer für den christlichen Glauben gewesen als Nicht-Mitglieder. Unter Berufung auf die lutherische , Zwei-Reich-Lehre“ betonte Meiser: ,,The church must not permit itself to be affected by chances in the political scene." Im Gegensatz dazu stand sowohl Meisers wie Oberkirchenrat Bogners Versicherung, die bayerische Landeskirche werde keine politisch belasteten Pfarrer aus den Ostgebieten aufnehmen. Herman, selbst Lutheraner, vermochte die Argumentation nicht zu überzeugen. Er hielt Meiser entgegen: ,,It was not logical to urge that the church should not permit itself to be affected by political changes under the Allies, when as a matter of fact the presence of Nazi pastors indicates that the church in the past had in fact been affected by political changes incident to Hitler's assumption of power." Weiterhin betonte Herman, daß Pfarrer, die ihren Irrtum wirklich einsähen, wohl die Versetzung auf eine andere Stelle oder in den Ruhestand als einen Teil der notwendigen Buße akzeptieren würden ${ }^{118}$.

Je schärfer sich die evangelische Kirche gegen die politische Säuberung wandte, um so stärker verlangte die Militärregierung die Entnazifizierung der Pfarrerschaft. Um dem wachsenden Druck zu begegnen, fertigte der Landeskirchenrat am 8. November 1945 eine Aufstellung an, die die Anstrengungen der Kirchenleitung zur Selbstreinigung dokumentieren sollte. Das Schreiben an die Militärregierung beginnt selbstbewußt mit den Sätzen: ,,Der Einfluß der Deutschen Christen und der NSDAP war in der Bayerischen Landeskirche geringer als in allen anderen Landeskirchen Deutschlands. Die Geistlichen, die den ,Deutschen Christen' angehörten oder der Weltanschauung der NSDAP nahe-

116 LKAN, LKR 216, Schieder an Landeskirchenrat vom 4.12.1945.

117 NA, RG 84, 737/3, Interviews with leading Bavarian Churchmen vom 6. 11.1945, Besprechung mit Kreisdekan Kern am 13.10.1945. Vgl. Besprechung mit Althaus am 14.10.1945.

${ }^{118}$ Ebenda, Besprechung mit Meiser am 16.10.1945. 
standen, sind im Laufe der Jahre Zug um Zug ausgeschieden. Wir geben darüber folgende Ubersicht. " ${ }^{119}$ Die Aufstellung enthielt jedoch weder die Namen aller DC-Pfarrer, deren Anzahl der Landeskirchenrat in einem Entwurf des Schreibens noch mit 60 bis 70 angegeben hatte ${ }^{120}$, noch die Namen der NSDAP-Pfarrer, nicht einmal der Träger des Goldenen Parteiabzeichens. Vielmehr hatte die Kirchenleitung bereits Mitte Mai beschlossen, der Militärregierung nur diejenigen Pfarrer auf Anforderung zu nennen, die bis zuletzt den Deutschen Christen angehört hatten ${ }^{121}$.

Unter der Uberschrift - ,Freiwillig ausgeschieden sind, weil sie bei uns keinen Boden für ihre völkischen Ideen fanden" - stehen die Pfarrer: Friedrich Klein, Wolf Meyer, Heinrich Schulz, der Erlanger Theologieprofessor Wilhelm Vollrath sowie Siegfried Leffler und Julius Leutheuser. Die beiden Letztgenannten wechselten bereits 1927 auf eigenen Wunsch nach Thüringen über, wo sie die Kirchenbewegung Deutsche Christen gründeten ${ }^{122}$. Auch bei Klein, dem Leiter der Arbeitsgemeinschaft nationalsozialistischer evangelischer Pfarrer und Vorstandsmitglied des bayerischen Pfarrervereins, sind Vorbehalte angebracht, da er 1933 als Kontaktmann Meisers zum Reichsbischof fungierte und Mitte 1934 die Stelle eines Superintendenten in der Altpreußischen Union übernahm ${ }^{123}$. Das verlockende Angebot einer Professur in Jena veranlaßte Ende 1933 Meyer, einen radikalen DC-Aktivisten, zum Ausscheiden aus der bayerischen Landeskirche ${ }^{124}$. Vollrath nahm 1939/40 einen Ruf nach Breslau an ${ }^{125}$, und Schulz wurde NSDAP-Kreisleiter in Nördlingen.

Unter der Rubrik ,entlassen“ wurden 15 Pfarrer angeführt: Vikar Heinz Arndt (1935), Hans Baumgärtner (1934), Dr. Ludwig Beer (1934), Studienprofessor Dr. Karl Braun (ca. 1935), Religionslehrer Dr. Gustav Bub (ca. 1938), Heinrich Daum (ca. 1935), Hans Gollwitzer (1935), Theodor Hoffmann (1942), Friedrich Hormess (1934), Ludwig Klinger (1941), Friedrich Kroll (1937), Vikar Heinz Preiss (1934), Hans Sommerer (1934), Friedrich Schneidt (1940) und Karl Brunnacker (1934). Auch ohne Einsicht der nicht zugänglichen Personalakten lassen sich etliche fehlerhafte bzw. falsche Angaben feststellen: Hoffmann, ein radikaler Deutscher Christ, wurde 1942 nicht entlassen, sondern legte sein Amt nieder, bevor er aus der Kirche austrat ${ }^{126}$. Kroll übersiedelte 1937 auf eigenen Wunsch nach Berlin und nahm dort eine Pfarrstelle an ${ }^{127}$; ebenso schied Klinger 1941 auf eigenes Ersuchen aus ${ }^{128}$. Vikar Preiss, der die Amtsenthebung Meisers 1934 unterstützt hatte und deshalb von Nürnberg wegversetzt werden sollte, trat im Oktober 1934 in die „Landesstelle Franken“ des Reichspropagandaministeriums ein; aus der Kandidatenliste wurde er aber erst am 19. März 1935 gestrichen ${ }^{129}$. Studienrat Bub

119 NA, RG 260, 5/341-1/7, Landeskirchenrat an OMGB vom 8.11.1945.

120 LKAN, LKR 216, Entwurf, o. D. Vermutlich bezog sich der Landeskirchenrat mit dieser Angabe auf den Stand von 1936/38. 1933/34 zählten zu den Deutschen Christen 100 bis 200 Pfarrer. Vgl. Baier, Deutsche Christen Bayerns, S. 52.

121 LKAN, LKR 1759a, Vollsitzung des Landeskirchenrats vom 15.5.1945.

122 Vgl. Baier, Deutsche Christen Bayerns, S. $17 \mathrm{ff}$.

${ }^{123}$ Ebenda, S. $79 f$.; Verantwortung, Bd.1, S. 535.

124 Ebenda, S. 57, Anm. 62.

125 Ebenda, S. 327 f., Anm. 146.

126 Ebenda, S.350.

${ }^{127}$ Ebenda, S. 185, Anm. 52.

${ }^{128}$ Auskunft des LKAN vom 18.10.1985.

129 Baier, Deutsche Christen Bayerns, S. 189, Anm. 80. 
konnte als staatlich angestellter Lehrer wohl kaum von der Kirche entlassen werden; eher dürfte es sich so verhalten, daß er als weltanschaulicher Schulungsleiter der NSDAP ab 1938 keinen Religionsunterricht mehr erteilte ${ }^{130}$. Ahnliche Vorbehalte sind im Fall des Studienprofessors Braun angebracht. Brunnacker zählte, wie der Landeskirchenrat selbst in einer Anmerkung angab, nicht zu den angeblich entlassenen Pfarrern, da Meiser seine vorläufige Amtsenthebung vom November 1934 in eine Beurlaubung vom Dienst umgewandelt hatte ${ }^{131}$. Fraglich ist auch, ob Daum, bevor er nach Thüringen wechselte, überhaupt entlassen war.

Nicht nachgeprüft werden konnten die Fälle Schneidt und Braun, so daß die Uberprüfung von 13 Angaben anhand der verfügbaren Literatur in mindestens fünf Fällen zu starken Zweifeln führt. Als von der Landeskirche tatsächlich entlassen, können nur sechs bis acht der genannten 15 Pfarrer gelten. Sie betrafen allesamt Deutsche Christen, die sich nicht dem landeskirchlichen Regiment Meisers, sondern dem Reichsbischof Müller unterstellt hatten. Insofern sind diese Entlassungen in erster Linie als Disziplinarmaßnahmen gegen renitente DC-Pfarrer zu werten, die, obwohl sie in Diensten der bayerischen Landeskirche standen, die Autorität und Disziplinargewalt ihres Landesbischofs nicht anerkannt hatten. In der Literatur ist jedenfalls kein Fall bekannt, daß in Bayern ein DC-Pfarrer wegen Verbreitung der deutsch-christlichen Irrlehre, entsprechend dem Verständnis der Barmer Theologischen Erklärung von 1934, aus dem Dienst entlassen worden wäre.

Interessant ist auch die Analyse der Rubrik der in den Ruhestand versetzten Pfarrer. Die Liste enthält - ohne Altersangaben - für den Zeitraum von 1933 bis 1945 die Namen von acht DC-Pfarrern: Adolf Linke (1934, 70 Jahre), Heinrich Daum (1935, 77 Jahre), Gottfried Fuchs (1935, 54 Jahre), Franz Merkel (1937, 64 Jahre), Heinrich König (1938, 74 Jahre), August Schramm (1940, 64 Jahre), Arnold Kiessling (1941, 72 Jahre) und August Wenz (1941, 61 Jahre). Als Kuriosum findet sich in der Aufstellung auch der Nürnberger Dekan Martin Weigel, der bereits 1925 in den Ruhestand gegangen war. Eindeutig disziplinarischen Charakter kann man nur der Ruhestandsversetzung von Pfarrer Fuchs zusprechen. Die übrigen DC-Pfarrer waren in den Altersruhestand oder aus gesundheitlichen Gründen vorzeitig in Pension gegangen.

Für das Jahr 1945 gab die Aufstellung, wieder ohne Altersangabe, zwölf in den Ruhestand versetzte DC-Pfarrer an: Friedrich Auer (68 Jahre), Wilhelm Brather (68 Jahre), Dr. Ernst Daum (44 Jahre), Heinrich Griebel (50 Jahre), Johannes Hatz (57 Jahre), Ernst Keupp (76 Jahre), Konrad Munzert (63 Jahre), August Müller (53 Jahre), Josef Ruck (68 Jahre), Robert Schmidt (67 Jahre), Johann Stadelmann (61 Jahre) und Wilhelm Wolfrum (57 Jahre). Bei Berücksichtigung des Ruhestandsalters können hiervon vier bis fünf Pensionierungen als Selbstreinigungsmaßnahmen angesehen werden. Wohl um die Bilanz eindrucksvoller erscheinen zu lassen, enthielt die Aufstellung des Landeskirchenrats auch noch die Namen von zehn bis 1945 verstorbenen DC-Pfarrern. Im Entwurf waren außerdem die Namen von sieben Pfarrern genannt worden, die sich von den Deutschen Christen losgesagt hätten ${ }^{132}$. Sie wurden in dem Schreiben an die Militärregierung

${ }^{130}$ Vgl. ebenda, S. 126, Anm. 215.

131 Ebenda, S. $199 \mathrm{ff}$.

${ }^{132}$ Heinrich Bestelmeyer, Willi Döbrich, Frank Karl, Willy Wangemann, Christian Weigand, Karl Werlin und Studienprofessor Alfred Brüderlein. 
nicht mehr erwähnt; vermutlich um sie vor weiteren Nachforschungen der Special Branch zu schützen.

Insgesamt fällt die Bilanz der Selbstreinigung, wenn man die irreführenden Angaben des Landeskirchenrats abzieht, bescheiden aus: Zwischen 1933 und 1945 hatte die Kirchenleitung unter Meiser maximal acht DC-Pfarrer entlassen und einen weiteren in Ruhestand versetzt. Nach dem Zusammenbruch des Dritten Reiches erfolgten nochmals vier bis fünf Disziplinarmaßnahmen. Von einer energischen Selbstreinigung der bayerischen Landeskirche von „Geistlichen, die den ,Deutschen Christen' angehörten oder der Weltanschauung der NSDAP nahegestanden haben", wird man kaum sprechen können. Die Handlungsweise Meisers, lediglich einige Pfarrer, die bis zuletzt den Deutschen Christen angehört hatten, in den Ruhestand zu versetzten, ansonsten jedoch alle NSDAP-Pfarrer gegenüber der Militärregierung zu verteidigen, wurde vom Landessynodalausschuß im März 1946 nachträglich gebilligt ${ }^{133}$.

\section{Das Scheitern der Militärregierung}

Die Sichtung der Fragebögen der evangelischen Geistlichen ergab Anfang April 1946, daß entsprechend den allgemeinen Entnazifizierungsrichtlinien 170 Pfarrer als ,,mandatory removal" und weitere 66 als ,, adverse recommandation" eingestuft waren. Die Liste der betroffenen Pfarrer wurde Meiser zur Stellungnahme übergeben, doch nach einer Frist von sechs Wochen hatte die Militärregierung lediglich in 25 Fällen eine Antwort erhalten, während alle Verhandlungen mit der katholischen Kirche zur Zufriedenheit der Militärregierung abgeschlossen waren. Daraus zog Captain Alfred Pundt, der zuständige Offizier der ERA-Branch, den Schluß, die Kirchenleitung sabotiere bewußt die Entnazifizierung der Pfarrerschaft; er verlangte deshalb mehr Personal, um intensivere Nachforschungen anstellen zu können ${ }^{134}$. General Muller leitete das Memorandum an General Adcock nach Frankfurt weiter und stellte zur Behebung der Mißstände drei Alternativen zur Wahl: 1. Die Entnazifizierung der Pfarrerschaft wird künftig ohne Beteiligung der Kirche direkt von der ERA-Branch durchgeführt. 2. OMGUS stellt mehr Personal zur Verfügung. 3. Alle beanstandeten Pfarrer werden den noch zu bildenden deutschen Spruchkammern übergeben ${ }^{135}$. Eine Woche später, am 11. April, wurde auf höchster Ebene über das weitere Vorgehen beraten, wobei außer Frage stand, daß die am Widerstand Meisers festgefahrene Entnazifizierung sofortige Maßnahmen erfordere. Um ein Exempel zu statuieren, wurde der Religious Affairs Officer Hoiberg nach München abkommandiert, um zehn der schlimmsten Fälle auszuwählen. Anschließend sollte das Sonderministerium angewiesen werden, diese Fälle sofort vor den Spruchkammern zu verhandeln ${ }^{136}$.

${ }^{133}$ LKAN, LKR 201, Landessynodalausschuß an Landeskirchenrat vom 7.3.1946.

${ }^{134}$ NA, RG 260, 5/341-1/6-10, Memorandum vom 4.4.1946. Eine Aufstellung vom 15.6.1946 nennt namentlich jedoch nur 156 ,"mandatory removal“ Fälle.

135 NA, RG 260, 5/341-1/6-10, Muller an Adcock vom 4.4.1946.

136 NA, RG 260, 5/341-1/6-10, Aktennotiz vom 11.4.1946. Vgl. NA, RG 260, 5/339-1/6, Adcock an Muller vom 12.4.1946. 
Hoiberg machte sich sofort ans Werk, so daß Ministerpräsident Hoegner bereits Ende April die Liste der zehn vordringlichsten Fälle erhielt, mit dem ausdrücklichen Vermerk „,top priority“"137. Einen ersten Anhaltspunkt für Hoibergs Nachforschungen boten die vorliegenden Fragebogen, insbesondere wenn ein Pfarrer Ämter in der NSDAP oder in anderen NS-Organisationen wahrgenommen hatte. Bei den meisten der genannten Pfarrer hatte der Landeskirchenrat, obwohl die Militärregierung seit Ende 1945 auf Entlassung drängte, bis Mitte April noch keine Stellungnahme abgegeben. Wie nicht anders zu erwarten, ergaben die Befragungen der Ermittler, die vor Ort weiteres Belastungsmaterial beschaffen sollten, in der Regel kein einheitliches Bild. An drei Fällen sollen im folgenden die Recherchen der Militärregierung und die sich daraus ergebenden Verhandlungen mit dem Landeskirchenrat nachgezeichnet werden.

Unser erster Fall, den die Militärregierung auf Platz 9 der Liste gesetzt hatte, beschreibt die Schwierigkeiten der Wahrheitsfindung am Beispiel eines durchschnittlichen DC- und NSDAP-Pfarrers. Im Falle des 53jährigen Pfarrers H. aus dem Dekanat Coburg, Mitglied der NSDAP von 1931 bis 1945 und in den ersten Jahren des Kirchenkampfes aktiver Deutscher Christ, sahen sich die amerikanischen Ermittler mit widersprüchlichen Aussagen konfrontiert: Ein Angestellter des Landratsamtes, KPD-Mitglied, bezeichnete $\mathrm{H}$. ohne jeden Zweifel als , ,aktiven Nazi“", der auch als solcher 1938 und 1942 - diese beiden Stichjahre gab der ,Inspection Report" vor - in der Gemeinde bekannt gewesen sei. $\mathrm{H}$. habe sein priesterliches Amt mißbraucht, da er vor dem Altar SA-Männer in Uniform gesegnet habe. In den letzten Kriegsjahren habe er sich aufgrund der ihm bekannt gewordenen NS-Verbrechen ein wenig vom Nationalsozialismus gelöst. Nach Auskunft des SPD-Bürgermeisters war H. ebenfalls 1938 und 1942 als ,, aktiver Nazi“" ortsbekannt; einen Gesinnungswechsel habe er nicht bemerken können. Der vorgesetzte Dekan bekundete, daß H. nach 1934 ,,definitiv" kein aktiver Nazi mehr gewesen sei, daß aber die Meinung in der Gemeinde darüber gespalten sei und ihn die Kirche deshalb auf eine andere Pfarrstelle versetzt habe ${ }^{138}$. Eine andere Auskunft hatte das Dekanat Coburg am 19. Oktober 1945 dem Landeskirchenrat erteilt, als es berichtete, H. sei durch sein ständiges Auftreten in Parteiuniform in der Gemeinde ,,unmöglich“ geworden. Immer wieder höre man die Meinung: ,,Man müsse an der Kirche irre werden, die solche Leute weiter öffentlich wirken läßt, während der kleinste Parteigenosse an niedrigster Stelle seinen Posten verliere." Der Dekan empfahl deshalb die Versetzung, die die Kirchenleitung Mitte November 1945 bewilligte ${ }^{139}$. Der evangelische Kreisschulrat sagte aus, $H$. habe sich 1933/34 als , aktiver Nazi“" hervorgetan, danach sei er nur mehr ,nominelles Mitglied“" gewesen. Die letzte Zeugenaussage stammte von einer Hausfrau, die zu Protokoll gab, daß sie als Halbjüdin ihr Haus nicht oft verlassen habe. Ihr allgemeiner Eindruck sei jedoch, daß H. kein besonders aktiver Nazi gewesen sei ${ }^{140}$. Nach den amerikanischen Richtlinien wurde H., da er bereits 1931 in die Partei eingetreten war, als aktiver Nazi eingestuft. Offen bleibt, weshalb gerade dieser Fall, der nichts Spektakuläres besaß, in die

137 NA, RG 260, 10/66-1/4, OMGB, Monthly Report Education and Religion vom 3. 5. 1946; Namensliste vom 15.6.1946, in: NA, RG 260, 5/341-1/6-10.

${ }_{138}$ NA, RG 260, 5/341-1/9, Inspection Report vom 18.4.1946.

139 LKAN, LKR 1188, Dekanat Coburg an Landeskirchenrat vom 19.10.1945; LKAN, LKR $1759 \mathrm{a}$, Vollsitzung des Landeskirchenrats vom 13./14.11.1945.

140 NA, RG 260, 5/341-1/9, Inspection Report vom 18.4.1946. 
Liste der vordringlichsten Fälle aufgenommen wurde. Ausschlaggebend war vermutlich, daß der Landeskirchenrat die erste Vorstellung der Militärregierung vom 12. November 1945 unbeantwortet gelassen hatte. Die Spruchkammer verurteilte H. im September 1946 als Minderbelasteten (Gruppe III) zu einer Sühnezahlung von 1000 RM und zu zwei Jahren Predigtverbot. In der Revision wurde er als Mitläufer eingestuft. Da die Militärregierung dagegen Einspruch erhob, konnte der Fall erst 1948 mit einem Gnadenerlaß endgültig abgeschlossen werden ${ }^{\mathbf{1 4 1}}$.

Von anderem Kaliber ist der Fall K., der wie kein anderer die Militärregierung erregte, so daß sie ihn auf den ersten Platz setzte. Pfarrer K., Jahrgang 1902, gehörte zu den Altparteigenossen mit Goldenem Parteiabzeichen. Er war 1925 der NSDAP beigetreten (Mitgliedsnummer 9929) und bereits 1923 der SA, in der er den Rang eines Oberscharführers bekleidete. Von 1932 bis 1935 wirkte K. im bayerischen Oberland als NSDAPKreisamtsleiter für Schulung, von 1935-37 als Kreisamtsleiter für Kultur, ab 1940 als NSV-Zellenleiter. 1936 enthielt sein parteiamtlicher Beurteilungsbogen der Eintrag: „,Kämpfer der alten Garde, zuverlässig und einsatzbereit [...] genießt überall gutes Ansehen. " ${ }^{142}$ Im Kirchenkampf versuchte K. zwischen der Landeskirche und der NSDAP zu vermitteln, weshalb ihn Meiser unter allen Umständen halten wollte. Erste Vorstellungen der Militärregierung vom 18. Oktober und 3. November 1945 sowie vom 15. Februar 1946 waren unbeantwortet geblieben. Anfang März ergaben die Recherchen folgendes Bild: Der frühere, mit einer Jüdin verheiratete katholische Bürgermeister, den die örtliche Militärregierung abgesetzt hatte, sagte aus, daß K. weder 1938 noch 1942 als aktiver Nazi gegolten habe. Er habe vielmehr in beherzter Weise von der Kanzel gegen die NSDAP gepredigt, auch sei er nie antisemitisch eingestellt gewesen. Seiner Ansicht nach sei K. lediglich als ,,nominelles Mitglied“ zu bezeichnen, da er nicht zu den örtlichen Parteizirkeln gehört habe. Der neue CSU-Bürgermeister, ein jüngerer Mann, erklärte den Ermittlern nach einigem Zögern, daß K. ein Nazi war und noch sei. Als Mitglied der Bekennenden Kirche sei es ihm völlig unverständlich, wie man zugleich Geistlicher und aktives NSDAP-Mitglied habe sein können. Die Ortsgemeinde habe sich jedoch in einer Resolution für den Verbleib von K. ausgesprochen. Ein katholischer Sozialdemokrat gab zu Protokoll, daß die Arbeiterschaft K. als , ,aktiven Nazi“ betrachte. Ein aus der Kirche ausgetretenes KPD-Mitglied äußerte, er kenne $K$. gut und man müsse ihn ohne jeden Zweifel als einen , aktiven Nazi“" bezeichnen, der die Kanzel für politische $Z_{\text {wecke miß- }}$ braucht habe. Noch im Februar 1946 habe er gegen die Russen gepredigt. Ein Lehrer, der als Mitglied einer protestantischen Sekte den Treueeid auf Hitler verweigert hatte und deshalb in den Ruhestand versetzt worden war, bezeichnete K. als einen Nazi bis 1938, der gegen 1942 seine politische Gesinnung geändert habe. Als er K. vorgeschlagen habe, vor der Gemeinde ein persönliches Schuldbekenntnis abzulegen, habe ihn dieser jedoch nur ausgelacht. Die Meinung der Gemeinde sei geteilt. Viele seien der Ansicht, es wäre besser, wenn K. zurücktreten würde. K. sei eindeutig kein Anhänger der Demokratie, doch treffe dies für viele Pfarrer zu. Die Haltung der lutherischen Pfarrerschaft sei im allgemeinen von unbedingtem Gehorsam gegen den Staat geprägt gewesen, doch gebe es auch die Bibelstelle, daß man Gott mehr gehorchen müsse als den Menschen.

\footnotetext{
141 BayHStA, MSo 1415, Spruchkammerurteil vom 28. 9. 1946; LKAN, LKR 227, Aktennotiz Rusams über Besprechung mit Präsident Bodenstein am 15.1.1948.

142 BDC, Personalakt K.
} 
Als die Ermittler den katholischen Ortsgeistlichen befragten, wollte sich dieser nicht so recht äußern: ,,So weit ich weiß, war K. kein Propagandist für die Nazi-Sache. Er trug keine Uniform, wohl aber das Goldene Parteiabzeichen. Daß K. ein positiver Christ ist, zeigte sich bei seinem offenen Protest gegen die Entfernung der Kruzifixe aus dem Dorfschulhaus durch die Nazis." Zu der eigentlichen Angelegenheit wollte der katholische Pfarrer keine Aussage machen, sagte aber nach mehrmaligen Nachfragen lächelnd, wie es im Bericht heißt, er persönlich könne es nicht verstehen, daß ein Geistlicher das Goldene Parteiabzeichen getragen habe; die katholische Bevölkerung wundere sich nur. Als letzter Bericht liegt noch die Aussage eines Sekretärs von Kardinal Faulhaber vor, der in der selben Schule wie K. Religionsunterricht erteilt hatte. Er erklärte unumwunden, K. sei „eindeutig in Wort und Gesinnung“ ein Nazi gewesen, ab 1942/43 habe er sich jedoch gemäßigt ${ }^{143}$.

Am 22. März 1946 beantwortete Meiser das Schreiben der Militärregierung vom 3. November 1945, in dem die Entlassung gefordert war: K. habe das Goldene Parteiabzeichen „,unverdientermaßen“ bekommen, da er niemals Ämter und Funktionen ausgeübt habe. Der SA habe er von 1934 bis 1939 lediglich als zahlendes Mitglied angehört. Diese Angaben waren, wie die Recherchen der Militärregierung und später der Spruchkammer ergaben, nachweislich falsch; K. mußte sich deshalb auch wegen Fragebogenfälschung verantworten. Während des Kirchenkampfes habe K. begeistert auf Seiten der Bekennenden Kirche gekämpft und in seiner Eigenschaft als alter Parteigenosse der Kirche wertvolle Dienste in Konflikten mit Parteistellen geleistet: , He has been a critical observer of Party activities, always uttering his criticism without concealment, and disclosing, without any doubt, his complete disapproval of Party's attitude relative to Church and Christianity. On that account he was repeatedly objected to by Party agencies." 144 In der Ausübung seiner dienstlichen Pflichten habe K. stets das Ordinationsgelübde befolgt. Auch habe sich die Kirchengemeinde einmütig für sein weiteres Verbleiben im Amt ausgesprochen. Nach eingehender Untersuchung sehe die Kirchenleitung deshalb keinen ausreichenden Grund, ihn zu entlassen, wohl aber ziehe sie seine Versetzung in Betracht. Seine Tätigkeit als NSDAP-Kreisamtleiter für Schulung und Kultur in den Jahren 1932 bis 1937 fand keine Erwähnung und Bewertung. Was Meiser allein interessierte, war die Haltung im Kirchenkampf. Hier war der Altparteigenosse ein willkommener Interessenvertreter der Kirche gegenüber Partei- und Staatsstellen gewesen. Die aus dieser Lobbytätigkeit resultierenden partiellen Konflikte dienten als Beweis der antinazistischen Gesinnung.

Im Gegensatz zu der Darstellung Meiser gegenüber der Militärregierung steht der Beschluß des Landeskirchenrats von Ende Mai 1945, K. zu beurlauben, da er ein aktiver Nationalsozialist gewesen sei ${ }^{145}$. Wenig später forderte der Landeskirchenrat ihn auf, sich um eine andere Pfarrstelle zu bewerben. Dieser Beschluß wurde am 25. September zurückgenommen, nachdem sich einige Oberkirchenräte sowie der Kirchenvorstand der Ortsgemeinde für K. ausgesprochen hatten. Auch das zuständige Dekanat war nun der Ansicht, daß K. , ,kein Aktivist der Partei gewesen sei und daß kein Grund vorliege, aus denen die Kirche nach dem Pfarrergesetz das geistliche Amt entzieht ${ }^{\text {"146. }}$. Dennoch

143 NA, RG 260, 5/341-1/9, Inspection Report vom 3.3.1946.

144 NA, RG 260, 5/341-1/9, Landeskirchenrat an OMGB vom 22.3.1946.

145 LKAN, LKR 1188, Vollsitzung des Landeskirchenrats vom 31.5.-2.6. 1945.

146 LKAN, LKR 223, Aktennotiz, o. D. 
scheinen gewisse Zweifel geblieben zu sein, denn Mitte Januar 1946 beschäftigte sich der Landeskirchenrat nochmals mit der Frage, ob K. gegenüber der Militärregierung , unbedingt " verteidigt werden solle ${ }^{147}$. Das Ergebnis der neuerlichen Beratungen war das oben zitierte Schreiben Meisers.

Die zuständige Spruchkammer stufte K. im September 1946 als NS-Aktivisten in Gruppe II ein und verurteilte ihn zu 3 Jahren Arbeitslager, Vermögenseinzug bis auf 7000 RM, Pensionsverlust und zu 10 Jahren Predigtverbot. In der Urteilsbegründung hieß es: „Seinem Einwand, das Goldene Parteiabzeichen nur deshalb getragen zu haben, um seinen kirchlichen Einfluß zur Geltung zu bringen, kann die Kammer keinen Glauben schenken." ${ }^{148}$ Am 25. Oktober untersagte der Landeskirchenrat K., vorläufig zu predigen. Als K. dennoch mit Zustimmung seines Dekans weiterhin predigte, stellte ihn die örtliche Militärregierung wegen Mißachtung des Spruchkammerurteils am 10. Februar 1947 unter Hausarrest ${ }^{149}$. Vier Tage später verständigte der Referent für Entnazifizierungsfragen im Landeskirchenrat Rusam den zuständigen Referenten im Sonderministerium, daß „Gefahr im Verzug“ sei, da die Militärregierung die Einweisung in das Arbeitslager fordere. Theo Rahde erklärte, daß er bereits ,,nachdrücklich" die sofortige Durchführung des Berufungsverfahrens gefordert habe, was ihm vom Präsidenten der Berufungskammer München zugesagt sei ${ }^{150}$. Am 25. Februar erhielt Rusam einen Termin bei Präsident Schullze, dem Leiter der Rechtsabteilung des Sonderministeriums, der ihn darauf aufmerksam machte, daß der Vollzug des Spruchkammerurteils nur vom Generalkläger nach Vorlage einer amtsärztlichen Bescheinigung der Haftunfähigkeit außer Kraft gesetzt werden könne. Noch am gleichen Tag sprach Rusam beim Generalankläger im Kassationshof vor ${ }^{151}$. Bei einer Besprechung Meisers mit Sonderminister Loritz am 27. Februar erklärte dieser, nach der Rechtslage müsse K. verhaftet werden, sofern er nicht erneut Haftunfähigkeit nachweisen könne ${ }^{152}$. Nunmehr sah sich der Landeskirchenrat zum Handeln gezwungen und enthob K. am 3. März mit sofortiger Wirkung seines Amtes. Drei Tage später teilte dann die Kirchenleitung der Militärregierung mit, K. sei ,,zur

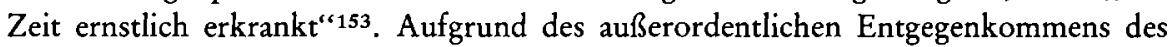
Sonderministeriums fand im gleichen Monat die erneute Verhandlung vor der Berufungskammer statt, die K. nun in die Gruppe III der ,,Minderbelasteten“ einreihte und ihn somit vor dem Arbeitslager bewahrte, andererseits aber am Predigtverbot festhielt. $\mathrm{Da}$ die Militärregierung gegen die Herabstufung Widerspruch einlegte, mußte der Kassationshof eingeschaltet werden, dessen Entscheidung jedoch nicht bekannt ist. Zwischenzeitlich wurde $\mathrm{K}$. vom Landeskirchenrat in den vorläufigen Ruhestand versetzt, bis er 1950 nach Abschluß der Entnazifizierung wieder als Pfarrer tätig werden konnte.

Einen anderen Typus verkörperte unser drittes Beispiel. Pfarrer W., Jahrgang 1894, gehörte seit Dezember 1933 der SA an, nicht aber der NSDAP, die seinen Aufnahmeantrag von 1938 wegen seines Pfarrberufes abgelehnt hatte. Ab Herbst 1939 diente W. als

${ }_{147}$ LKAN, LKR 1759 a, Vollsitzung des Landeskirchenrats vom 15.-17.1.1946.

148 BayHStA, MSo 1415, Spruchkammerurteil vom 27.9.1946.

${ }^{149}$ LKAN, LKR 210, Aktennotiz über Besuch von Frau K. bei Meiser am 18.2.1947.

150 LKAN, LKR 227, Aktennotiz Rusams über Telefonat mit tho Rahde am 14.2.1947.

151 LKAN, LKR 214, Aktennotiz Rusams über Besprechung mit Präsident Schullze am 25. 2. 1947;

Aktennotiz Rusams über Besprechung mit Staatsanwalt Kurz am 25. 2.1947.

152 LKAN, LKR 214, Aktennotiz über Besprechung mit Loritz am 27.2.1947.

153 NA, RG 260, 5/341-1/9, Landeskirchenrat an OMGB vom 6.3.1947. 
Hauptmann in der Wehrmacht, wobei offenbleiben muß, ob er als 46jähriger Pfarrer einberufen worden war oder sich, wie viele evangelische Pfarrer, freiwillig zur Front gemeldet hatte. Die Ermittlungen vor Ort zeigen das bekannte Bild unterschiedlicher Zeugenaussagen, das Geflecht familiärer und politischer Rücksichtnahmen ${ }^{154}$. Die Militärregierung hielt es jedenfalls für erwiesen, daß W. als aktiver Nazi einzustufen sei, und setzte ihn auf Platz 5 der Liste. Entscheidend war dabei sein Rang als SA-Scharführer und die Weigerung des Landeskirchenrats vom 12. November 1945, W. deshalb zu entlassen. Nicht bekannt war der Militärregierung, daß Pfarrer W. im Freikorps Epp gegen die Münchner Räterepublik gekämpft hatte. Ebenfalls nicht bekannt war ihr seine kirchenpolitische Stellung. Als führendes Mitglied der bayerischen Deutschen Christen hatte W. den , Ansbacher Ratschlag“ mitunterzeichnet, dessen völkische Theologie eine Gegenerklärung zu Barmen darstellte. Im Oktober 1934 stellte er sich dann dem Reichsbischof Müller zur Verfügung, der ihn während Meisers Hausarrests als kommissarischen Bischof für Franken einsetzte.

Im Mai 1946 beantwortete der Landeskirchenrat ein Schreiben der Militärregierung vom Dezember 1945 und begründete die Weigerung, W. zu entlassen. Die Ermittlungen des Landeskirchenrats hätten ergeben, daß W. in die SA eingetreten sei, um bei der „Neugestaltung des deutschen Volkslebens" den Einfluß der Kirche zu wahren. Als ihm 1938 die Aufnahme in die NSDAP verweigert worden sei, habe er aus der SA austreten wollen: , Statt der erbetenen Entlassung kam aber seine Beförderung zum SA-Scharführer, so daß er in der SA auch weiterhin verblieb und Dienst machte bis zu seiner Einberufung zum Heeresdienst im August 1939. “Im März 1935 [sic!] habe er sich den Deutschen Christen angeschlossen, von denen er sich dann 1939 gelöst habe. ,, Während des Krieges fand er nach verschiedenen Aussprachen wieder den Weg zur Ordnung der Kirche und der Gemeinschaft der Amtsbrüder zurück. W. gehörte zu jenen Menschen, die vom besten Willen beseelt waren, die sich aber von der Partei täuschen ließen und dann für längere Zeit diesem Irrtum verfielen; um so bedeutender ist, daß er in einer Zeit, da die Partei noch auf der Höhe ihrer Machtstellung stand, eine innere Loslösung und schließlich eine völlige Abkehr und Umkehr vollzog. " 155 In dem Entlastungsschreiben an die zuständige Spruchkammer erklärte der Landeskirchenrat: Pfarrer W. habe den Nationalsozialismus ,,rein äußerlich nur geringfügig unterstützt. Durch die einwandfreie Ausübung seines geistlichen Amtes hat er die innere Ablehnung des Nationalsozialismus durch die Tat bewiesen. [...] Pfarrer W. dürfte deshalb als Mitläufer [... .] zu werten sein. " "156 Die naheliegende Frage, ob ein Pfarrer, der noch 1938 der NSDAP beitreten wollte und auch späterhin als SA-Scharführer wirkte, den Nationalsozialismus innerlich ablehnen und als führender Deutscher Christ sein geistliches Amt einwandfrei im Sinne des Evangeliums ausüben konnte, scheint sich für die Kirchenleitung nicht gestellt zu haben.

Die Verhandlung vor der Spruchkammer ergab, daß W. seine Funktion als Untergruppenführer des Reichsluftschutzbundes (1937-39) wie seine Auszeichnung mit dem SAWehrsportabzeichen unterschlagen hatte. Die vom öffentlichen Kläger benannten Zeugen bestätigten übereinstimmend, ,daß der Betroffene größten Einfluß auf seine Gemeinde ausgeübt hatte und man seinen Worten nicht nur in religiösen Dingen Glauben

\footnotetext{
154 Vgl. NA, RG 260, 5/341-1/9, Inspection Report, o. D.

${ }^{155}$ LKAN, LKR 223, Landeskirchenrat an OMGB vom 11.5.1946.

${ }^{156}$ LKAN, LKR 223, Kirchliches Gutachten vom 7.8.1946.
} 
schenkte“. Wie so oft, konnte sich der Beschuldigte an nichts mehr erinnern; dafür besaßen die Zeugen ein besseres Gedächtnis. So wußten sie etwa noch genau, daß Pfarrer W. während eines Fronturlaubs im September 1943 bei einer Beerdigung die Gemeinde angeklagt habe, ,, nicht mehr fest genug an den Führer und an den Sieg zu glauben“"157. Die Spruchkammer verurteilte W. im August 1946 als ,, Nazi-Aktivisten“ in Gruppe II, verfügte den Einzug seines Vermögens zu 75 Prozent als Sühnemaßnahme und verhängte fünf Jahre Predigtverbot, Pensionsverlust und ein Jahr Arbeitslager. W. legte mit Unterstützung des Landeskirchenrats Berufung ein; die Berufungskammer bestätigte jedoch den Spruch und verschärfte das Urteil auf zwei Jahre Arbeitslager. Nun wurde wieder Rusam im Sonderministerium vorstellig, das detaillierte Tips zur weiteren Verfahrensweise gab, um eine Kassation des Urteils der Berufungskammer herbeizuführen. Präsident Schullze schätzte die Aussichten als ,,nicht sehr günstig“ ein, da ein materieller Grund zur Kassation nicht gegeben sei, sondern nur ein formaler Verstoß vorliege, da die Berufungskammer die Sühnemaßnahmen nicht einzeln aufgeführt habe ${ }^{158}$. Dennoch hob der Kassationshof im Februar 1947 das Urteil wunschgemäß auf und wies die Spruchkammer an, ein neues Verfahren durchzuführen ${ }^{\mathbf{1 5 9}}$. Der weitere Verlauf des Verfahrens ist nicht bekannt. 1949 war Pfarrer W., der sich seit 1946 im ,,zeitlichen Ruhestand" befand, aber zeitweise als Amtsaushilfe eingesetzt wurde, wieder regulär im Dienst.

Von den zehn Fällen, unter ihnen neun Pfarrer und ein Kirchenbeamter, an denen die Militärregierung ein Exempel statuieren wollte, wurden im Herbst 1946, in der ersten Runde des Spruchkammerverfahrens, sechs in Gruppe II, drei in Gruppe III und einer als ,,entlastet“ eingestuft. Im weiteren Verlauf fochten acht Pfarrer das Spruchkammerurteil an und erreichten bis Juni 1948 folgende Eingruppierung: Aus der Gruppe II der NS-Aktivisten wurden zwei Pfarrer zu Minderbelasteten herabgestuft, die gegen das Urteil erneut Revision einlegten, und zwei weitere Pfarrer zu Mitläufern; in einem Fall wurde das Spruchkammerurteil, anscheinend ersatzlos, kassiert. In der ursprünglichen Gruppe III der Minderbelasteten verblieben zwei Pfarrer, von denen einer das Urteil der Berufungskammer weiterhin anfocht, ein weiterer Pfarrer wurde zum Mitläufer erklärt ${ }^{160}$. Der Ausgang der Revisionsverfahren ist nicht bekannt. 1949/50 waren sieben wieder als Pfarrer tätig, ein Pfarrer und der Kirchenbeamte befanden sich im Ruhestand; ein weiterer Pfarrer war inzwischen verstorben.

Im vorzeitigen Ruhestand befand sich der mittlere Kirchenbeamte X., der als NSDAP-Zellenleiter, wie die Fränkische Landeszeitung über die Spruchkammerverhandlung berichtete, ,, als ein übler Denunziant bei seinen Nachbarn bekannt und gefürchtet war", während ihm die kirchlichen Gutachten das beste Zeugnis ausstellten. Die Spruchkammer verurteilte ihn als ,NS-Aktivisten“ zu 11/2 Jahren Arbeitslager und zog 50 Prozent des Vermögens als Sühneleistung ein ${ }^{161}$. Im Februar 1946 versetzte der Landeskirchenrat den Kirchenbeamten auf eigenes Ersuchen wegen Krankheit, so die offi-

157 Fränkische Landeszeitung vom 17.8.1946.

158 LKAN, LKR 277, Aktennotiz Rusams über Besprechung mit Ministerialrat Hertle und Landgerichtsdirektor Erber vom Sonderministerium vom 16. 1. 1947; LKAN, LKR 214 Aktennotiz Rusams über Besprechung mit Staatsanwalt Kurz vom 25.2.1947.

${ }^{159}$ LKAN, LKR 227, Aktennotiz Rusams über Besprechung mit tho Rahde vom 16.4.1947.

160 LKAN, LKR 214, Spruchkammerverfahren gegen Geistliche nach dem Stand vom 1.6.1948.

${ }^{161}$ BayHStA, MSo 1415, Spruchkammerurteil vom 20.8.1946. Vgl. NA, RG 260, 5/341-1/9; Fränkische Landeszeitung vom 21.8.1946. 
zielle Begründung, in den Ruhestand. Die zweite Ruhestandsversetzung betraf Pfarrer L., Jahrgang 1881, der als überzeugter Nationalsozialist (1933-1945) und Deutscher Christ (1934-1942) ebenfalls politische Gegner denunziert hatte. Den Ermittlern der Militärregierung erklärte der zuständige Dekan, daß L. ,, vielleicht etwas mehr als ein rein nomineller Nazi“" gewesen sei. Der SPD-Bürgermeister gab hingegen zu Protokoll, L. sei ein , ,aktiver Nazi“ gewesen, der ,,von der Kanzel herab die Nazi-Führer bei jeder Gelegenheit gelobt und auf die politischen Ereignisse verwiesen" habe. Auch sei ihm die Denunziation eines politischen Gegners bekannt. Weiterhin lag die Aussage eines KZ-Häftlings vor, der angab, daß L. ihn als Hauptbelastungszeuge für acht Jahre ins Konzentrationslager gebracht habe ${ }^{162}$. Dieser Vorfall konnte in einem $3000-S e e l e n-D o r f$ in der Nähe von Coburg kaum unbekannt geblieben sein, so daß sich die Frage stellt, weshalb L. erst ein Jahr nach dem Ende der NS-Diktatur in den Ruhestand versetzt wurde, obwohl die Militärregierung seit Oktober 1945 seine Entlassung forderte.

Die Spruchkammer stufte L. als Minderbelasteten ein, verurteilte ihn zu 2000 RM Sühne und verhängte ein zweijähriges Predigtverbot ${ }^{163}$. Daraufhin führte der zuständige Dekan, selbst Parteigenosse, Beschwerde beim Landeskirchenrat: L. könne keinesfalls als NS-Aktivist gelten, sondern zähle vielmehr zu jenen, ,,denen durch den Betrug der führenden Männer des 3. Reiches schwer äußerer und seelischer Schaden zugefügt " worden sei. Der Spruchkammervorsitzende, ein KPD-Landtagsabgeordneter, habe die Kammer zu einem Tribunal umfunktioniert, das aus , ,linkspolitischer Orientierung, von $\mathrm{Haß-}$ und Rachegefühlen geleitet, politische Gegner aus dem öffentlichen Leben zu entfernen und zu bestrafen" suche. Der Vorsitzende habe sich zu dem , unglaublichen Vorwurf" verstiegen, , ,es sei für einen Pfarrer belastend, daß er vor Gericht als Zeuge geladen, nicht das Zeugnis verweigert oder falsche Angaben gemacht habe, um den jungen Menschen vor dem Gefängnis zu bewahren. ,Ich habe oft gelogen, um mich vor dem $\mathrm{KZ}$ zu retten.' Das sagt ein Vorsitzender [...], nachdem er eben die Zeugen bei der Eidesbelehrung ermahnt hat, die reine Wahrheit zu sagen. Das ist empörend und macht ihn meines Erachtens nach als Vorsitzenden weiterhin unmöglich. " 164 Diese Auffassung machte sich der Landeskirchenrat zueigen und beschwerte sich im Oktober 1946 beim Sonderministerium über den Vorsitzenden und den öffentlichen Kläger der Spruchkammer Coburg-Land, da sie eine bewußt antikirchliche Einstellung an den Tag gelegt hätten. Nach eingehender Untersuchung wies das Sonderministerium die Beschwerde als unbegründet zurück $^{165}$. 1949, nach Abschluß der Entnazifizierung, wurde L. nicht mehr in den Dienst genommen, da er mittlerweile das Pensionsalter erreicht hatte.

Diese Fallbeispiele aus der Liste der zehn vordringlichsten Fälle zeigen, daß die bayerische Landeskirche, wie der amerikanische Geheimdienst OSS bereits Ende 1945 konstatiert hatte ${ }^{\mathbf{1 6 6}}$, zu keiner durchgreifenden Selbstreinigung bereit war und selbst aktive $\mathrm{Na}$ tionalsozialisten und führende Deutsche Christen mit allen Mitteln gegenüber der Militärregierung verteidigte. Das Verhalten Meisers, der in diesem Punkt die Pfarrerschaft geschlossen hinter sich wußte, läßt sich nur als eine Politik bewußter Obstruktion bezeich-

162 NA, RG 260, 5/341-1/9, Inspection Report vom 22.11.1945 und 18.4.1946.

163 BayHStA, MSo 1415, Spruchkammerurteil vom 8.10.1946.

164 LKAN, LKR 201, Dekanat Coburg an Landeskirchenrat vom 30.9.1946 und 9.10.1946.

165 LKAN, LKR 201, Generalkläger am Kassationshof an Landeskirchenrat vom 8.3. 1947.

166 IfZ, MA 1478, OSS, Situation Report - Central Europe vom 12.12.1945. 
nen. Eine Aufstellung der Militärregierung für Bayern vom 15. Juni 1946, die auf der Auswertung der Fragebogen von 80 Prozent aller bayerischen Geistlichen beruhte, nannte namentlich 156 evangelische Pfarrer und Kirchenangestellte, die nach den allgemein gültigen Richtlinien in die höchste Entlassungskategorie ,,mandatory removal“ fielen ${ }^{167}$. Mit merklicher Verbitterung notierte der Bericht an OMGUS, daß von ihnen bislang kein einziger vom Landesbischof entlassen worden sei. Im Unterschied dazu verlaufe die Zusammenarbeit mit der katholischen Kirche problemlos. Die sehr kleine Anzahl belasteter katholischer Pfarrer - eine genaue Angabe enthielt der Bericht nicht - sei von den jeweils zuständigen Bischöfen entfernt worden ${ }^{168}$.

In der Tat war Mitte 1946 die Entnazifizierung der evangelischen Pfarrerschaft in eine Sackgasse geraten. Einerseits schrieb die ,Military Government Regulation 8-901.4“ verbindlich vor, daß die Militärregierung politisch belastete Pfarrer nicht selbst entlassen dürfe, sondern diese Fälle der zuständigen Kirchenleitung übergeben müsse, die dann von sich aus die notwendigen Maßnahmen treffen werde; andererseits verweigerte sich Meiser hartnäckig einer solchen Kooperation: , In each case he has defended the clergymen in question, saying that when he joined the party he didn't understand it and when he did understand, he remained to fight it, or that he joined so that he could obtain a scholarship for further study. The Bishop claims that he purged church of undesirable members before the Americans arrived. " 169 Zusätzlich sah sich die Militärregierung mit dem Problem konfrontiert, daß die chronische personelle Unterbesetzung der Religious Affairs Abteilung nur in seltenen Einzelfällen eine gründliche Untersuchung vor Ort erlaubte. Der Fall, daß die Kirchenleitung die Entnazifizierung der Pfarrerschaft derart massiv abblocken würde, war in den Vorschriften nicht vorgesehen gewesen. Damit stand die Militärregierung in Bayern vor einer Situation, die sie aus eigener Kraft nicht mehr zu lösen vermochte.

\section{Die Mitläuferfabrik}

Einen Ausweg aus dem Dilemma erhoffte man sich in der Militärregierung von dem im März 1946 verabschiedeten Befreiungsgesetz, das die Durchführung der Entnazifizierung den deutschen Länderregierungen übertrug und damit die amerikanische Militärregierung von der Notwendigkeit enthob, gegen die Obstruktionspolitik Meisers mit harten, aber in den USA unpopulären Maßnahmen vorzugehen.

Damit trat bis zur Installierung der deutschen Spruchkammern eine Pause ein, die der Landeskirchenrat zu Verhandlungen mit Ministerpräsident Hoegner und dem Sonderministerium nutzte. Insbesondere bemühte sich die Kirchenleitung, eine Ausnahmegenehmigung für die Weiterbeschäftigung derjenigen Pfarrer zu erreichen, die nach Art. 58 BefrG aufgrund der formellen Schuldvermutung nach Gruppe I und II bis zum Abschluß des Spruchkammerverfahrens nur in ,,gewöhnlicher Arbeit", d.h. nicht als Geistliche, beschäftigt werden durften. Davon waren unter anderem alle NSDAP-Mitglieder vor

167 NA, RG 260, 15/125-1/3, List of Clergymen in Mandatory Removal Category vom 15.6.1946.

Die Liste enthält 161 Namen, darunter befinden sich 2 katholische Pfarrer und 3 doppelte Namensnennungen, so daß sich als korrekte Angabe 156 ergibt.

${ }_{168} \mathrm{NA}, \mathrm{RG} 260,15 / 125-1 / 3$, OMGB an OMGUS vom 17.7.1946.

169 NA, RG 260, 10/87-2/43, Draft of Report vom 8.7.1946. 
dem 1. Mai 1937 - das Gros der belasteten Pfarrer - betroffen ${ }^{170}$. Während Hoegner eine solche Ausnahmeregelung aus parteitaktischem Kalkül befürwortete, um die Gunst der evangelischen Wähler zu gewinnen, lehnte sie der Staatsminister für Sonderaufgaben, Heinrich Schmitt (KPD), nach Rücksprache mit der Militärregierung ab ${ }^{\mathbf{1 7 1}}$. Für die Praxis ergaben sich daraus keine Konsequenzen, da der Landeskirchenrat diese Bestimmung des Befreiungsgesetzes mit stiller Duldung des Sonderministeriums, das ab Juni 1946 das katholische CSU-Mitglied Anton Pfeiffer leitete, ignorierte.

Ein weiteres Zugeständnis stellte die Dienstanweisung des Sonderministeriums dar, die auf einen Beschluß des Länderrats zurückging. Demnach mußte der öffentliche Kläger mindestens vier Wochen vor Anklageerhebung dem Minister einen Bericht vorlegen, der anschließend dem zuständigen Bischof zur Stellungnahme zugeleitet wurde ${ }^{172}$. Zu einer „,noch weitergehenden Sonderbehandlung" hatte sich Schmitt, der die Entnazifizierung als Mittel des politischen Elitenaustausches begriff, im Interesse einer ,strengen, aber gerechten "Durchführung des Befreiungsgesetzes außerstande gesehen ${ }^{173}$. Zugleich erreichte die Kirche, daß in allen Spruchkammerverhandlungen der zuständige Dekan als ,,Sachverständiger" für das Verhältnis von Staat und Kirche im Dritten Reich hinzugezogen werden konnte ${ }^{174}$.

Im Sommer 1946, als die Entnazifizierung allgemein stagnierte, wurden die Pfarrer intensiv auf die kommenden Verhandlungen vorbereitet. Im Mai erging an die belasteten Pfarrer die dienstliche Aufforderung, ,, sich so rasch als möglich die nötigen Unterlagen und Zeugnisse für ihre Rechtfertigung zu beschaffen " und sie dem Dekanat zur Beglaubigung einzureichen. Der Landeskirchenrat sagte die Erstellung eines entlastenden Gutachtens zu und erteilte detaillierte Ratschläge zur Verteidigung ${ }^{175}$.

Zur Information der Dekane und der Spruchkammern erstellte die Kirchenleitung ein Merkblatt mit dem Titel: ,, Was war die ,Bekennende Kirche‘ oder ,Bekenntnisfront' in den Jahren 1934-1945?“ Während der Kirchenkampf des Jahres 1934 korrekt als der Kampf der bayerischen Landeskirche für den Erhalt der kirchlichen Autonomie gegen den ,Machtanspruch des NS-Staates über die Kirche“ beschrieben wurde, diente die Schilderung der weiteren Entwicklung der Legendenbildung: Der Kampf der Bekennenden Kirche habe sich in späteren Jahren , gleichzeitig zu einem Kampf für Recht und Gerechtigkeit im Leben des ganzen Volkes" ausgeweitet und sich dabei ,,gegen alle Bedrükkung und Vergewaltigung, insbesondere gegen das Unrecht der Konzentrationslager, gegen die Ermordung von Geisteskranken und gegen die Verfolgung und Ausrottung der Juden" gerichtet. Damit nahm die bayerische Kirchenleitung den partiellen Widerstand

${ }^{170}$ Nach der maßgebenden Interpretation der Militärregierung bedeutete der Art. 58 BefrG ein generelles Predigtverbot. Vgl. NA, RG 260, 5/341-1/6-10, OMGUS-Anweisung an Länderregierungen vom 23.8.1946.

171 BayHStA, MSo 1413, Aktennotiz Hoegners vom 22.5.1946; LKAN, LKR 201, Aktennotiz Bogners vom 31.5.1946 und 3.6.1945; LKAN, LKR 227, Schmitt an Landeskirchenrat vom 31.5.1945; Hoegner an Meiser yom 15.6.1946.

172 Mitteilungsblatt des Sonderministeriums, Nr.1/2 vom 8. 8.1946.

${ }^{173}$ LKAN, LKR 227, Schmitt an Landeskirchenrat vom 6. 9. 1946. Zur Konzeption Schmitts, später Pfeiffers vgl. Niethammer, Entnazifizierung, S. $338 \mathrm{ff}$.

${ }^{174}$ LKAN, LKR 201, Rundschreiben des Landeskirchenrats vom 6. 9. 1946; LKAN, LKR 227, Aktennotiz Bogners über Besprechung mit Pfeiffer am 3.8.1946.

175 LKAN, LKR 225, Rundschreiben des Landeskirchenrats vom 27.5. 1946; LKAN, LKR 201, Rundschreiben vom 29.7.1946. 
des bruderrätlichen Flügels der Bekennenden Kirche für sich in Anspruch, von dem sie sich im Dritten Reich aus politischen Gründen stets öffentlich distanziert hatte. Ferner hieß es, daß auch NSDAP-Mitglieder, wenn sie sich der Bekennenden Kirche anschlossen, - wozu sich bekanntlich die gesamte Landeskirche als Institution rechnete - ,,innerlich der NS-Weltanschauung und dem DC-Geist fernestanden und daß sie die Treue zu ihrer Kirche, die Liebe zu ihrem Volk und den Gehorsam gegen die göttlichen Gebote von Recht und Wahrheit höher stellten als die Zugehörigkeit zur Partei“. Damit sei „,einwandfrei" bewiesen, daß sie als Mitglieder der Bekennenden Kirche in einer „,Kampf- und Widerstandsbewegung“ gegen den Nationalsozialismus tätig gewesen seien ${ }^{176}$.

Anfang September 1946 verschickte die Kirchenleitung weitere Materialien, um zu beweisen, daß der , Kampf der Bekennenden Kirche, obwohl seinem tiefsten Wesen nach ein Glaubenskampf, schließlich in der Tat zum aktiven Widerstand gegen Staat und Partei" geführt habe. Dabei handelte es sich vor allem um kirchenfreundliche Stellungnahmen von führenden Nationalsozialisten, die belegen sollten, daß die ,Erwartung der schon frühzeitig zur NSDAP gestoßenen Geistlichen, die Bewegung werde zu einer Förderung des Christentum gegenüber der Gottlosenpropaganda und zu einem Aufschwung kirchlichen Lebens führen“, berechtigt gewesen sei. Was allerdings den aktiven kirchlichen Widerstand anging, blieb der Nachweis dürftig ${ }^{177}$.

Zur gleichen Zeit stellte die ERA-Branch verbittert fest, daß in Bayern seit eineinhalb Jahren die Entnazifizierung der Pfarrerschaft festgefahren war. Während bis August 1946 in Groß-Hessen die Kirchenbehörden beider Konfessionen 136 Pfarrer und kirchliche Angestellte entfernt hätten, in Württemberg gar 144, seien es in Bayern gerade $41^{178}$. Nicht minder unzufrieden war man mit der Tätigkeit des bayerischen Sonderministeriums, das bis zum 24. September erst die Fälle von sechs Pfarrern vor den Spruchkammern verhandelt hatte. Am 12. August wies Clay seinen Entnazifizierungsberater Walter Dorn an, für eine strikte Durchführung der Anordnungen Sorge zu tragen: ,, We had been extraordinarily lenient with the church [...] although we had given the church every consideration in permitting its leaders to clean their own households, many clergymen who are considered by our Special Branch to be Mandatory Removals are still continuing in office. "179 Am 23. August befahl OMGUS den Ministerpräsidenten der US-Zone, alle Spruchkammerverfahren gegen Geistliche bis zum 1. Oktober 1946 definitiv abzuschließen; der Termin wurde später auf den 20. Oktober 1946 verlängert ${ }^{180}$. Die Spruchkam-

176 LKAN, LKR 201. Abdruck: Noorman, Protestantismus, Bd. 2, S. $101 \mathrm{f}$.

${ }^{177}$ LKAN, LKR 225, Rundschreiben des Landeskirchenrats vom 16.9.1946. Als einziger Beleg wurde aus der Denkschrift der (bruderrätlichen) 2. Vorl. Leitung der Bekennenden Kirche an Hitler vom Mai 1936, die als „Protestschrift des Rates der Deutschen Evangelischen Kirche“ vorgestellt wurde, zitiert, von der sich jedoch die Bischöfe der ,,intakten" Landeskirchen damals distanziert hatten. Vgl. Meier, Kirchenkampf, Bd.2, S. 145 f.; Greschat, Widerspruch.

${ }_{178}$ NA, RG 260, 5/338-3/13-17, Taylor an Dorn vom 12.8.1946. Die Angabe von 144 entfernten württembergischen Pfarrern und Kirchenangestellten ist mit Sicherheit stark übertrieben. Vgl. Kap. V/1.

179 NA, RG 260, 5/339-1/6, Aktennotiz Dorns über Besprechung mit Clay und Adcock vom 23.8.1946.

$180 \mathrm{NA}, \mathrm{RG} 260,5 / 341-1 / 6-10$, OMGUS an OMGB, OMGH, OMGWB vom 23.8.1946; NL Hoegner 125, OMGB an Hoegner vom 24.8.1946 und 26.9.1946; NA, RG 260, 5/339-1/6, OMGUS an OMGB, OMGH, OMGWB vom 3.10.1946. 
mern mußten nun innerhalb von nur drei Wochen unter großen Schwierigkeiten und unter Aufhebung der vereinbarten vierwöchigen Informationsfrist die vom Sonderministerium bisher verschleppte Entnazifizierung in einem überstürzten Gewaltakt nachholen. Das kam der Kirchenleitung nicht ungelegen, wie eine Aktennotiz des Entnazifizierungsreferenten im Landeskirchenrat zeigt: ,,Vielleicht ist es sogar ganz günstig, wenn gerade diese schwersten Fälle von dem öffentlichen Kläger, unkorrekt ' behandelt werden; um so eher ist ein Grund zum Einspruch gegeben."181

Ende September verschärfte OMGUS die Gangart und teilte dem Entnazifizierungsausschuß des Länderrats mit, nach dem 30. September dürfe kein Pfarrer, dessen Verfahren bis dahin nicht positiv abgeschlossen sei, weiter amtieren. Die selbe Order erhielt auch Sonderminister Pfeiffer, der sie am 1. Oktober dem Landeskirchenrat übermittelte ${ }^{182}$. Dieser wies sofort, trotz ,,ernster Bedenken“, 28 Pfarrer an, sich der ,Dienstgeschäfte zu enthalten“. Ausdrücklich betonte Meiser, diese Entscheidung, mit der die Kirchenleitung erstmals dem Weiterbeschäftigungsverbot des Befreiungsgesetzes Rechnung trug, sei nur aufgrund der angedrohten ,,schwerwiegenden Folgen " getroffen worden ${ }^{183}$.

Bis zum 20. Oktober hatten die Spruchkammern die Fälle von 204 aktiven evangelischen Pfarrern und Kandidaten verhandelt; eine Aufstellung der Militärregierung vom November 1946 nennt als Gesamtzahl 257, einschließlich der pensionierten und außerbayerischen Pfarrer im Dienste der bayerischen Landeskirche. Die vom Landeskirchenrat und der Militärregierung geführten Statistiken ergeben folgende Aufschlüsselung der Urteile:

Entnazifizierungsstatistik vom Oktober und November $1946^{184}$

\begin{tabular}{lrrrrrr}
\hline $\begin{array}{l}\text { Einstufung } \\
\text { Gruppe }\end{array}$ & \multicolumn{2}{c}{$\begin{array}{c}\text { Landeskirchenrat } \\
\text { (Oktober 1946) } \\
\text { absolut }\end{array}$} & $\%$ & \multicolumn{2}{c}{$\begin{array}{c}\text { Militärregierung } \\
\text { (November 1946) }\end{array}$} & \multicolumn{2}{c}{$\begin{array}{c}\text { Bayern allgemein } \\
\text { (Oktober 1946) } \\
\text { absolut }\end{array}$} & $\%$ \\
\hline I & 0 & 0 & 0 & 0 & 23 & 0,2 \\
II & 8 & 3,9 & 11 & 4,3 & 373 & 3,0 \\
III & 23 & 11,3 & 29 & 11,3 & 1348 & 10,8 \\
IV & 102 & 50,0 & 133 & 51,7 & 9563 & 76,0 \\
V & 71 & 34,8 & 84 & 32,7 & 1263 & 10,0 \\
\hline Summe & 204 & 100 & 257 & 100 & 12570 & 100 \\
\hline
\end{tabular}

Die Gesamtzahl der aktiven Pfarrerschaft, einschließlich der hauptberuflichen Religionslehrer und Anstaltsgeistlichen, gab der Landeskirchenrat im Oktober 1946 mit 1453, darunter 272 außerbayerische Pfarrer, an; hinzu kamen weitere 252 Pfarrer im Ruhestand ${ }^{\mathbf{1 8 5}}$. Von den ersten Urteilen der deutschen Spruchkammer waren rund zwei Drittel aller belasteten Pfarrer der evangelischen Landeskirche erfaßt. Im Vergleich dazu war

${ }^{181}$ LKAN, LKR 216, Rusam an Vischer vom 17.8.1946.

${ }^{182}$ LKAN, LKR 216, Pfeiffer an Meiser vom 1.10.1946.

${ }^{183}$ LKAN, LKR 225, Rundschreiben des Landeskirchenrats vom 4.10.1946.

184 LKAN, LKR 214, Statistik des Landeskirchenrats nach dem Stand vom 24. 10. 1946; NA, RG 260, 15/125-1/3, OMGB an OMGUS vom 14.11.1946.

${ }^{185}$ LKAN, LKR 214, Ubersicht vom 1.10.1946. 
die katholische Kirche, in deren Diensten nach einer Schätzung von Prälat Neuhäusler 8-9000 Pfarrer standen, so gut wie gar nicht betroffen. Die Statistik der Militärregierung verzeichnete im November 1946 lediglich elf belastete katholische Geistliche, wovon einer als , ,minderbelastet", die anderen als Mitläufer eingestuft worden waren. Vier katholische Pfarrer hatten der NSDAP von 1933/34 bis 1937/38 angehört; die übrigen fielen aufgrund ihrer Mitgliedschaft in anderen NS-Organisationen unter das Befreiungsgesetz $^{186}$. Während sich der Anteil der belasteten evangelischen Pfarrer bis zum Abschluß der Entnazifizierung 1949/50 kontinuierlich von 15,1 Prozent auf 24,9 Prozent der gesamten Pfarrerschaft erhöhte, d. h. von 257 auf 431 Spruchkammerverfahren $^{187}$, stieg die Zahl der belasteten katholischen Pfarrer nur geringfügig an. 1947 waren dem Sonderministerium lediglich 15 Verfahren bekannt ${ }^{188}$.

Diese äußerst geringe Quote von ca. 0,2 Prozent, zudem fast ausschließlich Mitläuferfälle, wurde von keiner anderen sozialen Schicht oder politischen Gruppierung in Bayern auch nur entfernt erreicht. Die geschlossene Distanz des katholischen Klerus verweist zum einen auf die von Anfang an größere Resistenz gegenüber dem Nationalsozialismus; sie war aber auch eine Folge des im Reichskonkordat festgelegten Verbots der parteipolitischen Betätigung von Pfarrern, auf dessen strikte Einhaltung die katholischen Bischöfe aus taktischen wie prinzipiellen Erwägungen größten Wert gelegt hatten. Nach den Kriterien des Befreiungsgesetzes, dessen Kernstück die nachweisbare Mitgliedschaft in NS-Organisationen bildete, konnte die katholische Kirche, trotz ihres Arrangements mit dem NS-Staat, als politisch völlig unbelastet gelten.

Diese Legitimation konnte die evangelische Kirche bei ihrer Kritik an der Entnazifizierung nicht für sich in Anspruch nehmen, da sie ein starkes Eigeninteresse an der Verhinderung einer durchgreifenden politischen Säuberung haben mußte. Eine Aufschlüsselung, die 95 Prozent der von der Entnazifizierung betroffenen evangelischen Pfarrerschaft erfaßt, zeigt - ohne Doppel- und Mehrfachmitgliedschaften - folgendes Bild der „,formalen Belastung“"

Formalbelastung der bayerischen Pfarrerschaft (424 von 431 vom Befr $G$ betroffene Pfarrer) ${ }^{189}$

\begin{tabular}{|c|c|}
\hline \multicolumn{2}{|c|}{ Mitgliedschaft in der NSDAP } \\
\hline vor 1930: 7 & \\
\hline 1930: 15 & 1934: \\
\hline 1931: 18 & 1935: \\
\hline 1932: 17 & nach 1935: \\
\hline
\end{tabular}

Parteianwärter 209

SA und SS (fördernde Mitgliedschaft)

Studenten-SA und NS-Studentenbund

Sonstige NS-Organisationen

(HJ, NSV, NSKK etc.)

19

58

100

38

186 NA, RG 260, 15/125-1/3, OMGB an OMGUS vom 14.11.1946.

${ }^{187}$ LKAN, LKR 201, Statistik des Landeskirchenrats nach dem Stand vom 1.2.1950. 1950 zählte die Landeskirche 1730 Pfarrer, einschließlich der Missionare und Ruhestandsgeistlichen.

188 BayHStA, MSo 1413, Stand der Entnazifizierung der Landeskirche in Bayern, o. D. (1947).

${ }^{189}$ LKAN, Zusammengestellt aus: Spruchkammerverfahren gegen Geistliche. Stand 1.6.1948 (LKAN, LKR 214) und Spruchkammerurteile (BayHStA, MSo 1415 und 2377). 
Besonders schwer wog nach den Kriterien des Befreiungsgesetzes der Eintritt in die NSDAP vor dem 1. Mai 1937 (Schuldvermutung NS-Aktivist); das traf für etwa 200 evangelische Pfarrer zu. Mit ,,besonderer Sorgfalt" sollten weiterhin alle Parteianwärter, Mitglieder der HJ vor 1939 sowie alle SA- und SS-Mitglieder geprüft werden. Hier ist zu berücksichtigen, daß der Beitritt von Pfarrern zur SA oder SS - im Unterschied zu vielen Arbeitslosen - keiner wirtschaftlichen Notlage entsprungen war. Anders zu bewerten ist die Mitgliedschaft im NS-Studentenbund oder in der Studenten-SA, die ab 1934 für Theologiestudenten Pflicht war. Als politisch stark belastet müssen demnach mindestens 267 Pfarrer gelten, deren Fälle zum größten Teil im Oktober und November 1946 in der 1. Instanz verhandelt wurden.

Untersucht man die in den Akten des Sonderministeriums nur unvollständig überlieferten, 111 vorhandenen Spruchkammerurteile ${ }^{190}$, so zeigt es sich, daß die Spruchkammern in der Beurteilung der Formalbelastung stark voneinander abwichen. Eine Minderheit legte die im Anhang des Befreiungsgesetzes angeführten Maßstäbe an und sah in der Parteimitgliedschaft von Pfarrern eine wesentliche Förderung des Nationalsozialismus. In einigen Urteilsbegründungen der Gruppe II und III wurde besonders die Verantwortung der Pfarrer als lokale Meinungsführer und moralische Instanz hervorgehoben: „,Hätte als Geistlicher unbedingt aus der Partei austreten müssen, nachdem er sich überzeugt hatte, daß die Partei kirchenfeindlich eingestellt war." Oder: Der Betroffene ,, wirkte natürlich auch auf die zivile Umgebung, so daß auch aus den Reihen der Bevölkerung viele zur Partei stießen, welche sonst durch ihre religiöse Orientierung abgehalten worden wären." In der 1. Instanz wurden laut Statistik 40 Pfarrer als NS-Aktivisten (Gruppe II) oder Minderbelastete (Gruppe III) eingestuft. In der Verurteilung von bis zu drei Jahren Arbeitslager und Einzug des Vermögens bis zu 75 Prozent in Gruppe II kam der Strafcharakter des Befreiungsgesetzes zum Ausdruck. In der Praxis hatten diese Sühnemaßnahmen kaum Folgen, da sie, mit einer Ausnahme, nicht vollstreckt wurden und die Berufungskammern wenige Monate später in aller Regel zugunsten der betroffenen Pfarrer entschieden. Die harten Urteile in 1. Instanz verweisen auf den Willen etlicher Spruchkammern, den strengen Maßstab des Befreiungsgesetzes auch auf die Pfarrerschaft anzuwenden.

In den meisten Fällen ist jedoch bereits für die ersten Verfahren die Charakterisierung des Spruchkammerwesens als ,,Mitläuferfabrik “, als ,, white-washing “ gerechtfertigt ${ }^{191}$. Typisch dafür sind Urteilsbegründungen wie diese: ,Hat insbesondere sogar den Mut aufgebracht, den Namen des Führers in das allgemeine Gebet nicht aufzunehmen und seinen Gläubigen als Begrüßung das ,Grüß Gott' empfohlen" (NSDAP 1930-45). Oder: Der Parteieintritt (NSDAP 1935-45) ,,dürfte wohl aus dem Grunde erfolgt sein, weil er sich dadurch leichter Kritik an den Maßnahmen des Nationalsozialismus erlauben durfte". Ein anderer, ebenfalls Parteigenosse seit 1935, ,,stand auf dem Boden der Bekenntniskirche. Hat sich nie für den Nationalsozialismus betätigt.“ Vielfach hieß es, der Betroffene (NSDAP 1932-45) ,, ist frühzeitig von der Ideologie des Nationalsozialismus ab-

190 BayHStA, MSo 1415 und 2377. Ein namentliches Verzeichnis aller Spruchkammerverfahren gegen Pfarrer liegt für das Jahr 1946 nicht vor. Die Urteile von 119 evangelischen Pfarrern und 25 kirchlichen Angestellten übermittelte das Sonderministerium am 18.10.1946 an OMGB. Vgl. NA, RG 260, 15/125-1/3.

${ }^{191}$ Vgl. Niethammer, Entnazifizierung, S. 405 ff.; Ettle, Entnazifizierung in Eichstätt, S. 125 ff.; Woller, Gesellschaft, S. $131 \mathrm{ff}$. 
gerückt. Er hat durch seine Haltung als Seelsorger bewiesen, daß er in keiner Weise innerlich mit der Partei verbunden war. Sein Eintritt in die NSDAP erfolgte 1932 tatsächlich in gutem Glauben an die sozialen Versprechungen." $\mathrm{Zu}$ welcher Akrobatik Spruchkammern fähig waren, zeigen folgende Urteilsbegründungen: , Wir konnten uns dem Antrag des Anklägers insofern nicht anschließen, da durch die Ablehnung der Aufnahme des Betroffenen in die NSDAP seine Gegnerschaft erwiesen ist." So konnte auch der verhinderte Eintritt in die NSDAP zum Widerstand gegen das NS-Regime werden; was um so grotesker war, da der betreffende Pfarrer als aktiver Deutscher Christ und Mitarbeiter des ",Instituts zur Erforschung des jüdischen Einflusses auf das deutsche kirchliche Leben“" bekannt war. Erstaunlich ist auch die Begründung eines Mitläuferurteils mit dem einzigen Satz: , ,Die Kammer stellte mit höchstem Befremden fest, daß der Betroffene im Jahre 1937 der Partei beitrat, obwohl damals schon die Kirche sehr starken Verfolgungen ausgesetzt war. " Einen HJ-Scharführer (1934-36) stufte die Spruchkammer als entlastet ein, da er sich niemals zugunsten des Nationalsozialismus betätigt habe; dafür aber als Pfarrer ,,einer Widerstandsbewegung“, womit die Bekennende Kirche gemeint war, , , angehörte und nachweisbar regelmäßig teilnahm an Veranstaltungen anerkannter Religionsgesellschaften".

Was sich wie eine Blütenlese ausnimmt, charakterisiert Tenor und Tendenz vieler Urteilsbegründungen. Unverkennbar suchten die meisten Kammern, teilweise geradezu verzweifelt, nach Entlastungsgründen, während belastende Momente nicht ins Gewicht fielen. Nur in seltenen Fällen vermochten die Spruchkammern, die Herabstufung der vom öffentlichen Kläger aufgrund der Formalbelastung beantragten Eingruppierung in II oder III auf IV oder gar V stichhaltig damit zu begründen, daß der betroffene Parteipfarrer, wie es der Artikel 13 BefrG verlangte, ,,nach Maß seiner Kräfte aktiv Widerstand gegen die nationalsozialistische Gewaltherrschaft geleistet hat und dadurch Nachteile erlitten hat".

Die statistische Auswertung der erhaltenen 111 Spruchkammerurteile aus der 1.Instanz zeigt die Mitläuferfabrik in voller Aktion: Von 61 Pfarrern, die wegen ihres frühen Parteieintritts nach der Schuldvermutung des Befreiungsgesetzes als NS-Aktivisten galten, wurden 19, d. h. 31,1 Prozent, entsprechend der Schuldvermutung in Gruppe II oder III eingestuft; 47,5 Prozent galten als Mitläufer, weitere 21,4 Prozent gar als entlastet. Da in der vorliegenden Stichprobe (vgl. nächste Tabelle) die in Gruppe II und III eingestuften Pfarrer überproportional vertreten sind (19 von insgesamt 40), ist der prozentuale Anteil der zu Mitläufern und Entlasteten erklärten Pfarrer noch um einiges höher anzusetzen. Parteianwärter, Mitglieder der SA und SS (fördernde Mitgliedschaft) sowie sämtlicher anderer NS-Organisationen wurden ohne Ausnahme, auch wenn sie etwa als Scharführer, Ortsgruppenleiter oder Blockwart parteiamtliche Funktionen ausgeübt hatten, als Mitläufer oder Entlastete eingestuft und damit in der Bewertung der Mitgliedschaft von Theologiestudenten in der Studenten-SA oder im NS-Studentenbund gleichgestellt.

Mit dieser Entlastungsoffensive verstießen die Spruchkammern vielfach gegen die Bestimmungen des Befreiungsgesetzes, handelten aber entsprechend der Intentionen seiner deutschen Miturheber. Für die Militärregierung fiel das Ergebnis der Verfahren, deren Durchführung sie in einem politischen Kraftakt dem unwilligen Sonderministerium aufgezwungen hatte, natürlich unbefriedigend aus, da nur 40 von 209 Parteipfarrern in Gruppe II und III eingestuft worden waren. Es konnte für sie keine Beruhigung sein, daß 
sich hierin nur der allgemeine Trend der Entlastung und Rehabilitierung von NS-Aktivisten widerspiegelte, sondern steigerte die Empörung. Anfang November 1946 drohte Clay den Ministerpräsidenten unmißverständlich, die Besatzungsmacht werde die Entnazifizierung, wenn keine rasche Besserung erfolge, wieder in eigener Regie durchführen. Als erste Sofortmaßnahme ordnete er an, daß die Wiedereinstellung entlassener Mitläufer künftig der Zustimmung der Militärregierung bedürfe. Seine scharfen Worte vermochten jedoch weder die inneren Widersprüche des Befreiungsgesetzes zu überwinden noch die endgültige ,Fahrt der Entnazifizierung in die Sackgasse“ ${ }^{\text {“192 }}$ zu verhindern.

Auch der Widerstand der evangelischen Kirche blieb ungebrochen und verstärkte sich zusehends. Einen besonderen Konfliktstoff bot die Bewährungsfrist, die in Gruppe II und III automatisch verhängt wurde und den Betroffenen ausdrücklich untersagte, ,,als Lehrer, Prediger, Redakteur, Schriftsteller oder Rundfunk-Kommentator tätig zu sein“". Der Wortlaut des Gesetzes war in diesem Punkt eindeutig und wurde auch von den Juristen des Sonderministeriums übereinstimmend als unbedingtes Predigtverbot interpretiert ${ }^{193}$. Hatte es die Militärregierung bisher unterlassen, gegen die Predigttätigkeit derjenigen Pfarrer, die nach der Schuldvermutung bis zum Abschluß ihres Spruchkammerverfahrens als NS-Aktivisten zu gelten hatten, vorzugehen, so war die Situation nach dem Scheitern des Spruchkammerexperiments eine völlig andere. Gegen innere Widerstände aus seinem Mitarbeiterkreis legte Clay Mitte Oktober 1946 definitiv fest, daß das Beschäftigungsverbot des Artikel 58 BefrG auch das Predigen verbiete ${ }^{194}$.

Nach Abstimmung mit der EKD beschloß der Landeskirchenrat Mitte Oktober, eine weitere Kraftprobe mit der Militärregierung zu wagen und erteilte 20 vom Predigtverbot betroffenen Pfarrern die Weisung, in vollem Umfang als Geistliche weiterzuamtieren. Andere Pfarrer wurden hingegen angewiesen, sich vorerst an das Predigtverbot zu halten $^{195}$, um die Geduld der Militärregierung nicht überzustrapazieren. Auch diesmal fand sich das Sonderministerium unter Pfeiffer zu einer Sonderregelung bereit, standen doch die Landtagswahlen am 1. Dezember 1946 vor der Tür. Vor evangelischen CSU-Abgeordneten hatte Meiser bereits Mitte September ,,mit großem Nachdruck“, wie eine Aktennotiz festhielt, betont: , Die Unzufriedenheit mit der CSU sei in evangelischen Kreisen groß. Das Verhalten ihres Ministers in der Entnazifizierung habe den Kredit der Partei schon weitgehend verscherzt. Das würde sich bei der nächsten Wahl auswirken. "196

${ }^{192}$ Niethammer, Entnazifizierung, S. 420. Zur Drohrede Clay vom 5.11.1946 ebenda, S. $411 \mathrm{ff}$.

${ }^{193}$ Art. 16/8c und Art. 17/1 c BefrG. Vgl. BayHStA, MSo 1413, Gutachten von Oberlandesgerichtsrat Münch vom 17.1.1947, dem sich die Juristen des Sonderministeriums anschlossen; LKAN, LKR 227, Aktennotiz Rusams über Besprechung mit Ministerialrat Ziebell am 11.9.1946; NA, RG 260, 5/339-1/6, OMGUS-Anweisung an Länderregierungen vom 23. 8.1946.

194 Niethammer, Entnazifizierung, S. 412. Vgl. NA, RG 260, 5/338-3/13-17, Taylor an Dorn vom 17. 8. 1946; NA, RG 260, 5/339-1/6, Aktennotiz Dorns über Besprechung mit Clay und Adcock vom 23.8.1946.

195 LKAN, LKR 201, Haussitzung des Landeskirchenrats vom 22.10.1946; LKAN, LKR 214, Spruchkammerverfahren gegen Geistliche in Gruppe II und III. Aufstellung o. D. (Ende Oktober 1946).

${ }^{196}$ LKAN, NL Meiser 213, Aktennotiz Vischers über Besprechung mit evangelischen CSU-Abgeordneten am 18.9.1946. Von der CSU waren August Haußleiter, Dr. Johannes Semmler, Adam Küssel, Adam Sühler, Karl Mayr, Georg Riedel, Georg Bachmann, Heinrich Ehlhardt und Georg Mack erschienen. 


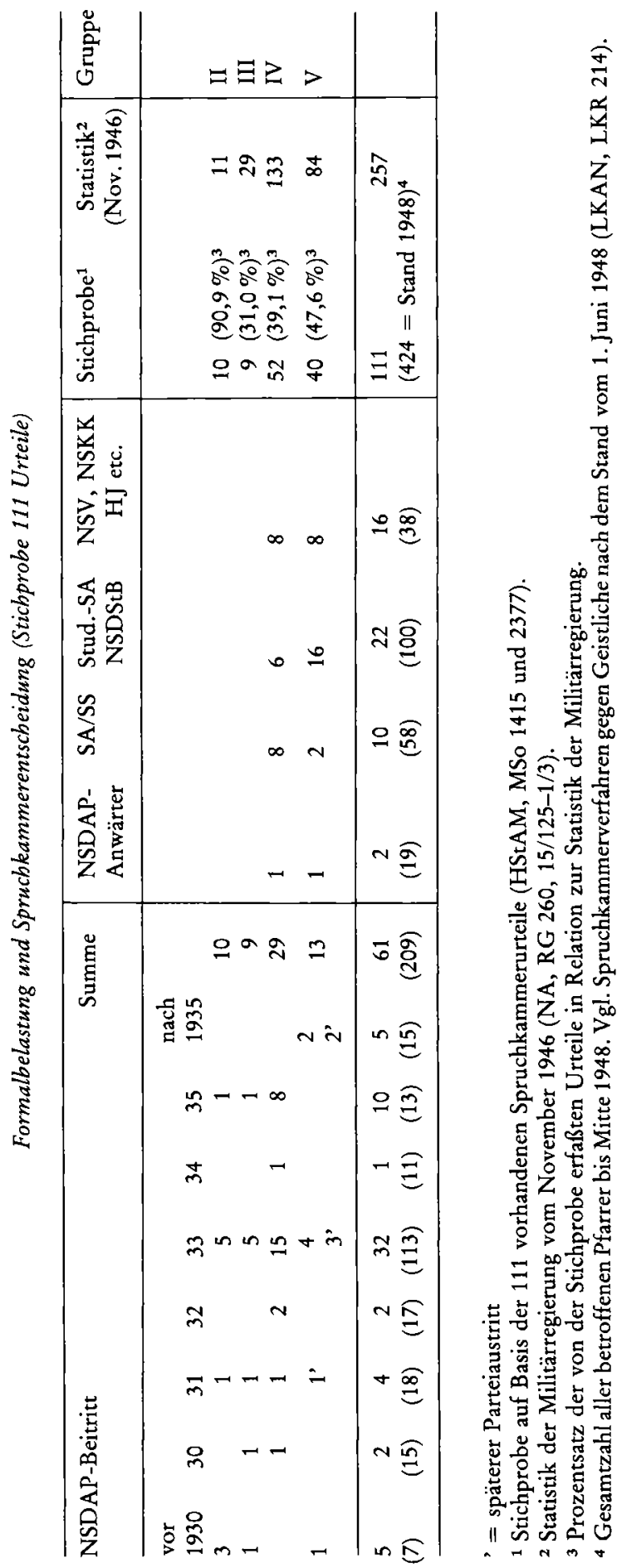


Die klaren Bestimmungen des Befreiungsgesetzes wurden auf zweifache Weise umgangen: Auf juristischer Ebene argumentierte man nun, das Urteil der Spruchkammer besitze bis zum Abschluß sämtlicher Berufungsverhandlungen keine Rechtskraft und deshalb bestehe keine Veranlassung, , Konsequenzen daraus zu ziehen, insbesondere dann, wenn die Spruchkammer keine einstweilige Anordnung getroffen hat "197. Diese Interpretation des Generalklägers Thomas Dehler (FDP) übernahm Pfeiffer ${ }^{198}$. Ziemlich ratlos mußte Clay auf der OMGUS-Stabskonferenz am 8. Februar 1947 zur Kenntnis nehmen, daß allein in Bayern in 36 Fällen das von den Spruchkammern verhängte Predigtverbot mißachtet wurde: , ,I thought we had cleaned up the situation. " Worauf der Leiter der Public Safety Branch, Minor Wilson, hilflos erwiderte: ,,Apparently not. [...] The point is the job was not accomplished by sending a cable from this headquarters saying it will be done. We have had innumerable occasions of failure to carry out such instructions. "199 Das Ergebnis der Konferenz war eine erneute Bestätigung des unbedingten Predigtverbots. Doch das Problem, daß die zuständigen deutschen Behörden, wo immer möglich, anhaltenden Widerstand leisteten, blieb bestehen.

Wirkungsvoller als der Versuch, mit juristischen Finessen die Anordnungen der Militärregierung zu überspielen, war es, das leidige Problem ganz aus der Welt zu schaffen. Bereits während der ersten Spruchkammerverhandlungen hatte Pfeiffer Meiser in Aussicht gestellt, alle harten Urteile kassieren zu lassen. Darauf berief sich nun die Kirchenleitung und verlangte die Kassation aller Urteile der Gruppe II. Das stieß jedoch im Sonderministerium auf Bedenken, da nach dem Befreiungsgesetz zuvor erst die Berufungsverhandlung stattfinden mußte ${ }^{200}$. Als Ausweg ordnete Pfeiffer die vordringliche Bearbeitung der von Pfarrern eingereichten Widersprüche an und instruierte die Berufungskammern, bis zum 20. Dezember 1946 alle vom Landeskirchenrat zu benennenden Einzelfälle neu zu verhandeln ${ }^{201}$. Die Kirchenleitung setzte sich für neun der elf in Gruppe II verurteilten Pfarrer ein - zwei Deutsche Christen erhielten keine Fürsprache - und erreichte mit einer Ausnahme die Aufhebung bzw. Herabstufung der Urteile. Am 16. Januar 1947 wurde das gleiche Verfahren für alle Pfarrer der Gruppe III mit dem Sonderministerium vereinbart ${ }^{202}$.

Gleichzeitig versuchte die Kirchenleitung durch Verhandlungen auf höchster politischer Ebene die Revision einiger rechtskräftiger Urteile zu erreichen. Denn in drei Fällen hatte die Berufungskammer zwar die Urteile der 1. Instanz in Gruppe II aufgehoben, die betroffenen Pfarrer jedoch nicht als Mitläufer, sondern als Minderbelastete eingestuft, was ebenfalls ein mehrjähriges Predigtverbot bedeutete; in einem Fall war die Einstufung eines Pfarrers als NS-Aktivist sogar bestätigt worden. Nunmehr setzte die Kirchenleitung das Sonderministerium massiv unter Druck, wobei sich der Entnazifizierungsreferent des Landeskirchenrats auf eine Besprechung Meisers mit Ministerpräsident Ehard

${ }^{197}$ LKAN, LKR 227, Aktennotiz Rusams über Besprechung mit Dehler am 16.10.1946.

198 LKAN, LKR 227, Aktennotiz Meisers vom 22.11. 1946.

199 IfZ, Fg 12/8, Minutes of Staff Meeting am 8.2.1947.

${ }^{200}$ LKAN, LKR 227, Aktennotiz Rusams über Besprechung mit Senatspräsident Hartmann am 15.10.1946 und Besprechung mit Generalkläger Dehler am 16.10.1946.

${ }^{201}$ LKAN, LKR 227, Aktennotiz Rusams über Besprechung mit Assessor tho Rahde vom 26.11.1946.

202 LKAN, LKR 227, Aktennotiz Rusams über Besprechung mit Ministerialrat Hertle und Landgerichtsdirektor Erber vom Sonderministerium am 16.1.1947; BayHStA, MSo 1414, Landeskirchenrat an Sonderministerium vom 7.1.1947 (Namensliste). 
vom 5. Februar 1947 berufen konnte. ,,Landesbischof erklärte“, wie Rusam in einer Aktennotiz festhielt, ,,daß angesichts der rechtskräftigen Einstufung mehrerer Geistlicher in Gruppe III mit Bewährungsfrist und Predigtverbot unmittelbar ein Konflikt zwischen Kirche und Staat drohe, da die Landeskirche von ihrem grundsätzlichen Standpunkt hinsichtlich des Predigtverbots nicht abgehen könne. Der Ministerpräsident bat Herrn Landesbischof, sofort Verhandlungen hierüber mit dem Sonderministerium aufzunehmen. Es sei sein dringlicher Wunsch, daß das Sonderministerium unter allen Umständen Mittel und Wege finde, um durch entsprechende Anordnungen oder Ausführungsbestimmungen zu dem Gesetz die Möglichkeit eines Konflikts auszuschalten. “203

Dem ,,Wunsch“ des Ministerpräsidenten vermochten sich die zuständigen Sachbearbeiter im Sonderministerium nicht zu entziehen. Ministerialdirektor Dr. Hertle, gab die Zusicherung, die Angelegenheit so rasch als möglich mit Minister Dr. Loritz zu besprechen und in dem genannten Sinne auf ihn einzuwirken". Auch Assessor tho Rahde versprach Rusam, die rasche Durchführung der Berufungsverfahren gegen die in Gruppe III eingereihten Pfarrer, ,umgehend in dem gewünschten Sinne zu bearbeiten “204. Widerstände gegen das partei- und wahltaktisch motivierte Ansinnen von Ministerpräsident Ehard, das der Aufforderung zur Rechtsbeugung nahekam, ergaben sich in der Rechtsabteilung des Sonderministeriums, deren kommissarischer Leiter Erich Schullze, Präsident der Berufungskammer München, erklärte, daß dem Standpunkt der Kirche hinsichtlich des Predigtverbots nur durch eine Gesetzesänderung Rechnung getragen werden kön$\mathrm{ne}^{205}$. Wenig später kapitulierten die Juristen vor dem politischen Druck und vor dem neuen Sonderminister Alfred Loritz, der binnen weniger Monate den labilen Verwaltungsapparat des Sonderministeriums vollends ruinierte und die Entnazifizierung hemmungslos seiner parteipolitischen Profilierung als Vorsitzender der Wirtschaftlichen Aufbau-Vereinigung (WAV) unterordnete ${ }^{206}$.

Der evangelischen Kirche kam Loritz in einer Unterredung mit Meiser am 27. Februar 1947 weit entgegen: ,,Der Minister schlägt eine Einigung vor hinsichtlich der rechtskräftig in Gruppe III eingestuften Geistlichen. Diese Geistlichen sollen auf eine andere Stelle versetzt werden. Das Sonderministerium wird von sich aus dulden, daß sie dann weiter amtieren. Landesbischof erklärt sich mit dieser Regelung einverstanden. " 207 Ferner versicherte Loritz, durch persönliches Eingreifen etliche, namentlich genannte Fälle im Sinne der Kirchenleitung zu lösen. Unter Umgehung der von rechts wegen zuständigen Instanzen wurde nun in bisher völlig unbekanntem Maße in laufende Verfahren eingegriffen und Einzelfälle vorentschieden. Einen Einblick in das geradezu familiäre Klima der gegenseitigen Besprechungen gibt die Niederschrift eines Treffens zwischen Rusam, Meiser und Loritz am 23. Mai 1947, aus der einige Auszüge zitiert seien:

,,Senior Rusam berichtet über die Schwierigkeiten, die im Falle des Pfarrers W. und U. aufgetreten sind. Der öffentliche Kläger von Gunzenhausen habe sich bereit erklärt, den Fall auf sich ruhen zu

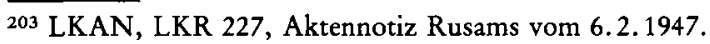

${ }^{204}$ Ebenda.

205 LKAN, LKR 214, Aktennotiz Rusams vom 25.2.1947.

${ }^{206}$ Zur , parasitären Amtsführung“ von Loritz vgl. Niethammer, Entnazifizierung, S. $446 \mathrm{ff}$. Zur WAV vgl. Hans Woller, Die Loritz-Partei. Geschichte, Struktur und Politik der Wirtschaftlichen Aufbau-Vereinigung (WAV) 1945-1955, Stuttgart 1982.

${ }^{207}$ LKAN, LKR 227, Aktennotiz Rusams über Besprechung zwischen Meiser und Loritz am 27.2.1947. 
lassen, wenn das Sonderministerium die volle Verantwortung für die Nichtdurchführung der Sühnemaßnahmen bzw. des Predigtverbots in dem vorliegenden Falle übernehme. Der Minister erklärt, $\mathrm{da} B$ er diese Verantwortung voll übernehme. Senior Rusam solle die Angelegenheit im Benehmen mit Herrn tho Rahde regeln. Er werde das diesbezügliche Schreiben an den öffentlichen Kläger von Gunzenhausen selbst unterschreiben.

Senior Rusam bringt den Fall Kirchenrat K. zur Sprache und bittet um Anweisung des Sonderministeriums auf beschleunigte Behandlung seines Kassationsantrages. Der Minister erklärt, Senior Rusam solle sich mit Präsident Full in Verbindung setzen, unter Berufung auf den Minister, und die vordringliche Behandlung des Falles erbitten. [...]

Der Landesbischof legte den Fall dreier Ortsgruppenleiter vor, deren beschleunigte Behandlung Kreisdekan Daumiller erbeten hat. Der Minister erklärte, die Fälle sollten an Präsident Schullze übergeben werden, unter Hinweis auf seine Befürwortung. Der Landesbischof bringt den Fall von Frau Minister Gürtner [des Reichsjustizministers] zur Sprache. Der Minister erklärt, daß der öffentliche Ankläger von Bad Tölz, der Abgeordnete Ellwein von der CSU, bestimmt gerecht vorgehen werde. Man solle zunächst abwarten, wie das Verfahren läuft. Der Minister fragt an, ob die Landeskirche ein Interesse an dem Fall der Frau Ludendorff ${ }^{208}$ habe. Sie beruft sich darauf, daß sie jetzt der evangelischen Kirche nahestehe. Der Landesbischof erklärt dazu, daß die Landeskirche keine Verbindung mit Frau Ludendorff habe. Es solle aber der zuständige Ortspfarrer gefragt werden, ob Frau Ludendorff neuerdings irgendwie Verbindung mit der Kirche gesucht habe. “209

Damit griff die Kirchenleitung massiv in die Entnazifizierung ein, deren unabhängige, streng rechtsstaatliche Durchführung sie stets gefordert hatte.

Nach der Entlassung von Loritz im Juni 1947 erklärte sich Schullze bereit, beim CSUStaatssekretär im Sonderministerium, Ludwig Hagenauer, der wenig später zum Sonderminister avancierte, zu sondieren, ob die mit Loritz getroffenen Vereinbarungen weiterhin aufrechterhalten werden könnten. Wiederum wies Rusam ,,eindringlich darauf hin, daß die Durchführung des Predigtverbots einen unmittelbaren Konflikt zwischen Kirche und Staat herbeiführen würde. Das biblisch fundierte Recht der Kirche stehe hier gegen ein schlecht fundiertes staatliches Recht. "210 Hagenauer, der sich der Brisanz der von seinem Vorgänger initiierten Rechtsbeugung bewußt war, stand vor dem Dilemma, entweder einen parteipolitisch unerwünschten Konflikt mit der Landeskirche oder mit der Militärregierung zu riskieren; beides konnte ihn die Stellung kosten. Als der rettende Ausweg Ende August 1947 gefunden war, informierte Schullze sofort den Landeskirchenrat: , Er sei mit dem Minister übereingekommen, daß die vorliegenden 5 rechtskräftigen Fälle auf dem Gnadenweg vorgelegt werden. Diese würden unmittelbar vom Sonderministerium an den Ministerpräsidenten zur Entscheidung hinübergegeben. Minister Hagenauer werde persönlich hierüber mit dem Ministerpräsidenten sprechen. Es sei zu erwarten, daß der Ministerpräsident die Gesuche genehmigt. Die Erledigung könnte im abgekürzten Verfahren innerhalb von etwa 14 Tagen erfolgen. " 211 Im , , abgekürzten Ver-

${ }^{208}$ Gemeint ist Mathilde Ludendorff, die 1946 als Fortsetzung des neuheidnischen „Bundes für Deutsche Gotterkenntnis“ den ,Bund für Gotterkenntnis“ gründete. Vgl. Hans Buchheim, Die organisatorische Entwicklung der Ludendorff-Bewegung und ihr Verhältnis zum Nationalsozialismus, in: Gutachten des Instituts für Zeitgeschichte, Bd. 1, München 1958, S. 356-369.

${ }^{209}$ LKAN, LKR 227, Aktennotiz Rusams über Besprechung zwischen Meiser und Loritz am 23.5.1947. Weitere Beispiele: LKAN, LKR 214 und 227.

${ }^{210}$ LKAN, LKR 227, Aktennotiz Rusams über Besprechung mit Präsident Schullze und Assessor tho Rahde am 9.7.1947.

${ }^{211}$ LKAN, LKR 227, Aktennotiz Rusams vom 6.9.1947. Vgl. Aktennotiz Rusams über Besprechung mit Schullze vom 29.8.1947 und 8.9.1947; Aktennotiz Rusams über Besprechung mit Bodenstein, Leiter der Gnadenabteilung im Sonderministerium, am 4. 12. 1947. 
fahren" wurde die Stellungnahme des öffentlichen Klägers umgangen, worauf Rusam besonderen Wert legte.

Im Oktober 1947 kam es zu einem ersten persönlichen Treffen zwischen Hagenauer und dem Landesbischof. Bei dieser Gelegenheit griff Meiser erneut die Entnazifizierung schwer an, worauf Hagenauer erklärte: , Die entstandenen Schäden sind gar nicht mehr gut zu machen. Eigentlich müßte später einmal ein Gesetz erlassen werden zur Wiedergutmachung der Schäden der Entnazifizierung. " Als sich Meiser nach der Einstellung der Berufungskammer Augsburg erkundigte, die für zwei Pfarrer in Gruppe III zuständig war, nannte sie Hagenauer ein , Schmerzenskind“. Der Vorsitzende stamme aus dem Sudetenland und habe Mitarbeiter eingestellt, , die der Militärregierung hörig sind. Es sind sehr unerfreuliche Zustände und das Ministerium ist sehr unglücklich darüber. Aber es ist schwer, etwas zu machen, weil die Leute von der Militärregierung gehalten werden.“ Deutlicher ließ sich der Unwille über Spruchkammern, die sich der massenhaften Entlastung von Nationalsozialisten widersetzten, kaum ausdrücken. Dennoch verweigerte sich Meiser der Bitte Hagenauers, die Landeskirche möge , aufbauwillige Kräfte" für die Spruch- und Berufungskammern werben, da man es einem ,, kirchlichen Mann nicht zumuten [könne], für ein Gesetz tätig zu sein, das die Kirche ablehnen muß“212.

Wie seine Amtsvorgänger, erklärte sich auch Hagenauer bereit, sämtliche Verfahren gegen Pfarrer mit Priorität durchzuführen. Entsprechende Aufstellungen über 19 vordringliche Berufungs- und fünf wiederaufgenommene Spruchkammerverfahren gingen dem Sonderministerium wenige Tage später zu. In allen Fällen handelte es sich um Pfarrer, die unter das Predigtverbot fielen. Im Dezember reichte die Kirchenleitung eine Liste mit weiteren 70 Fällen nach, die ebenfalls vordringlich herabgestuft werden sollten ${ }^{213}$. Im November 1947 erörterte Meiser erneut mit Hagenauer eine Reihe von Einzelfällen. Dabei setzte er sich unter anderem für einen internierten NSDAP-Kreisstellenleiter, einen Generalkonsul sowie für namentlich genannte Pfarrer ein. Außerdem beschwerte sich Meiser über zwei Spruchkammervorsitzende und einen öffentlichen Kläger, die den kirchlichen Entlastungsschreiben kein Gewicht zumessen würden. Hagenauer bat um eine schriftliche Beschwerde und erklärte im Falle des öffentlichen Klägers: ,,Es sei ihm lieb, daß dieser Fall auch seitens der Landeskirche aufgegriffen werde. Es lägen bereits von anderer Seite Beschwerden gegen den Kläger vor, jedoch werde er von der Militärregierung noch gestützt. “ Die Aktennotiz der Besprechung schloß mit der Bemerkung, daß eine ,,völlige Ưbereinstimmung in den grundsätzlichen Anliegen festgestellt werden konnte“ 214 .

Ebenfalls sehr entgegenkommend, erwies sich Arbeitsminister Heinrich Krehle von der CSU, als vereinzelt Arbeitsämter auf die Heranziehung der in Gruppe III verurteilten Pfarrer zu öffentlichen Sonderarbeiten, etwa der Schuttbeseitigung, bestanden. Auch in diesem Fall argumentierte der Landeskirchenrat, daß der Vollzug dieser Sühnemaßnahme einen unzulässigen Eingriff in die Rechte der Kirche darstelle: ,,Die Geistlichen

${ }^{212}$ LKAN, LKR 227, Aktennotiz Rusams über Besprechung zwischen Meiser und Hagenauer am 11.10.1947.

${ }^{213}$ BayHStA, MSo 1414, Landeskirchenrat an Sonderministerium vom 16. 10.1947; LKAN, LKR 229, Landeskirchenrat an Sonderministerium vom 11.12.1947.

${ }^{214}$ LKAN, LKR 227, Aktennotiz Rusams über Besprechung zwischen Meiser und Hagenauer am 6.11.1947. 
hätten selbstverständlich die bürgerlichen Folgen aus ihrem politischen Handeln zu tragen. Das geistliche Amt müsse jedoch streng davon getrennt werden. “ Die Verpflichtung zu öffentlichen Arbeiten hindere den Pfarrer an der Ausübung seines geistlichen Amtes und müsse deshalb abgelehnt werden ${ }^{215}$. Krehle schloß sich dem kirchlichen Standpunkt an, der die ,,bürgerlichen Folgen“ der NSDAP-Mitgliedschaft mehr oder minder aufhob und instruierte die Arbeitsämter entsprechend. ,In sämtlichen Besprechungen zeigte sich“", wie Rusam Mitte November 1947 seine Erfahrungen mit staatlichen Stellen auf einer Sitzung der Kirchenleitung zusammenfaßte, ,, weitgehendes Entgegenkommen bezüglich der besonderen Anliegen der Landeskirche und der Behandlung der Geistlichen. " 216

Um das gute Verhältnis zum Sonderministerium und die noch ausstehenden Berufungsverfahren nicht zu gefährden, verzichtete Meiser im Frühjahr 1948 darauf, die Kanzelabkündigung Niemöllers zur Entnazifizierung öffentlich zu unterstützen. Staatssekretär Camille Sachs versicherte Rusam dafür im Gegenzug, alle noch anstehenden Probleme ,,in unmittelbarer Fühlungnahme mit den zuständigen Stellen zu klären“"217. Die Erledigung der sogenannten ,,Restfälle“ bereitete keine Schwierigkeiten mehr, da 1948 nunmehr auch die amerikanische Militärregierung die Entnazifizierung im Interesse einer schnellen Konstituierung des westdeutschen Teilstaates so schnell wie möglich zum Abschluß bringen wollte ${ }^{218}$.

Ein abschließender Blick auf die Statistik zeigt das erfolgreiche Verhandeln der Kirchenleitung zur Aufhebung und Milderung der Spruchkammerurteile:

Der Herabstufungsprozeß von Oktober 1946 bis Januar $1949^{219}$

\begin{tabular}{|c|c|c|c|c|c|c|c|c|c|c|c|c|}
\hline Gruppe & 7.12 & $\begin{array}{r}1946 \\
\%\end{array}$ & 10.4 & $\begin{array}{r}1947 \\
\%\end{array}$ & 15.9 & $\begin{array}{r}1947 \\
\%\end{array}$ & 12.1 & $\begin{array}{r}1947 \\
\%\end{array}$ & 15.4 & $\begin{array}{r}1948 \\
\%\end{array}$ & 20.1 & $\begin{array}{r}1949 \\
\%\end{array}$ \\
\hline II & 10 & 3,6 & 4 & 1,2 & 4 & 1,0 & 3 & 0,8 & 2 & 0,5 & 1 & 0,2 \\
\hline III & 26 & 9,5 & 28 & 8,7 & 27 & 7,2 & 26 & 6,7 & 20 & 4,8 & 4 & 0,9 \\
\hline IV & 144 & 52,3 & 167 & 51,9 & 156 & 41,4 & 158 & 41,0 & 180 & 43,2 & 183 & 42,7 \\
\hline V & 95 & 34,6 & 123 & 38,2 & 163 & & 141 & & 150 & & 155 & \\
\hline WA $*$ & & & & & 27 & 50,4 & 57 & 51,4 & 65 & 51,6 & $\begin{array}{r}81 \\
5\end{array}$ & $\begin{array}{r}55,0 \\
1,2\end{array}$ \\
\hline Summe & 275 & 100 & 322 & 100 & 377 & 100 & 385 & 100 & 417 & 100 & 429 & 100 \\
\hline
\end{tabular}

* = Weihnachtsamnestie; $=$ noch nicht abgeschlossenes Verfahren

${ }^{215}$ LKAN, LKR 210, Aktennotiz Vischers über Besprechung mit Krehle am 17.10.1947. Vgl. LKAN, LKR 214, Landeskirchenrat an Arbeitsamt Hof i. B. vom 2. 4. 1947; Aktennotiz Rusams über Besprechung mit Regierungsrat Ultsch am 8.9.1947.

${ }^{216}$ LKAN, LKR 201, Vollsitzung des Landeskirchenrats vom 10.-12. 11. 1947.

217 LKAN, LKR 227, Aktennotiz Rusams über Besprechung mit Staatssekretär Sachs am 11.2.1948.

$218 \mathrm{Vgl}$. Niethammer, Entnazifizierung, $\mathrm{S} .483 \mathrm{ff}$.

${ }^{219}$ LKAN, LKR 214, Statistiken des Landeskirchenrats. 
Die Herabstufungen verliefen in zwei, deutlich voneinander geschiedenen Phasen: Anfang 1947 wurden die meisten Urteile der Gruppe II aufgehoben, ab Mitte 1948 die Urteile der Gruppe III. Im Januar 1949 befanden sich noch ein Pfarrer in Gruppe II und drei weitere Ruhestandspfarrer sowie ein aktiver Pfarrer in Gruppe III. Die übrigen Parteipfarrer konnten als ,,erfolgreich entnazifiziert" gelten.

\section{Die Entnazifizierung der Theologischen Fakultät Erlangen}

Der Erlanger Kirchenhistoriker Walther von Loewenich leitet in seinen Memoiren das Kapitel über die Stellung der Erlanger Theologischen Fakultät im Dritten Reich mit dem Urteil ein, sie sei nach 1945 Gegenstand einer heftigen, zum Teil berechtigten, zum Teil aber auch unsachlichen Kritik geworden ${ }^{220}$. Dieses Urteil kann auch für die Entnazifizierung der Fakultät gelten.

Die beiden profiliertesten Theologen, Paul Althaus und Werner Elert, hatten während der Weimarer Republik eine politische Theologie verfochten, deren zentrale Werte Volkstum und Staat waren, und damit die völkische Bewegung und den Antisemitismus zumindest partiell - als christlich legitimiert. Obwohl beide nie der NSDAP angehörten und immer gewisse Vorbehalte wahrten, erklärte Althaus 1932, er bekenne sich ,,jedem Dritten gegenüber“ zur NS-Bewegung, und Elert wäre 1933 beinahe den Deutschen Christen beigetreten. Politisch standen die Erlanger Theologen fest im deutschnationalen Lager und begrüßten den Nationalsozialismus als die Uberwindung der ,,nationalen Schmach" und der ungeliebten liberaldemokratischen „Systemzeit" ${ }^{\text {"221 }}$. Hermann Strathmann, bis 1930 Reichstagsabgeordneter der DNVP, anschließend des Christlichen Volksdienstes, und Hermann Sasse gehörten zu der kleinen Gruppe von Theologen, die bereits vor der Machtergreifung Hitlers die Unvereinbarkeit von Nationalsozialismus und Christentum klar erkannt hatten ${ }^{222}$, ohne allerdings gehört zu werden.

Theologisch vertraten die Erlanger eine Spannbreite, die von dem vergleichsweise aufgeweichten Luthertum Althaus' bis zum strikten Konfessionalismus Sasses reichte. Die theologische Begründung der Bekennenden Kirche in der Barmer Erklärung lehnten Sasse, Althaus und Elert, wenn auch aus unterschiedlichen Motiven, entschieden ab. Bezeichnete Sasse die Bekennende Kirche als Sekte, die den Boden des lutherischen Bekenntnisses verlassen habe, so war die Verwerfung bei Althaus und Elert sowohl politisch wie theologisch begründet. Charakteristisch für ihre völkische Argumentation ist der „Ansbacher Ratschlag“ vom Juni 1934, den auch führende bayerische Deutsche Christen mitunterzeichneten. Hier erhielten die ,,natürliche Ordnungen“", ,Familie, Volk, Rasse (das heißt Blutszusammenhang)", als Gegenerklärung zu Barmen den Rang einer ,,Uroffenbarung“. Weiterhin hieß es: , In dieser Erkenntnis danken wir als glaubende Christen Gott dem Herrn, daß er unserem Volk in seiner Not den Führer als, frommen und ge-

220 Loewenich, Erlebte Theologie, S. 159.

${ }^{221}$ Belege ebenda, S. $159 \mathrm{ff}$. Zur politischen Theologie von Althaus und Elert vgl. Tilgner, Volksnomostheologie, S. 179ff. Zu Althaus ausführlich Ericksen, Theologians, S.79-119.

222 Vgl. Strathmann, Nationalsozialistische Weltanschauung?, in: Christentum und Volkstum (Schriften im Auftrag des Christlichen Volksdienstes, 1), Nürnberg 1931; Sasse, Die Kirche und die nationale Bewegung, in: KJ 1932, S. 58-77. 
treuen Oberherrn' geschenkt hat und in der nationalsozialistischen Staatsordnung, gut Regiment', ein Regiment mit ,Zucht und Ehre' bereiten will." 223 Nicht minder peinlich war auch 1945 das Gutachten, das Althaus und Elert im Auftrag der Fakultät zur Einführung des Arierparagraphen in die Kirche verfaßt hatten: Für die neue Aufgabe der Kirche, „,Volkskirche der Deutschen zu sein“, würde ,,in der jetzigen Lage die Besetzung ihrer Ämter mit Judenstämmigen im allgemeinen eine schwere Belastung und Hemmung bedeuten. “ Die Kirche müsse daher ,, die Zurückhaltung ihrer Judenchristen von den Ämtern fordern“, wenngleich Ausnahmen möglich sein sollten ${ }^{224}$. Damit war die Berechtigung der Entlassung von Christen jüdischer Herkunft aus kirchlichen Ämtern, was der Pfarrernotbund unter Niemöller entschieden ablehnte, prinzipiell anerkannt.

In der Bejahung des Nationalsozialismus als politischer Herrschaftsform unterschied sich die Erlanger Fakultät in ihrer Gesamtheit kaum von anderen. Auch die führenden Köpfe der bruderrätlichen Bekennenden Kirche, mit Ausnahme von Barth, hatten 1933/34 Hitler begeistert begrüßt; darauf wies der Erlanger Kirchenhistoriker Friedrich Baumgärtel 1957 in seiner Schrift ,,Wider die Kirchenkampf-Legenden “ zur Ehrenrettung der Erlanger Theologen und des Luthertums nachdrücklich hin. Im Unterschied zur theologischen Fakultät Tübingen, von der 1933 vier Professoren der NSDAP beitraten $^{225}$, gehörte in Erlangen nur der Deutsche Christ Wilhelm Vollrath der Partei an; ein weiterer Parteigenosse war Paul Sprenger, der als reformierter Theologe extra facultatem stand $^{226}$.

Sofort nach der Besetzung Erlangens am 16. April 1945 forderte die örtliche Militärregierung den Juristen und ehemaligen DNVP-Reichstagsabgeordneten Friedrich Lent auf, ein politisches Gutachten über sämtliche Universitätsprofessoren zu erstellen. Für die theologische Fakultät benannte Lent Sasse als Gutachter. Wenig später ernannte die Militärregierung Theodor Süß zum Rektor der Universität und Sasse zum Prorektor. Das „Vertrauliche Memorandum“ Sasses vom 28. April wurde im Juni 1945 mit seinem Einverständnis den Mitgliedern der Fakultät und Landesbischof Meiser zugänglich gemacht.

Das Gutachten entsprach, wie von Loewenich urteilt ${ }^{227}$, vollkommen den Tatsachen, wenngleich es nicht frei von persönlichen Ressentiments war. Als entschiedener HitlerGegner und lutherischer Konfessionalist, der sowohl den Deutschen Christen, der Reichskirchenkonstruktion der Deutschen Evangelischen Kirche wie der Bekennenden Kirche unionistische Verfälschung des lutherischen Bekenntnisses vorwarf, hatte Sasse als doppelter Außenseiter während des Dritten Reiches unter seinen Kollegen keinen leichten Stand gehabt ${ }^{228}$. Althaus beurteilte er als einen Mann der Synthese, als einen

${ }^{223}$ In: Kurt Dietrich Schmidt (Hrsg.), Die Bekenntnisse und grundsätzlichen Äußerungen zur Kirchenfrage des Jahres 1934, Göttingen 1935, S. $102 \mathrm{ff}$.

224 Theologisches Gutachten über die Zulassung von Christen jüdischer Herkunft zu den Ämtern der Deutschen Evangelischen Kirche vom 25.9.1933, in: Ebenda, S. $182 \mathrm{ff}$.

${ }^{225}$ Vgl. Leonore Siegele-Wenschkewitz, Die Theologische Fakultät im Dritten Reich. „Bollwerk gegen Basel“", in: Semper Apertus. Sechshundert Jahre Ruprecht-Karls-Universität Heidelberg 1386-1986, Bd.3, Berlin 1985, S. 504-543; Wolfgang Huber, Theologie zwischen Anpassung und Auflehnung, in: Jörg Tröger (Hrsg.), Hochschule und Wissenschaft im Dritten Reich, Frankfurt 1984, S. 129-141.

${ }^{226}$ Loewenich, Erlebte Theologie, S. 184.

${ }^{227}$ Ebenda, S. 134 f. Dort wird auch der Inhalt des Gutachtens (LKAN, NL Meiser 45) referiert.

${ }^{228}$ Vgl. Martin Wittenberg, Hermann Sasse und „Barmen“, in: Wolf-Dieter Hauschild/Georg Kretschmar/Carsten Nicolaisen (Hrsg.), Die lutherischen Kirchen und die Bekenntnissynode 
Theologen des Sowohl-als-auch, der schon deshalb kein überzeugter Nationalsozialist habe werden können. Mit der Lehre von der göttlichen Ordnung des Volkstums sei er, ohne es zu wissen und zu wollen, zu einem Wegbereiter der Deutschen Christen geworden. Elert habe die Anlagen zu einem großen Führer des Luthertums besessen, doch in jeder entscheidenden Situation menschlich versagt. Als Professor und Dekan habe er sich äußerlich als Nationalsozialist gezeigt, obwohl er innerlich das Regime abgelehnt habe. Hans Preuß habe sich anfänglich sehr für den Nationalsozialismus begeistert, später aber an der Kirchenpolitik des Regimes gelitten. Strathmann sei Politiker aus Leidenschaft und habe sich, trotz seiner Gegnerschaft zur NSDAP, später für die militärischen Erfolge Hitlers begeistert. Oskar Grether, Wolfgang Trillhaas und von Loewenich stellte Sasse ein gutes Zeugnis aus; über Baumgärtel schrieb er nur kurz, er sei nie Nationalsozialist gewesen. Sasse verzichtete darauf, sein Urteil durch einzelne Belege, die leicht zu erbringen gewesen wären, zu erhärten. Trotz der weitgehend negativen Beurteilung empfahl er die Weiterbeschäftigung aller Kollegen ${ }^{229}$.

Sasse ging es vor allem um die Erneuerung der deutschen lutherischen Theologie, deren internationales Ansehen durch die politischen Sympathien ihrer führenden Repräsentanten für das NS-Regime stark gelitten hatte. Namentlich nannte Sasse in einem umfangreichen Memorandum vom Juli 1945 die völkisch orientierte Theologie Friedrich Gogartens und Althaus' als den Ausdruck eines , kranken Luthertums, das dem Nationalsozialismus die Tür in die Kirche auftat" ${ }^{\text {"230 }}$. Die Rückbesinnung auf den Kerngehalt der lutherischen Lehre war für Sasse untrennbar mit der Erkenntnis der politischen Mitverantwortung verbunden. Einem Kritiker schrieb er im Oktober 1945 zur Rechtfertigung seines Gutachtens über die theologische Fakultät: ,, Was haben wir getan, um den Nationalsozialisten an deutschen Universitäten einen Wall entgegenzusetzen? So müssen wir heute fragen, wenn wenigstens wir Männer der Kirche noch wissen wollen, was Buße ist. Auch Sie, verehrter Herr Amtsbruder, sind, wie ich weiß, entsetzt über die Zahl der Parteigenossen unter den bayerischen Pfarrern. Das sind unsere Schüler. Wir haben das zu verantworten, genau so wie wir diesen Krieg mitzuverantworten haben, den Hitler in ,Mein Kampf' schon mit zynischer Offenheit angekündigt hat und bei dessen propagandistischer Rechtfertigung lutherische Theologen mitgeholfen haben. Wo kämen wir hin, wenn man in kirchlichen Institutionen aus Kollegialität die eigene Schuld nicht mehr bekennen dürfte?" 231

Im Kollegenkreis stießen solche Äußerungen auf empörte Zurückweisung. Im Herbst 1945 umging die Fakultät Sasse und trug den Lehrstuhl des aus Altersgründen emeritierten Preuß, dessen Absetzung Strathmann verlangt hatte ${ }^{232}$, Loewenich an, der dieses Verfahren jedoch ablehnte. Nur mit Mühe konnte Sasse Nachfolger von Preuß werden, während Loewenich das damit freigewordene Extraordinat Sasses übernahm, , aber das Verhältnis zwischen ihm und der Fakultät blieb gestört. Vor allem zwischen Sasse und

von Barmen. Referate des Internationalen Symposiums auf der Reisensburg 1984, Göttingen 1984, S. 85-106.

229 LKAN, NL Langenfaß 125, Sasse an Meiser vom 15.2.1947.

${ }^{230}$ LWF, General Correspondence Germany, Series P, 1945-1949, Zur Lage des Luthertums vom Juli 1945.

${ }^{231}$ LKAN, NL Meiser 45, Sasse an einen namentlich nicht genannten „Amtsbruder“ vom 11128.10 .1945$.

${ }^{232}$ LKAN, NL Langenfaß 125, Sasse an Meiser vom 15.2.1947. 
Strathmann kam es zu keiner Versöhnung. "233 Daran vermochte auch die Feststellung des ,,Concilium Decanale“ vom Oktober 1945, Sasse habe nicht aus ehrloser Gesinnung gehandelt, nichts zu ändern. An Meiser schrieb Strathmann wenig später, Sasse habe von Anfang an als ,,unakademischer störender Fremdkörper" gewirkt. Eine Erholung der Fakultät sei nicht zu erwarten, ,,solange er hier ist" . Die , gesund empfindende" Erlanger Studentenschaft habe die Vorlesungen Sasses zurecht boykottiert ${ }^{234}$. Im Juni 1946 machte Strathmann den Vorgang in den USA bekannt und beschuldigte Sasse des Denunziantentums. Diese Attacke wurde auch in der renommierten Zeitschrift ,'The Christian Century", deren Schriftleiter Gustav Wienecke bei Strathmann promoviert hatte, abgedruckt $^{235}$.

Die Militärregierung zog aus dem Gutachten keine Konsequenzen. Die für das gesamte Erziehungswesen zuständige ERA-Branch besaß im Mai 1945 gerade $15 \mathrm{Fachleute}$ für die gesamte US-Zone und war allein mit der vordringlichen Reorganisation des Schulwesens hoffnungslos überlastet ${ }^{236}$. Die Uberprüfung des Universitätspersonals schien Zeit zu haben, da im Mai die Universitäten auf Anweisung von OMGUS geschlossen worden waren. Auch Special Branch sah keinen Grund zum Eingreifen, da die genannten Theologieprofessoren nicht der NSDAP angehört hatten und somit nicht unter die formalen Entlassungskriterien fielen. Im August 1945 nahmen auf Anweisung der Militärregierung die medizinischen Fakultäten den Lehrbetrieb wieder auf. Dies löste einen starken Druck auf die Wiedereröffnung der Universitäten insgesamt aus, so daß bereits im Dezember, Monate früher als geplant, in der US-Zone die meisten Universitäten und sonstigen höheren Lehranstalten ihre Tore öffneten. Die Entnazifizierung des Lehrkörpers übertrug die Militärregierung aus prinzipiellen Erwägungen weitgehend den Universitäten selbst, die damit über einen großen Entscheidungsspielraum verfügten ${ }^{237}$.

In Erlangen war Ende Mai von der örtlichen Militärregierung Althaus zum Vorsitzenden des universitären Entnazifizierungsausschusses ernannt worden. Wie er später zu seiner Rechtfertigung schrieb, habe die Erlanger Militärregierung , unsere und meine Arbeit ausdrücklich anerkannt. In manchen Fällen konnte sie Professoren usw. trotz unserer positiven Gutachten nicht halten, auf Grund der geltenden Richtlinien. Aber in einer nicht geringen Zahl von Fällen hat die Militärregierung Professoren usw., die zuerst abgesetzt waren, auf unser Eintreten hin auch wieder eingesetzt und bestätigt. "238 Einen wesentlich stärkeren Säuberungswillen entfalteten die Entnazifizierungsausschüsse anderer Universitäten. In Marburg entfernte Rektor Julius Ebbinghaus 50 Prozent des Lehrkörpers der juristischen Fakultät, 22 Prozent der medizinischen und etwa 30 Prozent der philosophischen Fakultät. Ähnlich rigoros verfuhr Karl Jaspers in Heidelberg. Dort wurden bis Ende 194564 Prozent des Lehrpersonals der medizinischen Fakultät, 63 Prozent der politischen Wissenschaften, 60 Prozent der naturwissenschaftlichen, 35 Prozent der juristischen und 29 Prozent der theologischen Fakultät entlassen ${ }^{239}$. Die größten

\footnotetext{
${ }^{233}$ Loewenich, Erlebte Theologie, S. 135.

234 LKAN, NL Meiser 45, Strathmann an Meiser vom 29.10. 1945.

235 Ebenso in ,,The Lutheran". Beglaubigte Abschriften, in: NA, RG 260, 10/110-1/7.

$236 \mathrm{Vgl}$. Tent, Mission, S. $44 \mathrm{ff}$.

237 Ebenda, S. $57 \mathrm{ff}$.

${ }^{238}$ NA, RG 260, 5/339-3/5, Althaus an Haußleiter vom 9.2.1947.

239 Tent, Mission, S. $81 \mathrm{ff}$.
} 
Probleme ergaben sich in München. Sie führten im März 1946 zur Entlassung des Rektors Albert Rehm und verzögerten die Wiedereröffnung der Universität bis Sommer $1946^{240}$. War die Entnazifizierung des Lehrkörpers bis Frühjahr 1946 weitgehend den Universitäten selbst anvertraut, so erfolgte nun eine drastische Kursänderung. Die Ursache war wie so oft - eine Serie amerikanischer Presseberichte, die der Militärregierung in Enthüllungsstories völliges Versagen bei der Entnazifizierung vorwarfen.

Einen ersten Anlaß bot ein Vortrag Niemöllers vor der Erlanger Studentenschaft im Januar 1946, der zweimal durch Tumulte aufgebrachter Studenten gestört wurde, als Niemöller zur Schuldfrage ausführte: ,,Es ist viel Jammer über unser Elend, über unseren Hunger, aber ich habe in Deutschland noch nicht einen Mann sein Bedauern aussprechen hören von der Kanzel oder sonst über das furchtbare Leid, das wir, wir Deutsche, über andere Völker gebracht haben, über das, was in Polen passierte, über die Entvölkerung von Rußland (Empörung, Scharren und Zwischenrufe: ,Und die Schuld der anderen??) und über die 5,6 Millionen toter Juden! Das steht auf unseres Volkes Schuldkonto, das kann niemand wegnehmen! [...] Wir fühlen uns schuldig deshalb, weil wir unserer Verantwortung, die wir tragen, nicht gerecht geworden sind." ${ }^{241}$ Die Zwischenrufe waren angesichts der erregten öffentlichen Diskussion des Stuttgarter Schuldbekenntnisses durchaus nichts Ungewöhnliches, wurden jedoch von den anwesenden Pressevertretern als Beweis für das Fortleben nationalsozialistischer Gesinnung unter der Erlanger Studentenschaft überinterpretiert, zumal am gleichen Abend mehrere Gebäude mit Parolen wie ,Niemöller - Werkzeug der Alliierten“, beschmiert worden waren ${ }^{242}$.

Im März und April 1946 griff die amerikanische Presse die Militärregierung scharf an. Im Mittelpunkt der Kritik stand die Münchner Universität, der bewußte Verschleppung der Entnazifizierung vorgeworfen wurde. Unter den verschiedenen Berichten zur Aufhellung der Münchner Situation befindet sich ein Report der Intelligence Branch vom Mai 1946: ,,The University of Munich is controlled now as in the past by a clique of extremely reactionary elements operating under the auspices of State Secretary Hans Meinzolt, who is in turn the confidence man of the Bishop for Bavaria, Hans Meiser."243 Weiter wurde Meinzolt, der bis zum erzwungenen Rücktritt Rehms als Staatskommissar für die Universität München wirkte, vorgeworfen, die Berufung demokratischer Professoren systematisch verhindert zu haben. Berichte aus anderen Städten, deren Vorwürfe im Kern zutrafen, wenn man die Bestimmungen des Befreiungsgesetzes zugrunde legt, verschärften die Krise. Aufgeschreckt durch die negative Presse, ließ sich Clay nunmehr täglich über den Stand der Dinge unterrichten. Im Herbst 1946 entschloß sich OMGUS, hart durchzugreifen. Am 21. September erging an alle Ländermilitärregierungen die Direkti-

${ }^{240}$ Ebenda. Vgl. ohne Schilderung der harten Konflikte Ursula Huber, Die Universität München ein statistischer Bericht über den Fortbestand nach 1945, in: Friedrich Prinz (Hrsg.), Trümmerzeit in München. Kultur und Gesellschaft einer deutschen Großstadt im Aufbruch 1945-1949, S. 156-160. Weitere Materialien: NA, RG 260, 5/298-3/24; 10/73-3/9-15; 10/87-32; $10 / 110-1 / 6 ; 15 / 125-1 / 15 ; 15 / 147-2 / 4$.

${ }^{241}$ Bericht der Neuen Zeitung vom 15.2. 1946 über Niemöllers Vortrag in der Neustädter Kirche in Erlangen am 22. 1. 1946. Vgl. Niemöller an den Rektor der Universität Erlangen vom 7. 2. 1946, in: Greschat, Schuld, S. $193 \mathrm{f}$.

${ }^{242}$ Memorandum Knappens an PHW-Division vom 12.2.1946. Zit. nach Tent, Mission, S. 74.

${ }^{243}$ Report vom 9.5. 1946. Zit. nach Tent, Mission, S. 86f. Zu den Ermittlungen gegen Meinzolt und das bayerische Kultusministerium vgl. NA, RG 260, 5/298-2/5. 
ve, daß künftig alle Schlüsselstellungen in Regierung und Verwaltung nur mit Personen besetzt werden dürften, die die für die weitere demokratische Entwicklung Deutschlands notwendigen ,,positive political, liberal and moral qualities" besäßen. Über das negative Auswahlkriterium der Nichtmitgliedschaft in der NSDAP hinaus galt nun für den weiten Bereich der ,,information control" und des gesamten Erziehungswesens der Nachweis demokratischer Gesinnung als unabdingbare Voraussetzung ${ }^{244}$.

Im Juli 1946 erschien ein groß aufgemachter Bericht der Presseagentur DANA über die Universität Erlangen: Linke Studenten würden von ihren Kommilitonen verprügelt, ohne daß die Universitätsleitung einschreite. Sie sei vielmehr beschäftigt, namentlich genannte Nazi-Professoren zu decken. Unter anderem wurde auch Althaus als Vorsitzender des Entnazifizierungsausschusses und Verfasser der Schrift ,, Die deutsche Stunde der Kirche" 245 scharf angegriffen. ERA-Branch bemühte sich vergeblich, diese Meldung im letzten Moment zu verhindern ${ }^{246}$. Die Vorwürfe griff Herbert Gessner, ein radikaldemokratischer Kommentator von Radio München, am 18. Juli auf, der ebenfalls Althaus für die unterbliebene Selbstreinigung verantwortlich machte und zudem auch aus den Schriften der Theologen Preuß und Strathmann zitierte. Einen Tag später mußte Althaus vor einer Kommission, bestehend aus Kultusminister Fendt (SPD), Dr. Barnett (ERABranch) und einem Vertreter der CIC, zu den Vorwürfen Stellung nehmen; anschließend wurde die Uberprüfung seiner Schriften beschlossen ${ }^{247}$. An der DANA-Meldung war Sasse nicht unbeteiligt ${ }^{248}$, doch kann man ihm das kommende Desaster kaum anlasten. Denn im Gegensatz zu Althaus hatte er frühzeitig begriffen, daß jeder Verschleppungsversuch der politischen Säuberung schwer auf die Universität zurückschlagen mußte. Voller Sorge hatte Sasse noch Ende Juni Ministerpräsident Hoegner aufgesucht, um ihn zum Eingreifen zu veranlassen. Im August schließlich trug Sasse nochmals mündlich und schriftlich dem Kultusminister seine Bedenken vor, ohne jedoch etwas auszurichten ${ }^{249}$.

Im Oktober und November 1946 untersuchten ad hoc zusammengestellte Inspektionsteams die einzelnen Universitäten. Waren nach den alten Richtlinien nur Personen der Schuldvermutung in Gruppe I und II automatisch zu entlassen gewesen, woran sich allerdings die universitären Entnazifizierungskommissionen oft nicht gehalten hatten, so wurde nun der Personenkreis auch auf die Gruppen III und IV, zum Teil auch V, ausgeweitet. Die zweite Entnazifizierungswelle kostete in Heidelberg 72 Professoren und Dozenten die Stellung, in Frankfurt 33. Prozentual am stärksten betroffen war Erlangen, die kleinste Universität, mit 30 Professoren und Dozenten; das entsprach 27 Prozent des gesamten Lehrkörpers ${ }^{250}$. Jetzt rächte sich der mangelnde Säuberungswille des früheren Rektors Süß, der selbst mehreren NS-Gliederungen seit 1933 angehört hatte und im Herbst 1946 als Abteilungsleiter für das höhere Schulwesen in das bayerische Kultusmi-

${ }^{244}$ NA, RG 260, 5/341-1/6-10, OMGUS-Direktive, Removal of important German officials vom 21.9.1946.

245 Göttingen 1933, S. 5: , Unsere evangelischen Kirchen haben die deutsche Wende von 1933 als ein Geschenk und Wunder Gottes begrüßt."

$246 \mathrm{Vgl}$. Tent, Mission, S. $92 \mathrm{f}$.

247 NA, RG 260, 5/339-3/5, Althaus an Haußleiter vom 9. 2.1947; NA, RG 260, 15/125-1/7, Field Inspection Report vom 14.10.1946.

248 NA, RG 260, 10/110-1/7, Erklärung Sasses vom 25.3.1947.

249 Ebenda.

${ }^{250}$ Tent, Mission, S. 98. 
nisterium berufen worden war. Zur gleichen Zeit war Sasse als Prorektor zurückgetreten, da er die weitere Verschleppung der Entnazifizierung nicht mehr verantworten zu können glaubte. Neben Süß wurde Althaus als Vorsitzender der universitären Entnazifizierungskommission zur Rechenschaft gezogen. Das Inspektionsteam stellte innerhalb weniger Tage ein umfangreiches Sündenregister zusarmmen:

Zahlreiche Professoren waren, obwohl sie der NSDAP angehört hatten, nicht entlassen oder von der Universitätsleitung als entlassen gemeldet und trotzdem weiterbeschäftigt worden. Unter ihnen befand sich etwa ein Jurist, der die Fememorde rechtsradikaler Organisationen während der Weimarer Republik 1932 für rechtens erklärt hatte, oder ein Arzt, der an der Universitätsklinik in großem Umfang Abtreibungen und Zwangssterilisationen an $Z$ wangsarbeiterinnen aus dem Osten vorgenommen hatte. Im Gutachten des Entnazifizierungsausschusses unter Althaus wurde der Arzt folgendermaßen beurteilt: „Wir treten mit besonderer Wärme für die Beibehaltung des wertvollen wissenschaftlichen Arbeiters und tüchtigen, beliebten Arztes ein." ${ }^{251}$ Andere Professoren waren nach Erlangen berufen worden, obwohl sie bereits an anderen Universitäten aus politischen Gründen entlassen worden waren. Nicht zuletzt hatte auch der Universitätssyndikus mehreren NS-Organisationen angehört und war von 1933 bis 1935 als Mitarbeiter Hans Franks, Hitlers Kronjuristen, tätig gewesen. Daß er entgegen einer Anweisung der Militärregierung beschäftigt war und einen Lehrauftrag wahrnahm, verbesserte den Eindruck keineswegs. Den neuen Rektor Eduard Brenner, der erst seit einigen Wochen im Amt war, traf nach Ansicht des Inspektionsteams nur geringe Schuld. Seine Führungsqualitäten wurden jedoch stark angezweifelt: ,,Conveniently enough he is and was always a Socialdemocrat which is suited to camouflage Nazi activities at the university and at the same time he is such a weak person that he is no trouble-maker at all to his Nazi colleagues who elected him although they are in the majority. "Als Hauptverantwortliche galten der frühere Rektor Süß, Staatssekretär Meinzolt, ehemals langjähriger Vizepräsident des Landeskirchenrats, und Althaus. Für die amerikanischen Entnazifizierer bestand kein Zweifel: ,,Prof. Althaus is more than any-one else accused by the few Anti-Nazi elements of the university for having sabotaged denazification." 252

Eine erste Untersuchung der theologischen Fakultät ergab ein günstiges Bild: keiner der 16 Professoren und Dozenten, einschließlich der emeritierten, hatte der NSDAP angehört; Gustav Stählin war allerdings Parteianwärter gewesen ${ }^{253}$. Weitere Recherchen des Inspektionsteams, das nun auch Sasse zur Mitarbeit heranzog, ergaben ein reichhaltiges Belastungsmaterial gegen vier Theologieprofessoren. Althaus wurden vor allem seine Schriften „Die deutsche Stunde der Kirche" und „Obrigkeit und Führertum" Verhängnis. Strathmann stolperte über zwei Artikel in den renommierten ,,Theologi-

251 NA, RG 260, 15/125-1/7, Field Inspection Report vom 14.10.1946. Vgl. Report vom 20.10.1946.

${ }^{252}$ Ebenda. Weitere Materialien: NA, RG 260, 3/166-1/11-16; 5/297-2/11; 5/298-3/23; $5 / 298-3 / 29 ; 5 / 300-2 / 19 ; 5 / 305-3 / 12 ; 10 / 87-3 / 3 ; 10 / 110-1 / 7 ; 15 / 125-1 / 7$; AG 45/17/7.

${ }^{253}$ NA, RG 260, 1/125-1/7, Aufstellung der Theol. Fakultät vom 6. 11.1946. Im Oktober 1946 gehörten der Fakultät an: Otto Procksch (em.), Hermann Strathmann, Hans Preuß, Paul Althaus, Friedrich Baumgärtel, Werner Elert, Walther von Loewenich, Gerhard Schmidt, Gustav Stählin, Georg Kempff, Karl Schornbaum, Walter Künneth, Friedrich Hauck, Oskar Grether, Leonhard Goppelt. Wilhelm Vollrath hatte Erlangen 1940 verlassen.

254 Gütersloh 1936. 
schen Blättern", in denen er 1939/40, auf dem Höhepunkt der siegreichen Feldzüge, Hitler als einen von Gott geschenkten Führer bezeichnet und das Urteil angefügt hatte: ,, Mit den Sätzen der Moral des Alltags ist dem gewaltigen Geschehen überhaupt nicht beizukommen. "255 Friedrich Hauck wurde als Verfasser mehrerer Schulgebete zu Ehren des „,Führers“ entlassen. Hans Preuß schließlich hatte jahrelang die Linie des deutschnationalen Geschichtsbildes von Luther zu Hitler gezogen ${ }^{256}$. Da alle vier Professoren keine Parteimitglieder gewesen waren, wurden sie im Februar 1947 auf Basis der OMGUS-Direktive vom 21 . September 1946 entlassen.

Im dunkeln bleiben die Auswahlkriterien. Sicherlich waren die vier entlassenen Theologen, einschließlich des CSU-Landtagsabgeordneten Strathmann, der auch aus dem Bayerischen Landtag ausgeschlossen wurde ${ }^{257}$, keine liberalen Demokraten gewesen; doch nach dieser Richtlinie hätte man fast alle Theologieprofessoren absetzen können. Mit der Entlassung von insgesamt 30 Professoren und Dozenten sowie weiteren 46 wissenschaftlichen und administrativen Hilfskräften sollte ein Exempel statuiert werden, das van Steenberg, der Leiter der Hochschulabteilung der Militärregierung für Bayern, damit begründete, daß die Universität Erlangen seit Mai 1945 die Möglichkeit besessen habe, den Lehrkörper allmählich zu entnazifizieren und so eine Gefährdung des Lehrbetriebs zu vermeiden. Sie habe aber ihre Chance nicht wahrgenommen und somit die Militärregierung zum Eingreifen gezwungen ${ }^{258}$. Dies war nur die halbe Wahrheit, denn mit der radikalen Säuberung sollte vor allem die amerikanische Presse und Offentlichkeit beruhigt werden.

Wie so oft in der Geschichte der Entnazifizierung brachte eine an sich notwendige Maßnahme durch die übersteigerte Ausdehnung des betroffenen Personenkreises mehr Schaden als Nutzen. Die unvermeidlichen Folgen benannte Rektor Brenner auf einer Konferenz im Juni 1947, an der Vertreter der Professorenschaft, des Kultusministeriums, der Kirchen und der ERA-Branch teilnahmen: , Alarming and increasing apathy of the people toward reorientation. " Er zeigte sich besorgt über das Umschlagen der bisherigen Indifferenz in offene Feindschaft bei denjenigen Professoren, die noch bis vor kurzem zur Mitarbeit an der demokratischen Umerziehung des deutschen Volkes bereit gewesen seien $^{259}$. Zu einer ähnlichen Einschätzung kam Herbert Gezork (ERA-Branch) in seinem Bericht zur Lage in Erlangen: ,, The presently prevailing unsettled situation causes a state of continuous unrest and tension, and is apt to re-awaken and strengthen nationalistic and national socialistic tendencies in the academic community of Erlangen." 260 Allenthalben mußte die Militärregierung feststellen, ,that we are about to lose the struggle for the sympathy and support of German intellectual circles in our zone" ${ }^{\text {‘261 }}$. Das bestätigte Alt-

255 Neutrale Ethik, in: Theologische Blätter 18(1939), Sp. 316f.; Welch eine Wendung durch Gottes Führung! Ebenda 19 (1940), Sp. $171 \mathrm{f}$.

256 So etwa: Luther und Hitler, in: Allgemeine Evang.-Luth. Kirchenzeitung 66 (1933), S. 970 ff., 994 ff.; auch als Sonderdruck im Freimund-Verlag, Neuendettelsau, 1933 erschienen.

257 Vgl. Alf Mintzel, Die CSU. Anatomie einer konservativen Partei 1945-1972, Opladen 1975, S.588, Anm. 192.

${ }^{258}$ Neue Zeitung vom 3.2.1947.

259 NA, RG 260, 10/87-3/3, Confidential Report to ICD-OMGB vom 25.6. 1947; LKAN, LKR 524, Tagungsbericht.

${ }^{260}$ NA, RG 260, 5/339-3/5, Report of Field Trip to Theologische Fakultät of Erlangen vom 24.4.1947.

261 Memorandum Kellermanns vom 28.11.1947. Zit. nach Tent, Mission, S. 106. 
haus aus seiner Sicht: ,Wir [...] werden verurteilt und gestraft ohne jedes Gehör und Verfahren! Solche Methoden nennen wir Deutsche nazistisch. Wir waren naiv genug, $1945 \mathrm{zu}$ erwarten, daß wir von ihnen erlöst werden sollten. Wir sind gründlich von dieser Illusion geheilt. Man kann sich denken, welche moralischen Eroberungen die Demokratie mit diesen Proben bei uns macht. "262

Neben den Studenten, die den Fortgang ihres Studiums gefährdet sahen und sich mit den entlassenen Professoren solidarisierten, erhob auch die Bezirkssynode des Kirchenbezirks Erlangen Protest: Die Ausbildung des Pfarrernachwuchses sei ernsthaft gefährdet. Althaus und Strathmann - Preuß und Hauck wurden nicht namentlich genannt - hätten ihre Ablehnung der NS-Weltanschauung niemals verhehlt, sondern im Gegenteil durch ihre klare Evangeliumsverkündigung die ,,innere Abwehrbereitschaft ${ }^{\text {"s }}$ der Gemeinden gegenüber dem Neuheidentum und den verderblichen Einflüssen des Nationalsozialismus gestärkt. Die Bezirkssynode erwarte ihre unverzügliche Rehabilitierung ${ }^{263}$. Dieser Protest wurde von der Landessynode im Mai 1947 einstimmig unterstützt. Meiser erklärte in seinem Tätigkeitsbericht vor der Synode: ,,Wir müßten die Zerstörung der Universität Erlangen oder die fast ausschließliche Ersetzung der entlassenen Professoren durch Dozenten katholischer Konfession auch als eine bewußte Brüskierung des gesamten evangelischen Bevölkerungsteils des Landes empfinden. [. . .] Aber niemand kann von uns verlangen, daß wir es unwidersprochen hinnehmen, wenn aus politischen oder konfessionspolitischen Gründen der bisherige Charakter der Universität Erlangen in sein Gegenteil verkehrt werden sollte. “264 Diese Äußerungen zeigen, daß die Entnazifizierung auch als ein verdecktes Kampfmittel der katholischen Kirche gegen den Protestantismus verstanden wurde.

Von Studenten und Kollegen heftig angefeindet, wandte sich Sasse hilfesuchend an Meiser: ,,Es wurde mir vorgeworfen, daß ich viel Zeit dem Kirchenkampf geopfert habe, statt am Schreibtisch zu sitzen. Ich habe das nie ohne Ihren Ruf, Hochwürdigster Herr Landesbischof, getan. [...] Ich habe keinen Ansbacher Ratschlag geschrieben. Ich habe die Verbote von Auslandsreisen getragen und damit einen großen Teil meiner ökumenischen Auslandsbeziehungen [...] in die Hände der politisch ,einwandfreien 'Theologen gehen sehen. Ich habe es - vielleicht war dies die größte Torheit - damals verhindert, daß Ordinarien unserer Fakultät zu den DC gingen. [...] Ich habe hier in Erlangen dafür immer nur Prügel bekommen." Zur Sache selbst erklärte Sasse, die Entnazifizierung sei ,, bewußt sabotiert" worden. ,,Es wurden Leute gerettet, die nicht gerettet werden konnten - aus persönlichen Gründen. [...] Wer sich heute als Außenstehender ein Urteil anmaßt, der ahnt nicht, was alles getan worden ist, um die Katastrophe zu verhindern. Der hat keine Vorstellung davon, welche Summe von Schuld und Schmutz sich angesammelt hatte. " Er erinnerte Meiser auch daran, daß die Kirchenleitung während des Dritten Reiches zur Absetzung des Erlanger Theologen Friedrich Ulmer und des Historikers Bernhard Schmeidters geschwiegen habe. Man könne doch nicht ihn für die politisch belastenden Schriften seiner Kollegen und für die ,,Verbrechen, die leider im Dritten Reich an

262 NA, RG 260, 5/339-3/5, Althaus an Haußleiter vom 9.2.1947. Zu seiner politischen Haltung nach 1945 vgl. Ericksen, Theologians, S. $109 \mathrm{ff}$.

${ }^{263}$ Erklärung der Bezirkssynode vom 9.2.1947, in: Verhandlungen der Landessynode 1946/47, S.19f. Weiterhin protestierten auch die Bezirkssynoden von Nürnberg und Fürth.

264 Ebenda, Bericht Meisers vom 6.5.1947. 
unserer Universität begangen worden sind“, verantwortlich machen: „Begreift man nicht, daß ich mich als Prorektor schuldig gemacht hätte, wenn ich zu allem geschwiegen hätte? Heute wagen es kirchliche Kreise, den Amerikanern Verbrechen gegen die Menschlichkeit vorzuwerfen, weil unter anderen Ärzten auch solche haben gehen müssen, die nach den uralten, ewigen Grundsätzen christlicher Ethik Mörder sind, und weil die mit ihnen müssen, die sie geschützt und nicht rechtzeitig für Ersatz gesorgt haben, obwohl der Ersatz da war. Und all das geschieht auf Pfarr- und Dekanatskonferenzen und lutherischen Synoden! Wenn das die neue bekennende lutherische Kirche sein soll, die aus dem Kirchenkampf hervorgegangen ist, dann kann ich von dieser Kirche und ihren Synoden nur schmerzerfüllt, aber mit aller Entschiedenheit Abstand nehmen. "265

Die Verbitterung Sasses, der bei aller Polemik die moralisch-ethischen Maßstäbe wieder ins rechte Lot rückte, ist unüberhörbar. Seine persönliche Tragik war es, daß er nach 1945 isoliert zwischen allen Fronten stand. Von Seiten der bruderrätlichen Richtung konnte er als scharfer Kritiker der Barmer Erklärung keine Unterstützung erwarten und im entschieden lutherischen Lager galt er als Denunziant. Die Antwort Meisers ist nicht bekannt; doch in mehreren Fällen hat der Landeskirchenrat Pfarrern, die vor den Spruchkammern als Belastungszeugen auftraten, ein Disziplinarverfahren angedroht ${ }^{266}$. Der Abschied Sasses gestaltete sich schwieriger als erwartet. Eine Anstellung an der streng lutherischen Missourisynode in den USA hatte sich nach der Intervention Strathmanns zerschlagen. Im August 1949 verließ Sasse endgültig Erlangen, nachdem er 1948 aus Protest gegen die Mitgliedschaft der bayerischen Landeskirche in der EKD zur Evangelisch-(alt)lutherischen Kirche übergetreten war, und nahm eine Professur an der kleinen lutherischen Kirche Australiens in North Adelaide an ${ }^{267}$. Althaus, Strathmann und Hauck konnten im Verlauf des Jahres 1948 ihre Lehrtätigkeit wieder aufnehmen. Die Entlassung von Preuß wurde im April 1949 in eine Ruhestandsversetzung (keine Emeritierung) mit Bezügen umgewandelt.

Auch am Beispiel Erlangen zeigt sich der zweischneidige Charakter der amerikanischen Umerziehungspolitik. Wohl vermochte die Militärregierung die Universitäten durch umfangreiche Entlassungen kurzfristig zu entnazifizieren, doch verfügte sie weder über eine langfristige Konzeption, noch vermochte ERA-Branch diese Lücken - mangels materieller und personeller Ressourcen - mit fachlich qualifizierten und gleichzeitig überzeugten Demokraten auszufüllen. Im Mittelpunkt stand die Entnazifizierung, die jedoch nur die negative Seite des angestrebten Elitenaustausches darstellen konnte; ein umfangreiches Programm zur gezielten Rekrutierung neuen Lehrpersonals fehlte hingegen völlig.

${ }^{265}$ LKAN, NL Langenfaß 125, Sasse an Meiser vom 15.2.1947.

$266 \mathrm{Vgl}$. LKAN, LKR $1759 \mathrm{~d}$, Vollsitzungen des Landeskirchenrats vom 23.-25.8. und 21.-24. 12. 1949.

267 Vgl. Loewenich, Erlebte Theologie, S. 136. 